University of Louisville

ThinkIR: The University of Louisville's Institutional Repository

$12-2011$

\title{
Acquisition of mathematical vocabulary using constant time delay with individuals with moderate and severe disabilities.
}

Connie Elaine Morrison 1974-

University of Louisville

Follow this and additional works at: https://ir.library.louisville.edu/etd

\section{Recommended Citation}

Morrison, Connie Elaine 1974-, "Acquisition of mathematical vocabulary using constant time delay with individuals with moderate and severe disabilities." (2011). Electronic Theses and Dissertations. Paper 1010.

https://doi.org/10.18297/etd/1010

This Doctoral Dissertation is brought to you for free and open access by ThinkIR: The University of Louisville's Institutional Repository. It has been accepted for inclusion in Electronic Theses and Dissertations by an authorized administrator of ThinkIR: The University of Louisville's Institutional Repository. This title appears here courtesy of the author, who has retained all other copyrights. For more information, please contact thinkir@louisville.edu. 
ACQUISITION OF MATHEMATICAL VOCABULARY USING CONSTANT TIME

DELAY WITH INDIVIDUALS WITH MODERATE AND SEVERE DISABILITIES

\title{
By
}

Connie Elaine Morrison

B.A., Eastern Kentucky University, 1997

M.A., University of Louisville, 2002

\begin{abstract}
A Dissertation
Submitted to the Faculty of the

Graduate School of the University of Louisville in Partial Fulfillment of the Requirements for the Degree of
\end{abstract}

Doctor of Philosophy

Department of Teaching and Learning

University of Louisville

Louisville, Kentucky

December 2011 
ACQUISITION OF MATHEMATICAL VOCABULARY USING CONSTANT TIME

DELAY WITH INDIVIDUALS WITH MODERATE AND SEVERE DISABILITIES

By

Connie Elaine Morrison

B.A., Eastern Kentucky University, 1997

M.A., University of Louisville, 2002

A Dissertation Approved on

October 27, 2011

By the following Dissertation Committee:

Debra Bauder

Dissertation Director

Thomas J. Simmons 


\section{DEDICATION}

This dissertation is dedicated to

My Mom

Lane

Nicholas

Katie

And

Chase 


\section{ACKNOWLEDGEMENTS}

I would like to thank Dr. Debra Bauder who saw in me the potential to achieve from the very beginning. From the start of my graduate work she encouraged and nudged me to grow and to reach.

I would like to thank my Mom who has shown me nothing but love and support my entire life. She has always lived her life in a way that showed Christ and his love. I hope that when my children are grown their love for me is just a fraction of the love I have for my Mom.

I would like to thank my children who have only known a Mother with homework. Who would come to the desk to offer me a smile and a kiss before they were shooed away so that "the paper" could get done. I hope they carry with them throughout their life the importance of education and the understanding that one never really stops growing and learning.

I would like to thank my husband who has never complained about helping with the kids and the house. Who at every turn has encouraged and loved me. He has supported me on this long journey—even delaying his own goals.

Most importantly, I would like to thank God for all the blessings in my life. I know that God has led me down this path. I pray daily that my actions are pleasing to Him and 
that I am obeying His commands. I do not know where He is leading me, but I know that I am ready to follow. 


\begin{abstract}
ACQUISTION OF MATHEMATICAL VOCABULARY USING CONSTANT TIME

DELAY WITH INDIVIDUALS WITH MODERATE AND SEVERE DISABILITIES
\end{abstract}

Connie E. Morrison

October 27, 2011

Constant Time Delay (CST) has been used extensively as a procedure to teach children with disabilities a variety of skills. There is a preponderance of evidence that this instructional strategy is a highly effective (Handen \& Zane, 1987; Koscinski \& Gast, 1993; \& Schuster, Stevens, \& Doak, 1990). However, there appears to be a lack of research regarding the use of CTD with children with moderate and/or severe disabilities in learning core content vocabulary. Therefore, the primary purpose of this study was to determine if students with moderate and severe disabilities could acquire core mathematical vocabulary content through the use of constant time delay (CTD) procedures.

This study examined the ability of $10^{\text {th }}$ graders with moderate and severe disabilities to acquire core content Geometry terms using constant time delay instruction. The investigation included six participants who were divided into two groups, a verbal group and a non-verbal group. All six participants qualified to participate in the state's alternate assessment. A single subject multiple probe baseline experimental research 
design was used. The results of this study were mixed. The verbal participants were able to reach criteria using CTD procedures. It should be noted the verbal group's research design was the multiple probe baseline research design. However, the nonverbal group was unsuccessful in reaching criteria through a multiple probe baseline design.

Therefore, case studies of these students were conducted. The participants from the nonverbal group were unable to reach criterion on any of the vocabulary words. The lack of reaching criterion might be due to several factors including the lack of verbal skills and/or having the prerequisite skills needed to participate in the instructional procedure. Therefore, procedural changes might be in order before replication of this study can be completed.

Analysis of the data indicates that additional studies are needed to determine if and to what degree the verbal status a participant has on acquisition of core content using CTD. Further research regarding skill and academic acquisition for children who are non-verbal is warranted based on these findings. 


\section{TABLE OF CONTENTS}

PAGE

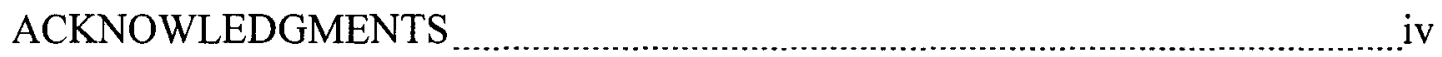

ABSTRACT

LIST OF TABLES

LIST OF FIGURES

CHAPTER I. STATEMENT OF THE PROBLEM _..................................... 1

Introduction

Special Education and Legislation .......................................................

Individual with Disability Education Act (IDEA) _...................... 1

No Child Left Behind Act (NCLB) ............................................... 3

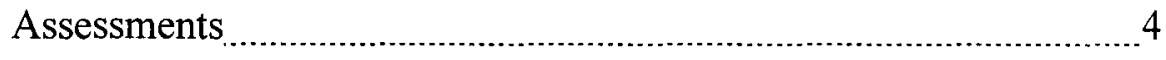

Alternate Assessment

Core Content Linkage

Vocabulary Instruction in Core Content _.................................... 8

Purpose of the Study

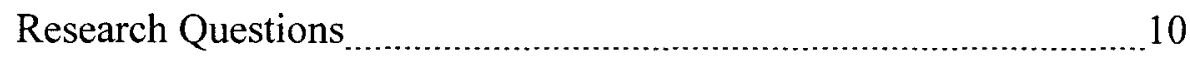

Significance of the Study

Definitions of Terms 
Conclusion 15

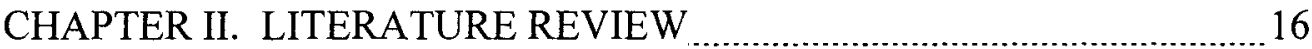

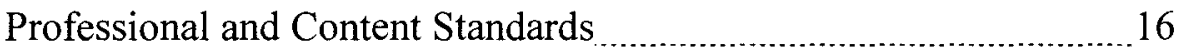

Common Core Standards (CCS) _....................................... 16

National Council of Teachers of English (NCTE) ..................... 18

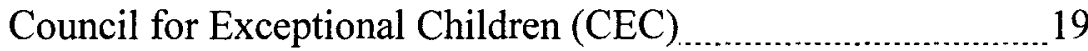

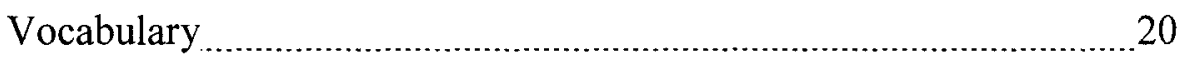

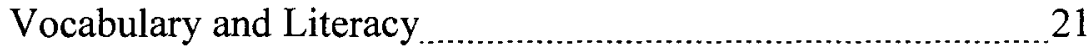

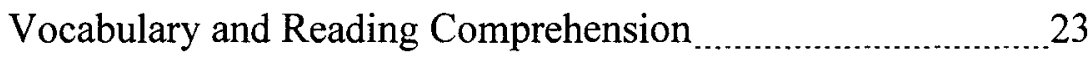

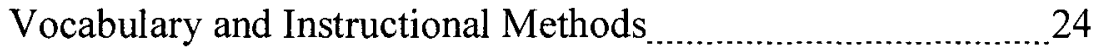

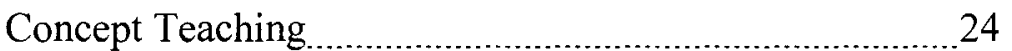

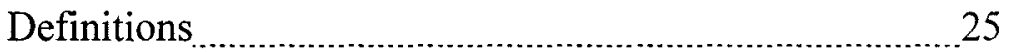

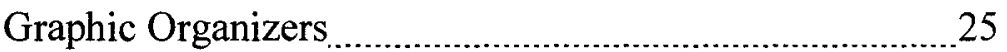

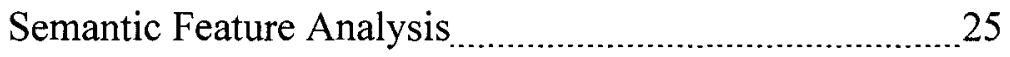

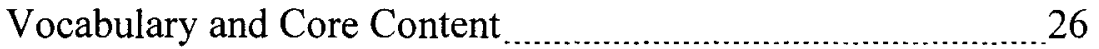

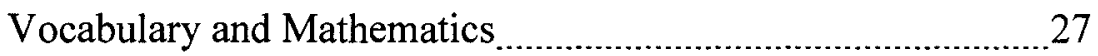

Vocabulary and Students with Learning Disabilities .................29

Vocabulary and Students with Moderate and Severe

Disabilities___ 30

Time Delay

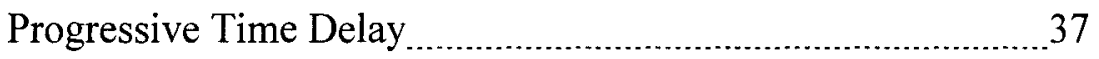

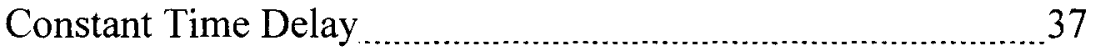

Constant Time Delay and Students with Disabilities ..........38 
Constant Time Delay and Students with Moderate and

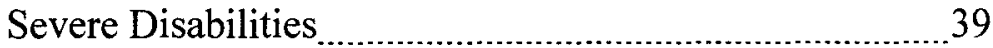

Constant Time Delay and Vocabulary ……………….......... 40

Conclusion

CHAPTER III. RESEARCH METHODOLOGY

Experimental Design

Permissions

Settings

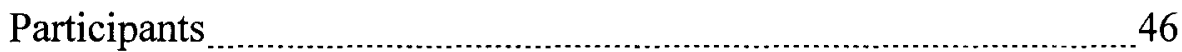

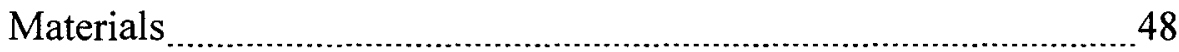

Definition and Response Flashcards _............................................. 48

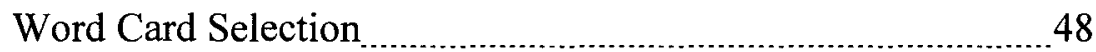

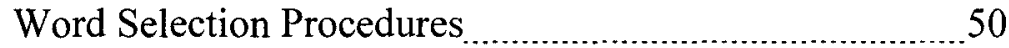

Social Validation of Word Selection ……......................... 50

Word Card Set Screening Procedures ............................................. 51

Word Sets

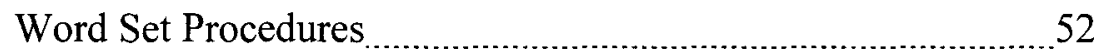

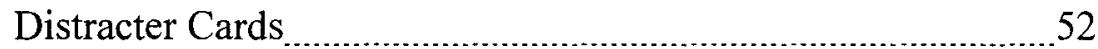

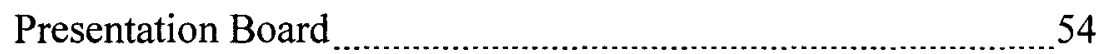

Measures

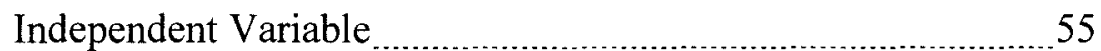

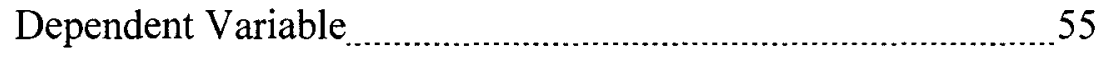

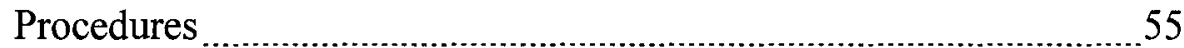


Baseline Sessions ........................................................................ 55

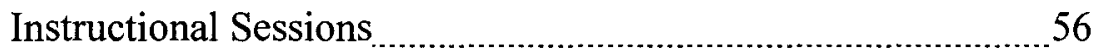

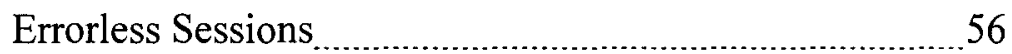

Five Second Delay Sessions …………………………......... 56

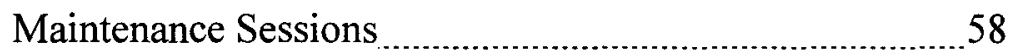

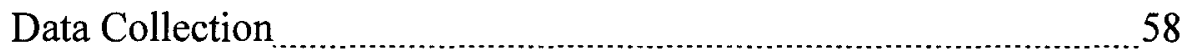

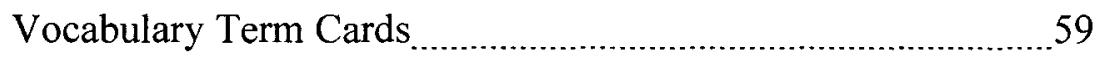

Generalization $\ldots$

Internal Validly $\ldots \ldots \ldots$

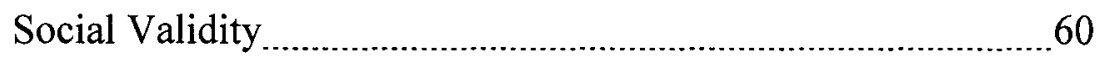

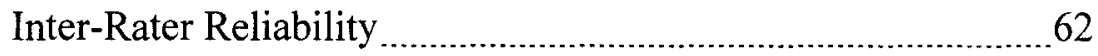

Procedures for Inter-Rater Reliability..................................62

Training

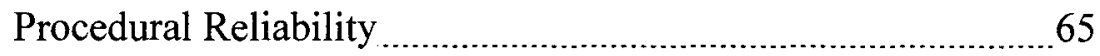

Procedures for Procedural Reliability ………………....... 65

Training

CHAPTER IV. RESULTS AND DATA ANALYSIS _.................................. 67

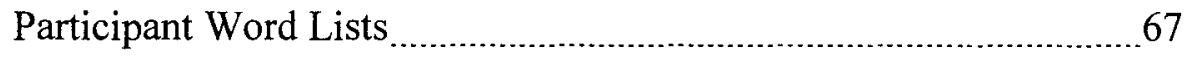

Results and Analysis of Group 1

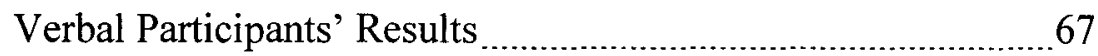

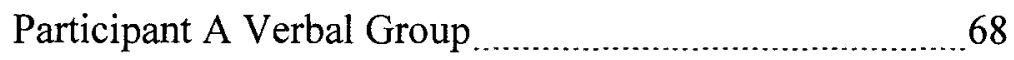

Screening

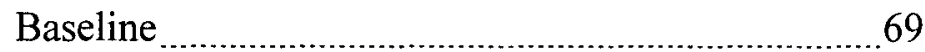


Instructional

Maintenance

Generalization 71

Participant B Verbal Group 71

Screening .72

Baseline 72

Instructional .72

Maintenance 73

Generalization 73

Participant C Verbal Group .73

Screening 74

Baseline 74

Instructional 78

Maintenance .78

Generalization 78

Verbal Group Participants' Summary 79

Results and Data Analysis of Group 2 80

Non-verbal Participants' Results 80

Participant D Non-verbal Group. 81

Screening. 83

Baseline 83

Instructional 84

Participant E Non-verbal Group. 88 
Screening

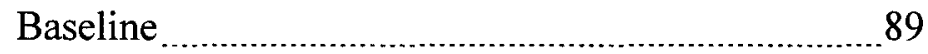

Instructional _......................................................... 89

Participant F Non-Verbal Group ............................................93

Screening

Baseline

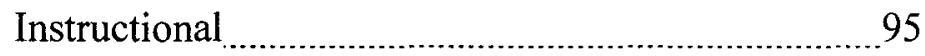

Non-Verbal Participants' Summary _............................................98

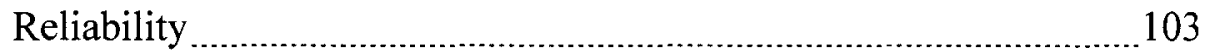

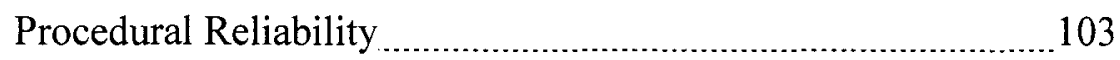

Inter-rater Agreement

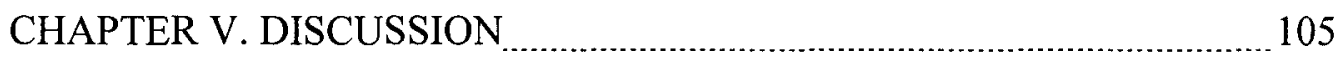

Overview of Purpose

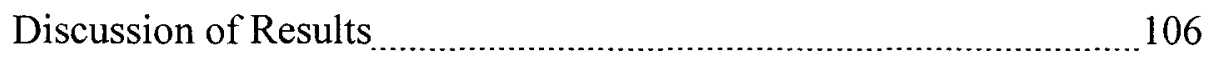

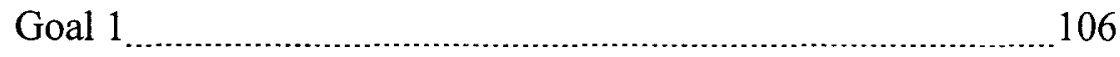

Goal 2

Discussion of Research Question Results _........................................108

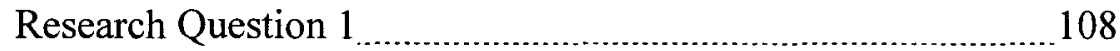

Research Environment

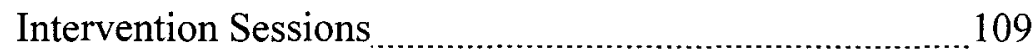

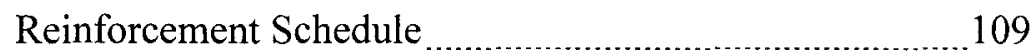

Length of Time Delay ............................................................110

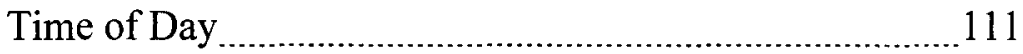


Content

Response Modes.

Communication Competence Factors

Participant Characteristics in Previous Studies 113

Research Question 2

Research Question 3

116

Implications of Findings

118

Implications Related to Empirical Knowledge Base 118

Implications of Practice 120

Implications for Pre-requisite Skills

Implications for the Field 122

Implications for Future Research 122

Limitations 124

Setting Limitations 125

Time Limitations 125

Generalization Limitations 126

Procedural Study Limitations. 126

Subject Pre-requisite Skill Limitations 127

Conclusion 128

REFERENCES 129

APPENDICES 144

CURRICULUM VITAE 191 


\section{LIST OF TABLES}

TABLE

1. Summary of Projects 32

2. Summary of Setting Demographics

3. Summary of Participants. 49

4. Vocabulary Target Terms. 53

5. Distracter Terms 57

6. Scripted Teacher Response. 61

7. Teacher Verification Results of Vocabulary Terms 64

8. Term Word List .68

9. Distracter Word Pairings 69

10. Session Times. 72

11. Angle Terms Replaced for Participant $C$ 78 


\section{LIST OF FIGURES}

FIGURE

PAGE

1. Baseline Sessions for Participant C

2. Summary Data for Participants A-C

3. Baseline for Participant D

4. Pattern Response Data for Participant D

5. Summary Data for Participant D

6. Pattern of Participation for Participant E 93

7. Summary Data for Participant E 96

8. Pattern of Response Rate for Participant F. 99

9. Summary Data for Participant $F$. 100 


\section{CHAPTER I}

\section{STATEMENT OF THE PROBLEM}

\section{Introduction}

Education in the United States has seen many changes in the last four decades. Congress, in the 1970's, instituted public laws that became the foundation of education reform. For example, the Education for All Handicapped Children Act in 1975, better

known as P. L. 94-142, was primarily responsible for granting access to free, appropriate public education for individuals with disabilities (Hardman \& Dawson, 2008). This hallmark legislation has evolved through the years, bringing new and sometimes controversial mandates to education including: inclusion, accommodations, testing, and accountability to all students--even those students who are the most severely cognitively challenged.

\section{Special Education and Legislation}

\section{Individual with Disabilities Education Act (IDEA)}

In 1990, amendments to P. L. 94-142 brought a name change to the act. P. L. 94142 is replaced with P. L. 101-476, the Individuals with Disabilities Education Act or IDEA. It is evident by this name change, that "person first" language was deemed to be more appropriate in reference to individuals with disabilities (Aleman, 1991). IDEA provided an expansion of services, including the expansion of the entitlement in all states for individuals from ages 3 to 21 . Additionally, IDEA designated "assistive technology" as a related service in individual education plans (IEP) and strengthened the law's 
commitment to greater inclusion in community schools (least restrictive placement). The law also provided funding for infant and toddler early intervention programs, and required, by age 16 , that every student have explicitly written in his/her IEP a plan for transition to employment or post secondary education (Aleman, 1991).

The reauthorization of IDEA (P. L. 105-17) in 1997 required that students with disabilities have access to the general curriculum (Roach, Elliott, \& Webb, 2005; Wakeman, Browder, Meier, \& McColl, 2007) and participate in district wide school assessments (Browder \& Cooper-Duffy, 2003; Johnson \& Arnold, 2007; Marion \& Pellegrino, 2006; Perner, 2007; Towles-Reeves, Kleinert, \& Muhomba, 2009). IDEA of 1997 also made provisions for accommodations for students and required states to design alternate assessments for the most severely cognitively challenged students (Browder \& Cooper-Duffy, 2003; Johnson \& Arnold, 2007; Marion \& Pellegrino, 2006; Roach, et al, 2005; Towles-Reeves, et al., 2009; Wakeman et al., 2007).

IDEA was amended to the Individuals with Disabilities Education Improvement Act of 2004, now known as IDEIA (P. L. 108-446). IDEIA of 2004 included extensive provisions aimed at ensuring that special education teachers and related service professionals, who service children with disabilities, were "highly qualified" (Wakeman et al., 2007). IDEIA of 2004 also these provisions early intervening services designed to encourage school districts to provide additional support for struggling students (Cortiella, $\&$ NCLD, 2006). IDEIA of 2004 relaxed the "discrepancy" requirement that meant the students no longer had to have a severe discrepancy between intellectual ability and academic achievement in order to be identified as having a specific learning disability, and it allowed for both parents or the school district to initiate a request for an 
educational evaluation (Cortiella, \& NCLD, 2006) Numerous mandates within IDEIA of 2004 align with another federal education program, No Child Left Behind Act (NCLB) (P.L. $107-110$ ), which was legislated in 2002.

\section{No Child Left Behind Act (NCLB)}

There were many new requirements for districts, schools, and teacher as a result of enacting No Child Left Behind (NCLB) Act of 2002. The intent of this law was to have all children, regardless of economic, culture, and/or disability meet state academic achievement standards in order to realize their full potential (NCLD Public Policy Staff, 2009). To accomplish this overarching goal, Title I of NCLB included funding of programs and resources by; placing a highly qualified teacher in every classroom; improving the qualifications of paraprofessionals; develop effective instructional practices and materials; provide professional development for teachers; and support parent involvement activities (20 U.S.C. 6301 et seq.)

Through this law, the federal government increased their interest in state assessment results and in the accountability of the states' assessments. This was realized in additional reporting requirements for state assessments of student achievement (Browder, Spooner, Algozzine, Ahlgrim-Delzell, Flowers, \& Karvonen, 2003; Johnson \& Arnold, 2007). NCLB required that all states conduct yearly statewide assessments that align with state grade level academic performance standards in grades 3 through 8 in reading/language arts, mathematics and science by 2007 (Browder et al., 2003; Browder \& Cooper-Duffy, 2003; Johnson \& Arnold, 2007). NCLB also specified that high school age individuals would complete assessments once in reading/language arts, mathematics and science by 2007 (Browder et al, 2003; Roach, et al., 2007). Furthermore, NCLB set forth a mandate that all students were to show adequate yearly progress (AYP) in reading 
and mathematics (Browder \& Cooper-Duffy, 2003; Roach, et al., 2007; Roach, et al., 2005).

In addition, NCLB added students with disabilities as a subgroup of participants in the accountability system for determining adequate yearly progress (AYP) (Wakeman et al., 2007). NCLB further required all students to meet $100 \%$ proficiency in reading and mathematics by the 2013-2014 school year (Browder et al., 2003; Browder \& CooperDuffy, 2003; Elliott \& Roach, 2007; Roach, et al., 2007; Wakeman et al., 2007). NCLB also established higher standards for teachers by requiring teachers of core academic subjects to be "highly qualified" (Wakeman et al., 2007).

\section{Assessments}

In the $1950 \mathrm{~s}$, in response to the work of James B. Conant, testing was used primarily in K-12 to identify gifted students and students for higher education (Linn, 2000). In the 1960 s, testing was used to determine the effectiveness of Title I and other federal programs (Linn, 2000). The use of assessments grew in the 1970s and the early 1980s, in which schools in 34 states initiated minimum graduation requirements based on test results (Linn, 2000). As a way to assess accountability and student progress, the use of standardized tests was initiated and is still commonly used in this manner (Linn, 2000).

Assessments may be divided into two categories, summative and formative (Popham, 2009). Summative assessments are broader in scope addressing long term goals. Formative assessments address short-term objectives (Popham, 2009). Accountability assessments, mainly standardized, are used by educational and political cohorts to ascertain the effectiveness of educational communities (Popham, 2009 
The end goal, for standards-based reform, was for the public school systems to equip all students to become successful members of the U.S. economy (Gong \& Marion, 2006; Johnson \& Arnold, 2007). Standards based assessment has provided an opportunity for policymakers to not only influence the constructs that are taught in the public schools but also to influence how the knowledge base of the constructs are to be measured and reported (Linn, 2000; Quenemoen, Lehr, Thurlow, \& Massanari, 2001).

Although there are limitations regarding statewide assessments, the assessments are one way to measure student learning. Assessments have provided a "report card" for teachers, schools, and the public. The assessments have shown, in part, whether or not a school is successfully educating its students, including students with disabilities. The ultimate goal of all high stakes testing is to raise academic standards for all students (Hardman \& Dawson, 2008; Perner, 2007; Roach, et al., 2005; Wakeman et al., 2007). One challenging question presently being considered was whether or not the system of assessment based accountability is actually improving education (Hardman \& Dawson, 2008; Linn, 2000; Quenemoen, et al., 2001).

\section{Alternate Assessment}

IDEA of 1997 was the beginning of the federal government's push toward standards-based reform and accountability. Students with disabilities were included in this federal mandate (Browder et al., 2003). Alternate assessments were proposed with the goal of promising to move students with disabilities to equal footing with regular education students in regard to reform, expectations, access, and instruction (Browder et al., 2003). Thus, the purpose for including students with disabilities in standards-based reform was to ensure that students with disabilities receive the same benefits and equality 
in educational opportunities as other students. The hope was that better instruction would lead students with disabilities to make higher achievements in both academic and functional areas (Kleinert \& Kearns, 2010).

Alternate assessments can be viewed as a way to increase awareness for students with disabilities within the school setting and within states' legislative bodies (Browder et al., 2003). Also, it has been the intent of the alternate assessments to raise the academic expectations for students with disabilities (Browder et al., 2003; Kleinert, Quenemoen, \& Thurlow, 2010). This is achieved in the design of the alternate assessment. When designing an alternate assessment, the amount of knowledge and skills, and the degree of learning in correlation with alternate achievement standards must be measured (Marion \& Pellegrino, 2006; Wakeman et al., 2007).

Currently, alternate assessments are the primary method through which students with the most severe cognitive challenges participate in state assessments (Kerns, 2010 \& Towles-Reeves, Kleinert, \& Muhomba, 2009). Therefore, alternate assessments are meant for only a small percentage of students (Elliott \& Roach, 2007; Johnson \& Arnold, 2007; Towles-Reeves, et al., 2009, Wakeman et al., 2007). The Department of Education estimated that nine percent of the special education population qualify for the alternate assessment (Kleinert \& Kearns, 2010). This nine percent of the moderate and severe population equate to one percent of the entire student population (Kleinert \& Kearns, 2010).

In response to NCLB mandates, the U. S. Department of Education (DOE) provided classification to alternate assessments. The U.S. DOE (2003) specifies three components to alternate assessment: (1) alignment with the state's content standards; (2) reporting 
progress separately in reading/language arts and mathematics; and (3) design and implementation so that results can be indicators of academic yearly progress (AYP) (Elliott, Compton, \& Roach, 2007; Elliott \& Roach, 2007; Perner, 2007). Furthermore, alternate assessments must also meet standards of high technical quality (validity), reliability, accessibility, objectivity, and consistency (Elliott, et al., 2007; Elliott \& Roach, 2007; Perner, 2007). States and Commonwealths were given the flexibility to create their own alternate assessments, basing them on modified achievement standards (AA-MAS) (Wakeman et al., 2007)

Now that all states are in line with the inclusion of all students into an accountability system, it is important to equalize the educational expectations for all students. This equalization requires special education students to have not only access to general education classroom but also requires core content instruction to cross over into the special education classroom (Altman, Lazarus, Quenemoen, Kearns, Quenemoen, \& Thurlow, 2010).

\section{Core Content Linkage}

As of 2004, the U.S. Department of Education (DOE) allows states to create alternate achievement standards for use in alternate assessments. The U.S. DOE states that the alternate assessment material "should show a clear link to the content standards for the grade in which the student is enrolled although the grade-level content may be reduced in complexity or modified to reflect pre-requisite skills" (Towles-Reeves \& Kleinert, 2006 p.31). The Council of Chief State School Officers (CCSSO) has approved four models for states to use in alignment studies: the Webb model, the Survey of Enacted Curriculum model, the "Achieve" model, and the Council for Basic Education 
model (Roach, Elliott, \& Webb, 2005). States can use these alignment studies to show validity of their assessments.

General classroom assessments for regular education students are designed to measure whether or not academic skills and concepts taught in classroom instruction have been learned by the group of students (Stiggins, 2004). The assessments are just a sample of the material covered. General assessments are group test typically used in regular education classroom. Also, "individual" is probably the strongest descriptor associated with the term alternate assessment (Hardman \& Dawson, 2008). Balancing functional instruction with mandates for core content linkage becomes the challenge of special education professionals.

Comparing special-needs-students alongside peers without disabilities in their same grade is nearly impossible. This is particularly true as students get older. For example, a regular education $10^{\text {th }}$-grade student's assignment might be to write an essay on the conflict and resolution of a story while a special education $10^{\text {th }}$-grade student might be asked to answer questions concerning the story's content with pictures. While both students might arrive at the correct answer, it will be difficult to compare both tasks as equal representations of the same level of knowledge and comprehension.

State assessments currently only determine if students have achieved adequate yearly progress (AYP) on academic goals, not functional goals. Large gaps of research exist in the literature concerning assessment and special education. Teachers and policy makers do not have access to sufficient data that might be applied to the alternate assessment (Browder et al., 2003).

\section{Vocabulary Instruction in Core Content}


English as a language has three times more words than the German language and six times more than the French language (Bromley, 2007). Beyond the sheer volume of the language is the fact that $70 \%$ of the most common words in the English language have multiple meanings (Bromley, 2007). Multiple words, multiple meanings, multiple spellings, and multiple pronunciations are attributes that turn ordinary words into vocabulary.

The foundation of vocabulary and its importance is not disputed in any of the literature. Vocabulary, as noted earlier, involves identifying and retrieving word knowledge. The essence of word vocabulary has two main functions. The first is learning and remembering words. The second is learning strategies that will enable future unknown words to become learned and remembered (Asselin, 2002).

All teachers are considered teachers of reading and writing (Kester Phillips, Foote, \& Harper, 2008). All content areas require reading as a foundational skill for students to access and understand content material. Therefore, vocabulary instruction should be integrated in all content classes (Taylor, Mraz, Nicholas, Rickelman, \& Wood, 2009). This is why it is necessary for all teachers to be able to effectively deliver vocabulary instruction within their classroom. Many teachers still rely on writing definitions as a primary teaching strategy for vocabulary instruction (Kester Phillips, et al., 2008). As noted in the previous example, without knowing or understanding the context of the sentence where the vocabulary word "tear" is located, it is impossible to synthesize word recognition into word understanding.

\section{Purpose of the Study}


The primary purpose of this study is to determine if students with moderate and severe disabilities can acquire core mathematical vocabulary content through the use of constant time delay (CTD) procedures (Touchette, 1971). Overwhelmingly, previous research studies have paired teaching functional skills with the lowest performing individuals using CTD (Bozkurt \& Gursel, 2005; Morse \& Schuster, 2000; \& Schuster, et al., 1988). In review of the literature, it appeared that individuals with mild mental disabilities or individuals with learning disabilities have more often received instruction in prior research projects using core content or academic based material. For example, Cybriwsky and Schuster (1990) and Koscinski and Gast (1993) taught multiplication facts (Knight, Ross, Taylor, \& Ramasamy, 2003). Keel, Slaton, and Blackhurst (2001) and Wolery, Cybriwsky, Gast, and Boyle-Gast, (1991) taught health and science words (Knight, et al., 2003). Stevens and Schuster (1987) taught spelling words and investigated the use of CTD with word definitions.

It is anticipated that this study will add to and expand the knowledge base of instructional procedures for individuals with moderate and severe disabilities. The study will expand the literature regarding procedures effective in the acquisition of core vocabulary content for these individuals.

\section{Research Questions}

The idea for this research project is born out of questions that began to emerge during teacher training on curriculum and assessment accountability. The first goal of this research study is to confirm that the long proven research based teaching strategy, constant time delay (CTD), may also be used to teach core content skills to students with moderate and severe disabilities. The second goal of this research study is to encourage 
other researchers and teachers to uncover additional crossover skills from the general education core content curriculum to include in the modified special education curricula.

The following research questions address the investigation of these goals. The primary research question in this study focuses on the use of constant time delay to teach core content mathematical vocabulary to $10^{\text {th }}$ graders who have moderate and severe disabilities. The secondary research question relates to the maintenance of learned vocabulary for $10^{\text {th }}$ graders who have moderate and severe disabilities.

Research Question 1. What are the effects of constant time delay on the acquisition of core content math vocabulary by $10^{\text {th }}$ graders with moderate and severe disabilities?

Research Question 2. What are the effects of constant time delay on the maintenance of acquired mathematical vocabulary by $10^{\text {th }}$ graders with moderate and severe disabilities?

Research Question 3. What are the effects of constant time delay on the generalization of acquired mathematical vocabulary by $10^{\text {th }}$ graders with moderate and severe disabilities?

\section{Significance of the Study}

This research study has two significant contributing factors. First, the study will expand the field's knowledge of the categorical uses of constant time delay (CTD) teaching strategies. Branching out from functional and chained tasks into core content skills will provide teachers with instructional supports and guidance for teaching mandated skills. Second, the study will contribute to the field's research on students with moderate and severe disabilities in core content instruction. Students with moderate and severe disabilities make up only $2 \%$ of the special education population and have rarely 
been the targeted subject groups regarding this focus area. Furthermore, research designed specifically for this population may spur additional research with this special population.

\section{Definition of Terms}

For the purposes of this investigation, the following terms are defined. These terms are generally consistent with the vocabulary used in special education nationwide.

\section{Constant Time Delay (CTD)}

Constant time delay is the "systematic increase of the delay interval that students have to perform a correct response prior to being prompted, thus transferring stimulus control form the prompt to the natural stimulus" (Collins, Hager, \& Galloway, 2011, p. 23).

\section{Core Content}

The core content is a subset of the Kentucky Program of Studies. The core content is a collection of essential skills that all students in the state of Kentucky should know. These essential skills are potential test question topics in the Kentucky state assessment (Kentucky Department of Education, Core Content, p. 133).

\section{Emotional Behavior Disorder (EBD)}

This term was defined as an individual who exhibits one or more of the following characteristics when compared to same age peers. Severe deficits in social competence or the inability to build or maintain satisfactory interpersonal relationships, Severe deficits in academic performance that can be linked to the individual's social-emotional problem, a state of depression or sadness, or physical symptoms or fears associated with personal or school problems. (707 KAR 1:002.) 


\section{Functionally Mentally Disabled (FMD)}

This term was defined as an individual who exhibits cognitive functioning and adaptive behavior deficits that are least three (3) or more standard deviations below the mean. Individuals also exhibit severe deficits in overall academic performance including acquisition, retention, and application of knowledge. Indication of FMD is typically found during the developmental stage of life (707 KAR 1:002.).

\section{Mild Mental Disability (MMD)}

This term was defined as an individual who exhibits cognitive functioning and adaptive behavior deficits at least two (2) but no more than three (3) standard deviations below the mean. Individuals also exhibit severe deficits in overall academic performance including acquisition, retention, and application of knowledge. Manifestation of MMD is typically during the developmental stage of life (707 KAR 1:002.).

\section{No Child Left Behind (NCLB) Act}

The reauthorization of the Elementary and Secondary Education Act in 2001 with four main objectives: accountability, scientific research, extended parental options, and extended local control and flexibility (No Child Left Behind: A parents guide, 2003).

\section{Other Health Impaired (OHI).}

Other health impaired describes individuals who process limited strength, vitality or alertness, including a heightened alertness to environmental stimuli that result in limited alertness with respect to the educational environment. The deficits are due to chronic or acute health problems such as asthma, attention deficit disorder or attention deficit hyperactivity disorder, diabetes, epilepsy, a heart condition, hemophilia, lead poisoning, 
leukemia, nephritis, rheumatic fever, and sickle cell anemia. The deficits adversely affects a child's educational performance (C. R. F. $\S 300.7$ (c) (9)).

\section{Orthopedic Impairment (OI)}

Orthopedic impairment refers to a severe orthopedic impairment that adversely affects a child's educational performance. Includes impairments caused by congenital anomaly (e.g., clubfoot, absence of some member, etc.), impairments caused by disease (e.g., poliomyelitis, bone tuberculosis, etc.), and impairments from other causes (e.g., cerebral palsy, amputations, and fractures or burns that cause contractures) (C. F. R. § 300.7 (c) (8)).

\section{Prompt}

A prompt is an act that follows an instruction/direction/request that increases the probability that the instruction/direction/request will be followed. The act can be either verbal or physical. (Alberto \& Troutman, 1999)

\section{Progressive Time Delay (PTD)}

Progressive time delay alludes to a near errorless instructional method that provides prompts to ensure correct responses. The prompts are provided systematically, but the interval between instructions and prompt gradually increases during the instructional sessions (Casey, 2008).

\section{Speech Language Impairment (SLI)}

Speech language impairment "means a communication disorder, such as stuttering, impaired articulation, language impairment, or a voice impairment, that adversely affects a child's educational performance." (C. F. R. § 300.7 (c) (11))

\section{Vocabulary Core Content Standard}


According to the Kentucky Department of Education, the vocabulary core content standard was stated as "RD-10-1.0.4 Students will interpret the meaning of jargon, dialect or specialized vocabulary found in a passage. DOK 2 (Kentucky Department of Education, Core Content, p. 154).

\section{Conclusion}

The pull to balance public education for all students has weaved special education and regular education students together through accountability and reporting. Federal mandates have expanded special education teaching into the general curriculum. Students with moderate and severe disabilities are expected to be taught and to show progress on core content skills. Utilizing scientifically based teaching procedures, such as constant time delay, allow special educators to successfully teach functional and academic skills in their special education classes. 


\section{CHAPTER II}

\section{LITERATURE REVIEW}

This chapter is designed to provide a description of vocabulary in the classroom today including a discussion on (a) professional and content standards (b) vocabulary, (c) time delay, and (d) a description of the literature concerning students with moderate and severe disabilities accessing the core content curriculum.

\section{Professional and Content Standards}

The current policy context for English Language Arts (ELA) as it relates to this study includes teacher knowledge and practice that are guided by professional and content standards. In this section summaries are provided that review the Common Core State Standards (CCS), the National Council of Teachers of English (NCTE) standards as they relate to ELA and students with disabilities, and the Council for Exceptional Children's (CEC) interpretation of how ELA standards affect students with disabilities.

\section{Common Core State Standards (CCS)}

The Council of Chief State School Officers (CCSSO) and the National Governors Association (NGA) first released a draft of the College and Career Readiness (CCR) standards in writing, reading, speaking, listening, language, and mathematics in 2009 with the final draft coming in June 2010 (CCSI, 2011). These standards convey the skills needed in order for individuals to be considered literate in the twenty-first century (CCSI, 
2011), and to ensure that all students in every state are prepared for college and work (Orlich, 2011; \& Phillips \& Wong, 2010).

The Common Core State standards (CCS) are state designed to set clear educational standards for English language arts (ELA) and mathematics (CCSI, 2011; \& Porter, McMaken, Hwang, \& Yang, 2011). It should be noted that Kentucky was the first state in the United States to adopt the common core standards in mathematics and ELA (KDE.edu, 2010).

The creation of the CCS was based on knowledge needed for future college and work (CCSI, 2011). The standards are intended to build on current state standards and are meant to be "fewer, clearer, and higher" (Phillips \& Wong, 2010, p. 38). The rigor of the standards stresses application of knowledge (CCSI, 2011). Additionally, international benchmarks have been included so that students can be prepared for experiences in the global community (CCSI, 2011; \& Porter et al., 2011).

The ELA standards of the CCS are divided into four categories reading, writing, speaking and listening, and language (CCSI, 2011). Vocabulary is an essential component of the language strand. The vocabulary standards (4-6) for grades 9 and 10 and grades 11 and 12 focus on understanding words and phrases and their nuances (CCSI, 2011). The standard also specifically addresses the acquisition of new vocabulary, in general academic and core content classes (CCSI, 2011). The vocabulary standards were written in a manner so that students will increase their vocabularies through reading, direct instruction, and conversations (CCSI, 2011). 
The common standards afford states the opportunity to share experiences, instructional strategies, and best practices for special population such as English language learners and students with disabilities (CCSI, 2011).

\section{National Council of Teachers of English (NCTE)}

The NCTE along with the International Reading Association (IRA) developed the Standards for English Language Arts (ELA) as a supplement to other national, state and local standards (NCTE, 2011) in 1996.

What was driving the creation of the common standards was the belief that literacy competency was only going to continue to rise in the coming years. Individuals would be expected to have dynamic literacy skills that today only a small percentage of the population possesses (Greer, et al., 1996).

The components of English language arts (ELA) are broader today than in the past (Phillips \& Wong, 2010). ELA today not only encompasses reading and writing, but listening, speaking, viewing, and visually representing (Carmichael, Wilson, Martino, Finn, Porter-Magee, \& Winkler, 2010; \& Greer, Smith, \& Erwin, 1996). The standards are designed to designate what students should understand and what students should be able to perform in regards to ELA (Carmichael et al., 2010; \& Greer, et al., 1996).

Three core beliefs are the foundation for the ELA standards (Greer, et al., 1996). The first belief is that students need to be to perform the literacy skills that they need for today and in the future (Greer, et al., 1996). The second belief is that the standards can become a map for all educators to use and it would ensure consistent educational goals (Greer, et al., 1996). The third belief is that standards establish educational expectations 
for all and will help to reduce the discrepancy found within the educational system across the nation (Greer, et al., 1996).

Spoken language provides individuals with most of their knowledge of language (Greer, et al., 1996). In today's society, spoken language and visual language are just as prominent as written language (Greer, et al., 1996). Written language is comprised of reading and writing. Spoken communication is comprised of speaking and listening, and visual language is comprised of viewing and visual representation (Greer, et al., 1996).

Many teachers share a belief that English language arts span all educational subjects (Greer, et al., 1996). All subjects require that students use language to solve problems, theorize and synthesize (Greer, et al., 1996).

Equality among the students also refers to the student with learning disabilities, hearing or visual impairments, emotional or behavior disorders, orthopedic or cognitive disabilities (Fuchs, Fuchs, \& Stecker, 2010; \& Greer, et al., 1996). While this population posed instructional challenges these populations of students are still represented by all of the aforementioned elements (Greer, et al., 1996).

\section{Council for Exceptional Children (CEC)}

Council for Exceptional Children (CEC) is a professional organization who is a leader in educational practice, policy, and standards for special education teachers (Crutchfield, 2003). CEC strives to provide leadership, expertise, and advocacy in the fields of special and gifted education (CEC, 2011). CEC not only has professional standards for special educators to guide them, but CEC also provides information and training for all areas of educational practice including the core content standards (CEC, 2011; Crutchfield, 2003). 
The Council for Exceptional Children (CEC) is hopeful that the Common Core Standards (CCS) will result in positive achievement for students with disabilities (CEC, 2011). CEC also believes that the CCS will continue to help increase access to the general curriculum for students with disabilities (CEC, 2011). The CCS must be interpreted with a broad scope when discussing students with disabilities (CEC, 2011). As always, students with disabilities will continue to need specialized instruction, supports and accommodations (Laarhoven, Munk, Lynch, Bosma, \& Rouse, 2007). Instructional strategies will have to incorporate instruction that is low enough for student to access while high enough to reach the standards (CEC, 2011).

\section{Vocabulary}

The term vocabulary refers to the definition or meaning that is prescribed to a word based in the context in which the word appears. The definition of vocabulary according to the Webster's Dictionary is "a statement of what a thing is" (Webster's New World Dictionary, p.362). Not only can the definition of a word vary based on the context in which the word is located, but the word's pronunciation can also change; consider the word "tear". The word "tear" may mean either the liquid running out of an eye or the act of destroying or pulling apart.

Vocabulary and reading comprehension were suggested to be linked to intelligence or world knowledge (Stahl \& Fairbanks, 1986). Vocabulary words, in content areas, typically build on each other as a means of establishing foundations within the context of the content (Spencer \& Guillaume, 2006).

When addressing vocabulary, teachers should consider three distinct categories in which all vocabulary words may be divided (Kester Phillips, Foote, \& Harper, 2008). 
The first category contains vocabulary words that students are familiar with and for which the student already knows the definition (Kester Phillips, et al., 2008). The second category contains vocabulary words that a student is familiar with, but he/she does not know the definition. A third category contains vocabulary words that a student is not familiar with; therefore, a student does not know the definition (Kester Phillips, et al., 2008).

Words may also be deemed as either low-frequency vocabulary or high-frequency vocabulary. High-frequency vocabulary terms occur in everyday forms of written and spoken communication. Low-frequency vocabulary terms are predominantly academic words associated with higher learning and professional lingo (Manzo, Manzo, \& Thomas, 2006).

In terms of vocabulary acquisition, students must obtain both an oral and textual vocabulary (Brown, 2007). It has been reported that one's receptive vocabulary may be four times greater than one's expressive vocabulary (Jalongo \& Sobolak, 2010). Accomplished readers, by the fourth grade, are able to read all of the words in their oral vocabulary (Graves \& Prenn, 1986). Therefore, it might be stated that a struggling student, as he/she ages, develops a widening discrepancy between his/her oral and textual vocabulary. Two groups that are especially vulnerable to low vocabulary knowledge are students from low socioeconomic backgrounds and students who are English as a second language speakers (Spencer \& Guillaume, 2006 \& Taylor et al., 2009).

\section{Vocabulary and Literacy}

Literacy is defined as competence in reading and writing (Harris, Hodges, \& 
International Reading Association, N. E., 1995). Literacy is multidimensional and multidisciplinary (Harris, Hodges, \& International Reading Association, N. E., 1995). The multidimensional side to literacy speaks to the variety of instructional methods used in literacy instruction. Literacy like vocabulary instruction crosses into every core content discipline taught within the walls of a school. Vocabulary as a component of literacy is supported through repetition embedded in content (Fisher \& Frey, 2004). Entire schools should carry the responsibility of literacy (Fisher \& Frey, 2004). Literacy is important to all content teachers and becomes the responsibility of all teachers because student achievement falls to all teachers (Allington, 2002; \& Fisher \& Frey, 2004). The critical skills that build literacy are reading, writing, speaking, listening, and viewing--skills that are needed in all content areas in all classrooms for successful learning (Fisher \& Frey, 2004). As students enter secondary school environments, their gap of known vocabulary and needed vocabulary has reached as much as 80,000 words (Fisher \& Frey, 2008).

Vocabulary is a dynamic part of literacy in every language, every word meaning, and every cultural nuisance (Burke, 2003). Knowing and understanding the foundations of vocabulary lead learners to deeper levels of learning (Burke, 2003; \& Pikulski \& Templeton, 2004). Enhanced vocabulary positively affects learners in several ways. Learners are able to understand difficult tasks (Burke, 2003). Learners increase their communications skills because they have the ability to use precise words in their descriptions (Burke, 2003). Learners achieve higher social standing due to increase test scores (Burke, 2003). Finally, learners find social validation through the use of common 
language and classroom discussions are richer and more meaningful due to the shared understanding of the vocabulary (Burke, 2003).

Vocabulary terms cross curriculum lines. Literacy functions differently among the various curriculum disciplines so it stands that the masters of each disciplines is who should be instructing students in the literacy of the field (Moore \& Hinchman, 2006). A single vocabulary term can have several meanings across different disciplines as well as different meanings within the same discipline (Moore \& Hinchman, 2006).

\section{Vocabulary and Reading Comprehension}

There is long standing research that supports the relationship between vocabulary knowledge, reading comprehension (Bromley, 2007; Bryant, Goodwin, Bryant, \& Higgins, 2003; Greenwood, 2002; Monroe \& Orme, 2002; Ouellette, 2006; Thelen, 1986), fluency, and achievement (Bromley, 2007). Vocabulary knowledge and reading comprehension have a strong positive correlation (Pearson, Hiebert, \& Kamil, 2007). Strong reading comprehension skills allow students to increase their core content knowledge (David, 2010) which is linked to the general curriculum and accountability. Research also shows that the relationship between reading comprehension and vocabulary grows stronger as the student progresses through school (David, 2010; Ouellette, 2006).

Reading comprehension and vocabulary skills equally impact reading development. Daneman (1991), as reported by Rupley, Logan and Nichols (1998/1999), noted that vocabulary is partially an outcome of reading comprehension skills and that reading comprehension skills are partially an outcome of vocabulary (Kieffer \& Lesaux, 2007). The size of a student's vocabulary predicts their reading comprehension level (David, 
2010; Pearson, Hiebert, \& Kamil, 2007). Furthermore, vocabulary instruction builds a powerful and positive relationship with reading comprehension (Lee \& Herner-Patnode, 2007). Students who have extended vocabulary knowledge are better able to derive meaning to unfamiliar words (Rupley, Logan, \& Nichols, 1998/1999).

\section{Vocabulary Instructional Methods}

Vocabulary instruction within core content areas is an important pre-reading activity that can be used to help strengthen student comprehension of core content material (Fisher \& Frey, 2004). One way teachers are able to address vocabulary within their core content is to use a sequence approach of "introduce, define, discuss, and apply" (Fisher \& Frey, 2004). This sequence teaching technique is especially useful in core content material (Fisher \& Frey, 2004).

Vocabulary teaching strategies include definition coping (Bromley, 2007; Kester Phillips, et al., 2008), context clues, graphic organizers, synonyms and antonyms ( Kester Phillips, et al., 2008), and sentence writing (Bromley, 2007). Vocabulary instructional methods vary widely. The following: concept teaching, definitions, graphic organizers, and semantic feature analysis are highlighted as follows.

Vocabulary instruction that is included in literacy curriculum has positive effects on all students (Jalongo \& Sobolak, 2010). Systematic vocabulary instruction has the ability to build student's oral and written communication skills ( Jalongo \& Sobolak, 2010; \& Pikulski \& Templeton, 2004).

Concept teaching. Frayer and associates first developed concept teaching in 1969 (Graves \& Prenn, 1986). Concept teaching is a multi-layer teaching tool. Concept teaching involves the introduction of an unfamiliar word/concept through describing the 
attributes of the word/concept (Kester Phillips, et al., 2008). Next, comparison is made between the new word/concept and previously known words/concepts.

Definitions. Dictionary look-up is perhaps the oldest version of vocabulary instruction. Students across time have been given a list of words to find, copy, and then forge into a sentence. Definitional word knowledge is a basic understanding of the word and does not allow the reader to infer meaning into a text (Rupley, et al., 1998/1999). Flanigan and Greenwood (2007) characterize dictionary look-up and writing as a "one size fits all" instructional approach. The use of the dictionary for vocabulary instruction has been repeatedly criticized (Graves \& Prenn, 1986). Memorization that a student exhibits with the typical Monday to Friday definition exercises becomes only a short term memorization drill and is not an exercise in learning (Misulis, 1999) or application of literacy knowledge in any authentic way.

Graphic Organizers. Graphic organizers provide students with a visual picture of how words/concepts are related (Blachowicz, Fisher, Ogle, \& Watt-Taffe, 2006; kester Phillips, et al., 2008; Monroe, 1998; Thelen, 1986; Thompson \& Rubenstein, 2000). Several instructional variations of graphic organizers exist: concept wheels, semantic word maps, and webbing are examples. Each of these methods uses shapes and lines to connect associations and related terms (Graves \& Prenn, 1986; Rupley, et al., 1998/19990).

Semantic feature analysis. Semantic feature analysis concentrates on the relationship of categorical words. The analysis underscores similarities and differences between words (Greenwood, 2002; Rupley, et al., 1998/1999). Semantic feature analysis 
uses categorization as a way to distinguish words and their meanings (Blachowicz, et al., 2006).

\section{Vocabulary and Core Content}

Content area teachers base instructional decisions on a time-cost relationship (Flanigan \& Greenwood, 2007; Greenwood, 2002). The time-cost relationship refers to the amount of instructional time any given classroom event consumes as well as the amount of teacher preparation time any given classroom event requires. Events that have an inverse relationship or an off balanced relationship will not typically be featured in multiple classroom environments. Therefore, any academic instructional strategy needs to be systematic and fruitful. Core content vocabulary has several unique characteristics. Core content vocabulary focuses heavily on the relationship between the words within the content (Armbruster \& Nagy, 1992). Core content vocabulary also involves terms that build on each other (Spencer \& Guillaume, 2006). For example, parallel lines are defined as coplanar lines that do not intersect. To fully understand the meaning of parallel lines ones would also have to know the definition of coplanar.

One important decision that content area teachers have to understand surrounding vocabulary is being able to not only determine what vocabulary words to teach, but what vocabulary words not to teach (Flanigan \& Greenwood, 2007).

Core content vocabulary differs from general vocabulary in three areas. First, core content vocabulary includes the terms that are mandatory for the student to know before he/she will be able to comprehend and learn the content unit (Armbruster \& Nagy, 1992). Second, core content vocabulary typically introduces words that are new concepts to students rather than simply introducing synonyms for words the student already knows 
(Armbruster \& Nagy, 1992). Third, core content vocabulary is not random groupings of unknown words (Armbruster \& Nagy, 1992). The vocabulary words within core content units are related and build on each other (Spencer \& Guillaume, 2006

Core content area textbooks are frequently written at a higher grade level than they are assigned (Mastropieri, Scruggs, \& Graetz, 2003). Core content textbooks also lack good structure and provide insufficient definitions (Mastropieri, et al., 2003).

All core content areas require reading skills. Mathematics has been recognized as the most difficult of the content areas for students to read (Monroe, 1998; Reehm \& Long, 1996; Schell, 1982). Schell (1982) describes mathematics as having, " more concepts per word, per sentence, and per paragraph than any other area" (p. 544).

\section{Vocabulary and Mathematics}

The National Council for Teachers of Mathematics (2000) substantiates mathematic as being a content area impacted greatly by vocabulary (Fisher \& Frey, 2004). The National Council for Teachers of Mathematics (2000) when describing mathematical vocabulary states vocabulary is, "factual, procedural, and conceptual understandings that are inexorably woven together in the study of mathematics" (Fisher \& Frey, 2004). Mathematical vocabulary requires not only surface knowledge but multi-dimensional understanding (Fisher \& Frey, 2004).

Mathematics is a language of symbols that represent fundamental concepts (Adams, Thangata, \& King, 2005; Miller, 1993; Oldfield, 1996; Reehm \& Long, 1996). The National Council of Teachers of Mathematics (NCTM) produced a Curriculum and Evaluation Standard for School Mathematics (1989) document that establishes communication as one of the necessary elements of mathematical instruction (Kidd, 
Madsen, \& Lamb, 1993; Monroe \& Orme, 2002). According to this document, NCTM outlines four communication standards that students should be able to demonstrate. First, students should be able to organize and consolidate their mathematical thinking though communication. Furthermore, students should be able to communicate their mathematical thinking coherently and clearly to peers, teachers, and others. Students should also be able to analyze and evaluate the mathematical thinking and strategies of others. Lastly, students should be able to use the language of mathematics to express mathematical ideas precisely (http://standards.nctm.org/document/appendix/numb.htm).

Students struggle with mathematical vocabulary due to the fact that mathematical terms are only found in content pieces. This limited exposure, to the mathematical vocabulary, decreases the likeliness of student knowledge and retention (Miller, 1993; Monroe \& Orme, 2002). A high volume of unfamiliar vocabulary words ensures vocabulary instruction as a primary component of mathematical literacy (Lee \& HernerPatnode, 2007; Monroe \& Orme, 2002). Mathematical vocabulary often defines intangible abstract numeral units (Monroe \& Orme, 2002). These units, unlike a square or circle, cannot become three-D manipulatives and therefore, challenge the mind. Carter and Dean (2006) state that vocabulary instruction, questioning, and anticipatory activities increase comprehension of mathematical text by students (Fisher \& Frey, 2008).

Garbe (1985) suggests that vocabulary is a skill that must be taught in mathematics (Lee \& Herner-Patnode, 2007). Students can be hindered in their ability to learn mathematics (Miller, 1993) when they do not understand the vocabulary (Lee \& HernerPatnode, 2007). Therefore, limited acquisition of the mathematical vocabulary also impacts the student's ability to use their knowledge related to new concepts. 
Additionally, acquisition of the mathematical vocabulary enables students to understand age-appropriate mathematical concepts (Lee \& Herner-Patnode, 2007).

Learning interference (Monroe \& Orme, 2002) is a characteristic of mathematical vocabulary that hinders student learning. The learning is hindered because the mathematical terms have different meanings in everyday language than they have within the mathematical content jargon (Monroe \& Orme, 2002; Reehm \& Long, 1996; Rubenstein \& Thompson, 2002; Thompson \& Rubenstein, 2000). For example, students might readily be able to define "yard" as a piece of land, but the student might not be able to define "yard" as a unit of measure. Multiple meanings of mathematical terms within the mathematics content further blur student comprehension (Adams, Thangata, \& King, 2005; Miller, 1993; Reehm \& Long, 1996; Rubenstein \& Thompson, 2002; Thompson \& Rubenstein, 2000). For instance, a 'square' is "a four-sided polygon with equal side and four 90-degree angles, and multiply a number by itself (Miller, 1993, p. 311).

Before any behavior becomes automatic the behavior must first be reinforced multiple times. True learning occurs only when one is able to apply and demonstrate the behavior within its context (Misulis, 1999). Hence, mathematical vocabulary affected by learning interferences forces a student to learn multiple meanings of some mathematical vocabulary in varying contexts.

\section{Vocabulary and Students with Learning Disabilities.}

Research in the field of vocabulary instruction, specifically for students with disabilities, has been lacking according to Jitendra, Edwards, Sacks, and Jacobson (2004). Studies are available where researchers include students with disabilities as members of their sample. Bryant, Goodwin, Bryant and Higgins' (2003) study is a review of six 
studies that target vocabulary instruction for middle and secondary students with learning disabilities. Their review highlights four separate vocabulary models: computer assisted instruction, fluency-building vocabulary practice, mnemonic strategies, and concept enhancement instruction. Their review found several points of interest. First, all of the studies involve some type of manipulative. Second, in all of the studies, the students made gains with limited instruction. Bryant et al. (2003) conclude that a variety of interventions are successful in improving vocabulary knowledge with students who have learning disabilities across content areas.

In their review of the literature on vocabulary instructional for students with learning disabilities Jitendra, Edwards, Sacks, and Jacobson (2004) found 19 articles from 1978 to 1996 . These 19 articles represented 27 separate studies (Jitendra et al., 2004). It should be noted that while these 19 articles and corresponding inquiries focus on special education students who are characterized as students with learning disabilities, the students were not moderate and severe special education students. Table 1 provides a listing of the 19 articles along with the given IQ levels of the participants in each of the studies. Limited generalizations might be drawn between special education students with learning disabilities and special education students with moderate and severe disabilities.

Jitendra et al. (2004) review concluded that vocabulary instruction for students with learning disabilities could lead to vocabulary acquisition. The review noted that the decision on which instructional methods to use rested with the intent of the vocabulary goal. For example, direct instruction strategies might be best suited when the purpose is to introduce students to new word and its definition (Jitendra et al., 2004).

\section{Vocabulary and Students with Moderate and Severe Disabilities}


In reviewing of journal articles involving vocabulary and moderate and severe disabilities, Browder and associates $(1998,2006, \&$ 2009) conducted a series of followup studies over the course of 10 years. The researcher's focus was on literacy skills with participants who the researchers described as having developmental disabilities. Browder, Wakeman, Spooner, Ahlgrim-Delzell, and Algozzine (2006) reviewed 128 studies that investigated teaching reading to students with severe cognitive disabilities. Six hundred and nineteen participants within the studies are classified by their researchers as being individuals with moderate mental disabilities. Additionally, 124 of the participants within the studies are classified by the researcher as being individuals with severe mental disabilities. However, IQ ranges for the classifications in the studies are not given. The majority of the studies measured sight word recognition and picture identification.

Browder et al. (2006) reported that only $24 \%(\mathrm{~N}=31)$ of the studies in their review state any measure of comprehension. Eighteen of the 31 studies focus on functional application of literacy such as reading a recipe. The remaining 13 studies have academic application such as question response to reading passages. Note that none of the 128 research projects investigate vocabulary acquisition.

McDonnell, Johnson, Polychronis, and Risen's (2002) research project taught two students (IQ's 50 and 55) to give verbal definitions of health and computer words respectively using embedded instruction. The two students are able to acquire the vocabulary definition for all of the target vocabulary (McDonnell et al., 2002).

All of the before mentioned articles included either only a small percentage of 
TABLE 1

Summary of Projects

\begin{tabular}{|c|c|c|}
\hline Citation & Intervention Description & IQ Scores \\
\hline Anders, Bos, \& Filip (1984) & Vocabulary look-up Vs. SFA & $85-115$ \\
\hline \multicolumn{3}{|l|}{ Boettcher (1983) } \\
\hline Study 1 & Reading Comprehension System CAI Program & Below Normal \\
\hline Study 2 & Reading Comprehension System CAI Program & $\mathrm{N} / \mathrm{A}$ \\
\hline Bos \& Anders (1990) & DI vs. SM vs. SFA vs. SSFA & 88.67 \\
\hline \multicolumn{3}{|l|}{ Bos \& Anders (1992) } \\
\hline Expt. 1 & SM vs. SFA vs. SSFA vs. DI & 96.93 \\
\hline Expt. 2 & SM vs. SFA vs. SSFA vs. DI & 91.97 \\
\hline Expt. 3 & SM vs. SFA vs. SSFA vs. DI & 94.00 \\
\hline Expt. 4 & SM vs. SFA vs. SSFA vs. DI & 92.38 \\
\hline Expt. 5 & SM vs. SFA & 92.63 \\
\hline Expt. 6 & SM vs. SFA & 90.63 \\
\hline
\end{tabular}




\section{TABLE 1}

continued

Citation

Bos, Allen, \& Scalon (1989)

Bos, Anders, Filip, \& Jaffe (1989)

Condus, Marshall, \& Miller (1986)

Herbert \& Murdock (1994)

Horton, Lovitt, \& Givens (1988)

Johnson, Gersten, \& Carnine (1987)

Koury (1996)

Mastropieri, Scruggs, \& Fulk (1990)
Intervention Description

IQ Scores

DI vs. SM vs. SFA vs. SSFA

96.93

SFA vs. DM

$85-115$

$\mathrm{KI}$ vs. $\mathrm{PC}$ vs. SE vs. C

Average

CAI No Speech vs. CAI Synthesized Speech vs.

CAI Digitized Speech

CAI (EI) vs. CAI (CI)

N/A

CAI (LTS) vs. CAI (STS)

N/A

Pre-taught voc w/o video anchors

Regular Ed.

Pre-taught voc w/ video anchors

Regular Ed.

Pre-taught voc w/ video anchors

LD

Keyword vs. DI

92.3 
TABLE 1

continued

Citation

Intervention Description

IQ Scores

Mastropieri, Scruggs, Levin, Gaffney,

\& McLoone (1985)

Expt. 1

MN vs. DI

95.6

Expt. 2

MN vs. DI

96.5

McLoone, Scruggs, Mastropieri,

MN vs. Directed Rehearsal

96.22

\& Zucker (1986)

MC vs. $M G$ vs. MP

Normal

Pany, Jenkins, \& Schreck (1982)

Expt. 2

MC vs. MG vs. MP vs. NM

Normal

Expt. 3

MP vs. No-instruction Control Normal

Schuster, Stevens, \& Doak (1990)

Constant Time Delay

89

Struggs, Mastropieri, Bakken,

AI vs. Textbook Instruction

84.92 


\section{TABLE 1}

continued

\begin{tabular}{llr}
\hline Citation & Intervention Description & IQ Scores \\
\hline Veit, Scruggs, \& Mastropieri (1986) & MN vs. DI & 92.5 \\
\hline
\end{tabular}

Note. AI-Activity/inquire oriented, C-Control, CAI- Computer assisted instruction, CI-Control items, DI-Direct instruction,

DM- Dictionary method, EI-experimental items, KI- Keyword-image, LTS-Large teaching set, MC- Meaning from context,

MG-Meaning given, MN-Mnemonic imagery, MP-Meaning practiced, NM-No meaning control, PC- Picture context, SE-

Sentence-experience context, SFA-Semantic features analysis, SM-Semantic mapping, SSFA-Syntactic/semantic feature analysis, STS-Small teaching set 
participants with moderate and severe disabilities or were looking at teaching functional skills. The reversal of what had been previously done in the research is the focus of the current study.

\section{Time Delay}

Time delay is a systematic teaching procedure that delivers near errorless work from its participants. Touchette (1971) is the originator of time delay. The underlying fundamentals of time delay deal with the transfer of stimulus control. Learners gain stimulus control when learning is achieved. The transfer of stimulus control is contrived through the use of regulated prompts from the instructor to the student during instruction. Time delay has two distinct methods-constant and progressive. The core foundation of time delay is very simplistic. A time delay teaching procedure solicits a single response from a participant and provides the correct response to the participant, if necessary, in the form of a prompt. The response might be a word, a number, or a label (Stevens \& Lingo, 2005).

The current body of research shows that constant time delay (CTD) prompting is an accepted and well established technique to use with children with autism and other disabilities. CTD has been used to teach verbal skills, rote skills, academic skills and leisure skills (Schuster, Morse, Ault, Doyle, Crawford, \& Wolery, 1998). Over time, CTD and progressive time delay (PTD) have become two of the most widely accepted intervention techniques. In 1987, Handen and Zane looked at 26 separate research publications from 1971 to 1986 . They found that CTD and PTD have been shown to be 
effective teaching techniques for individuals with many different types of disabilities (Walker, 2008).

Time delay techniques are described as prompting procedures that start with a 0 second delay which is altered systematically as acquisition is acquired. This allows for stimulus control to move from the verbal or physical prompt delivered by the facilitator to the learner (Kurt \& Tekin-Iftar, 2008; Schuster, et al, 1998; Walker, 2008). In progressive time delay procedures the delay starts at 0 seconds and then is increased systematically according to guidelines set by the researcher. In constant time delay, the prompting interval is set and does not change (Ault, Worley, Gast, \& Doyle, 1988).

\section{Progressive Time Delay}

Progressive time delay functions in the same manner as constant time delay with the exception of the timing of the delivery of the prompts for the correct answer by the instructor. In progressive time delay, the prompts from the instructor are consistent and progressive-increasing in duration. The instructor will begin with an initial time delay, most often zero seconds. As the student learns the material, the instructor will progress the time delay forward by one to two seconds. The prompting procedure continues to allow the student to always answer correctly. The progression of the time between question and prompt allows the student to move toward independent answering. A zero second constant time delay is also commonly referred to as errorless teaching.

\section{Constant Time Delay}

The foundation of constant time delay is the consistent and constant delivery of the prompt by the instructor. When the instructor finishes delivering the question, the instructor will wait the established delay time, and then the instructor will provide the 
prompt to the student answering the question. The prompt ensures that a correct response is always given by the student. Correct responses are met with positive reinforcement. Behavior that is praised is more likely to reoccur in the future which leads to more correct responses and more positive reinforcement.

According to Browder and Lalli (1991) and Browder and Xin (1998), constant time delay is the most widely used instructional teaching technique for sight word acquisition (Cohen, Heller, Alberto, \& Fredrick, 2008).

Constant time delay and students with disabilities. Many research articles have been published supporting the effectiveness of constant time delay teaching procedure. Two major reviews of literature conducted in the 1990's are on constant time delay. Wolery, Holcombe, Cybriwsky, Doyle, Schuster, Ault, and Gast (1992) examined constant time delay and discrete task. Shuster, Morse, Ault, Doyle, Crawford, and Wolery (1998) examined constant time delay and chained task.

The Wolery et al. (1992) review includes 36 studies. One hundred and seventy three individuals participated in the 36 studies. Only one of the participants is classified by researchers (Browder, Morris, \& Snell, 1981) as having severe mental retardation. Twenty-seven of the participants have moderate mental retardation listed as a primary diagnosis. The largest group of participants, representing $29 \%$ of the subjects $(\mathrm{N}=51)$, are individuals who did not have a known disability (Wolery et al., 1992). Ten percent of the participants in these 36 studies are individuals with moderate or severe mental disabilities.

Many different discrete response behaviors are included in the Wolery et al. (1992) review. These responses include sight words, letter recognition, spelling, addition, 
picture labeling, and word definitions among others. Sight words are the largest group of discrete responses represented. Eighteen of the 36 studies sought to teach sight word recognition. It is noted that word definitions or content vocabulary are the focus of only one (Schuster, Stevens, \& Doak, 1990) of the reviewed research studies.

Shuster et al. (1998) reported five similar characteristics that both literature reviews found concerning constant time delay with discrete and chained tasks. The researchers reported that discrete and chained tasks procedures "(a) have been effective with a wide range of students, ages, and disabilities, (b) have been effective in a variety of settings with an assortment of persons serving as trainers, (c) have been successful in both individual and group arrangements, (d) have employed a variety of prompts and other procedural parameters when delivering instruction, and (e) have been used in studies that are considered methodologically sound" (Schuster et al., 1998, p. 104).

Hughes and Fredrick's (2006) study looked at constant time delay and class wide peer tutoring. The study has several research questions, but the one pertinent part to this study involved student with learning disabilities mastering three 3-set vocabulary terms. Two of the three participants (IQ score: $90,101, \& 106$ ) were able to master all three word sets and maintain the knowledge for 7 weeks.

Constant time delay and students with moderate and severe disabilities. Ault, Gast, and Wolery (1988) and Gast, Ault, Wolery, Doyle, and Belanger (1988) reported that constant time delay has been used to successfully instruct students with moderate mental disabilities sight word recognition (Cohen et al., 2008).

Cohen et al. (2008) used constant time delay techniques to teach word reading with a decoding process to five students with mild and moderate mental disabilities. The 
participants' IQ's are reported as 56, 61, 57, 48, and 40 (Cohen et al., 2008). All five of the participants met criteria through the acquisition of decoding and reading words (Cohen et al., 2008).

The Collins, Evans, Creech-Galloway, Karl, and Miller (2007) study looked at the acquisition of functional and core content vocabulary recognition for four students with moderate and severe disabilities. The students' IQ's were reported as being 50, 40, 43, and 46 (Collins et al., 2007). The researchers found that students with moderate and severe disabilities were able to acquire recognition of both the functional and core content vocabulary words. While the Collins et al. (2007) study validated using core content with individuals with moderate and severe disabilities, this study only looked at the participants' ability to read the term, not define the term.

Constant time delay and vocabulary. Beyond teaching word recognition, time delay techniques have also been used to teach word definitions, a higher depth of knowledge skill. Schuster, Stevens, and Doak (1990) investigated expressive word definitions or vocabulary as a target skill. Three students participated in this research study. All three of the students were in a fifth grade. All three of the students received Learning Behavior Disability (LBD) resource room services as part of their educational plan. The students' IQs were listed as 76, 101, and 90. First, the students were asked to verbally recall definitions for words displayed on word cards. Second, the students were shown a target word and asked to provide the definition. Third, the students were given two sets of five words. The second set was initiated only after the first set reached criteria. The response criteria states that the students had to start reciting the definition within five seconds and that the student had to complete the definition within fifteen 
seconds in order for the response to be considered correct (Schuster, Stevens, \& Doak, 1990). Two of the three students were able to acquire the targeted words at $100 \%$, and they were able to maintain the knowledge at six, ten, and fourteen week follow-ups. The third student was able to acquire the definitions at $100 \%$ accuracy but fell to $93 \%$ retention at the ten week follow-up for the first set of words and at the fourteen week follow-up for the second set of words (Schuster, Stevens, \& Doak, 1990).

While the Schuster, Stevens, and Doak's (1990) study provided evidence that constant time delay instruction is a suitable method of instruction for vocabulary to the population of "mildly handicapped" students as referred to by the authors, generalizations cannot be made from this research for the effectiveness of using constant time delay instruction for vocabulary to students with moderate and severe disabilities.

\section{Conclusion}

The past 30 years has established a large body of research focused on teaching moderate to severe disabled individuals' functional skills (Collins et al., 2007). No Child Left Behind Act of 2001 has shifted teacher focus from solely functional skills to academic skills based on core content knowledge (Collins et al., 2007). Teachers have mandates from NCLB to use scientifically based research methods for instruction of the core content material (Browder \& Cooper-Duffy, 2003). Much of the research in this area does not focus on the student learning the definition of the vocabulary word. The sole focus of the research projects appears to have been to determine if the students can be taught how to read the sight word. Some of the investigations refer to the skill being targeted as vocabulary but upon inspections, the researchers' agenda appears only to be to 
teach the recognition of the word in its textual form in isolation, not the definition of the word.

The vocabulary gap within core content areas as well as in the general academic environment directly affects the level of student learning and testing results. While student learning is the focus, state and federal mandates, make testing a reality of the educational system.

This research study will expand the literature to include using constant time delay prompting procedures to teach core content material to high school individuals with moderate to severe disabilities. The vocabulary words are selected based on the tenth grade level curriculum as determined by the state's assessment guidelines. While the parameters for this study are modeled after the established state alternate assessment criteria, this research project will not be assessing or validating any part of the state alternate assessment. The mirroring of the grade level and content is employed only for the sole purpose of validating the researcher's decision to use mathematical core content vocabulary with $10^{\text {th }}$ graders.

One glaring inconsistency that the author discovered during the research for this study is the varying use of the classifying vocabulary for students with special needs including: developmental delay, learning disabled, mild mental disability, moderate mental disability and severe mental disability. Some authors provided the parameters of the IQ scores that they use in their classification, but a majority of the research articles did not provide such information. Still, other authors used participants that are classified with a learning disability but whose IQs range from 90-100. While these participants could have documented learning challenges, it is difficult, at best, to attempt to draw 
generalizations and conclusions about students with the same classification but whose IQs range is in the $50 \mathrm{~s}$ and $60 \mathrm{~s}$. Detailed analysis of this classification confusion far out reaches the scope of this research project. 


\section{CHAPTER III}

\section{RESEARCH METHODOLOGY}

The purpose of this chapter was to describe the methods used to examine constant time delay and vocabulary acquisition in this study. The major areas addressed include (a) experimental design, (b) participant section, (c) materials, (d) data collection, and (e) reliability procedures.

\section{Experimental Design}

A multiple probe design (Horner \& Baer, 1978; Murphy \& Bryan, 1980) across behaviors (vocabulary) with replication across participants was used to assess the effectiveness of constant time delay and the acquisition of mathematical core content vocabulary by $10^{\text {th }}$ graders with moderate and severe disabilities. Data were analyzed for each participant in regards to the mean percent correct for the vocabulary terms as a whole, and data were analyzed to determine the increase of knowledge for each individual vocabulary term. The multiple probe design has been used in numerous constant time delay research projects (Chandler, Schuster, \& Stevens, 1993; Koscinski \& Gast, 1993; Schuster, Stevens, \& Doak, 1990; Williams \& Collins, 1994).

In a multiple probe, multiple baseline design, baseline data are only collected intermittently on the participants waiting to begin the instructional phase and only intermittently during the instructional phase. The intermittent collection still provides acquisition and trend data. The intermittent baseline data decreases the likelihood of inappropriate behaviors and incidental learning. Participants might engage in 
inappropriate behaviors in response to anxiety and frustration relating to repeatedly being asked to perform a skill that is not yet in the participant's repertoire. Incidental learning might also occur from repeated exposure to the term and definition during multiple baseline sessions.

Multiple baseline research designs (Baer, Wolf, \& Risley, 1968) allow researchers to compare baseline data to intervention data. Replication establishes the presence of a functional relationship between the intervention and the behavior. One major drawback to multiple baseline designs, especially to institutional agencies such as schools and state agencies, is the staggered start time for each participant. The staggered start time lengthens the amount of time needed by the researcher to conduct the study (Kennedy, 2005).

Single subject experiment designs (Baer, Wolf, \& Risley, 1968) have dominated the special education research field (Horner, Carr, Halle, Odom, \& Wolery, 2005; \& Kennedy, 2005). Interpretations of single subject research are typically conducted through examination of data, not through statistical analysis (Horner et al., 2005). In single subject research functional relationships can be inferred after successful replication (Merchant, Renshaw, \& Young, 2006). The intervention will be introduced systematically to all seven of the participants. A replication of the study will be conducted concurrently with the primary study. The primary study will include verbal participants. The replication study will include non-verbal participants.

\section{Permissions}

Permission to conduct this project was granted by the principal of the high school where the research was conducted. Parent permission was also obtained (see Appendix 
A). Permission was also granted from the University of Louisville's Internal Review Board (IRB) (see Appendix B).

\section{Settings}

The study took place in a rural high school in Kentucky. Total school enrollment was 1426 students in grades 9-12 and grade 14. One hundred and thirty-five students in the school had an individual education plan (IEP), and 39 students in the school had a 504 plan.

Ninety percent of the student population was Caucasian. Three percent of the student population was African-American. Hispanic students accounted for 4.5 percent of the population, and 2 percent of the student population was registered as American Indian, Asian, or two or more races. Twenty-two percent of the student population qualified for the federal free or reduced-price lunches based on family income. Gender distribution was roughly equal (see Table 2 for summary of setting demographics).

The instructional sessions took place in an empty special education classroom. The adult and the student sat across from each other at a rectangle table that measured $4 \times 2$ feet.

\section{Participants}

Participants were six $10^{\text {th }}$ graders who through their IEP are assigned eligibility to participate in the Kentucky state alternate assessment. All six of the students spend the majority of their day in a special class. The six participants were in one of the three community based instruction (CBI) classrooms in this rural high school.

Four males and two females participated in the study. Five were Caucasian and one was Hispanic. One of the participants qualified for the federal free lunch program based 
on their families' income. The participants were divided into two groups: verbal and non-verbal. Group one consisted of the verbal participants and group two consisted of the non-verbal participants.

Table 2

Summary of Setting Demographics

Race Male Female

$\begin{array}{lll}\text { Caucasian } & 651 & 630\end{array}$

$\begin{array}{lll}\text { African-American } & 28 & 20\end{array}$

Hispanic/Latino $\quad 41 \quad 24$

Other 11 21 $\begin{array}{lll}\text { Total } & 731 & 695\end{array}$

Participants A, B, and C belonged to group 1. Participant A was a 16 year old verbal male classified with autism, mild mental disabilities, speech language impairment (SLI), and language speech sound production. Participant B was a 16 year old verbal male classified with functional mental disorder (FMD), and SLI expressive and receptive language and articulation. Participant $\mathrm{C}$ was a 16 years old verbal female classified with FMD and other health impairment (OHI).

Participants $\mathrm{D}, \mathrm{E}$, and $\mathrm{F}$ belonged to group 2 also referred toa s the non-verbal group. Participant D was an 18 years old non-verbal male classified with FMD. Even though participant $\mathrm{D}$ was two years older than the majority of the other participants he was only in his second year of high school and therefore was considered to be registered 
in the $10^{\text {th }}$ grade. Participant $\mathrm{E}$ was a 16 year old non-verbal female classified with multiple disabilities, FMD, OI, OHI, and SLI. Participant F was a 15 year old nonverbal male classified with FMD, SLI receptive and expressive language, and autism (see Table 3 for summary of participants).

\section{Materials}

In the section a detailed description of all of the material used in this research study will be presented. The researcher prepared the word sets, definition and response flashcards, the presentation board and the generalization materials for this study.

\section{Definition and Response Flashcards}

Instructional materials consist of $5 \frac{1}{2}$ inch X $81 \frac{1}{2}$ inch white index cards. The index cards were laminated for protection. Each index card holds one definition or one term. The definitions were computer printed in Times New Roman typeset using a 36 font in black. The beginning of the first word in the definition was capitalized, with punctuation at the end of the definition. Definitions were centered on the index cards (see Appendix $\mathrm{C}$ for an example of this instructional material).

The term cards featured the vocabulary terms. The terms were printed on the same $5 \frac{1}{2}$ inch by $81 / 2$ inch index card as the definition cards. The term cards were printed in Times New Roman typeset using a 72 font in black and laminated for their protection. The first letter of each term was capitalized (see Appendix $\mathrm{C}$ for an example of the instructional material).

\section{Word Card Selection}

Word selection procedures. The targeted mathematical vocabulary words came

from the glossary of the $10^{\text {th }}$ grade geometry textbook, Geometry (Glencoe Mathematics, 
Table 3

Summary of Participants

\begin{tabular}{llllll} 
Participant Gender Race Communication & Classification & $\begin{array}{l}\text { IQ Score } \\
\text { Teacher }\end{array}$ & $\begin{array}{l}\text { Adaptive Score } \\
\text { Adaptive Score } \\
\text { Parent }\end{array}$ \\
\hline
\end{tabular}

\begin{tabular}{llllllll}
\hline A & M & W & Verbal & MMD, SLI & 40 & 80 & 56 \\
B & F & W & Verbal & FMD, OHI & 40 & N/A & N/A \\
C & M & W & Verbal & Autism & 64 & 95 & 57 \\
D & M & H & Non-Verbal & FMD & N/A & 40 & 40 \\
E & M & W & Non-verbal & FMD, SLI, Autism & N/A & 43 & 40 \\
F & F & W & Non-Verbal & Multiple, FMD, & N/A & N/A & N/A
\end{tabular}

Note. Adaptive Behavior Assessment System 2nd Edition, 2000, Western Psychological Services. IQ score of NA indicates

that the student is not testable. Adaptive score of NA indicates that the adaptive assessment was not done on the student. FMD represents functional mental disability. MMD represents mild metal disability. 
2005 ) at the high school where the participants attended. A stratified randomization procedure was used to select 50 words from the glossary of the $10^{\text {th }}$ grade geometry textbook. Every fifth word was selected until the $50^{\text {th }}$ word was acquired (see Appendix D for vocabulary terms and definitions).

Social validation of word selection. Math teachers at the high school where the participants attended were given a survey of potential terms and asked to answer yes/no to whether the definitions were correct and that the terms were $10^{\text {th }}$ grade Geometry terms and yes or no to if the terms were commonly used.

Additionally, terms with definitions greater than 15 words and terms made up of multiple words were eliminated from the list of potential vocabulary terms (see Appendix E for modified list of vocabulary terms and definitions). The terms with greater than 15 words were eliminated to help control for an auditory processing confound based on the time it would take to deliver the definition and term choice. For example, the definition for the term "resultant" is the sum of two vectors. While the definition for the term "tessellation" is a pattern that covers a plane by transforming the same figure or set of figures so that there is not overlapping or empty spaces. Terms made up of more than one word were also eliminated to help control for unintentional visual cuing on the answer cards. Therefore, twenty-nine terms were eliminated from the original 50 word list leaving 21 vocabulary terms for the first teacher survey (See Appendix E).

Nine of the $14(64 \%)$ math teachers responded to the first teacher survey. The first teacher survey results excluded 14 of the 21 terms. The terms were excluded if four or more of the nine teachers marked 'no' for either incorrect definition or 'no' for a commonly used term. 
The math teachers were given a second survey with the 7 remaining terms from the first survey along with the 29 terms that had originally been eliminated due to either multiple word terms or definition length of 15 or greater words. The second survey had a total of 36 terms (see Appendix F for a list of the second survey). Seven of the $14(50 \%)$ math teachers responded to the second math term survey. Sixteen of the 36 terms were excluded by the math teachers. Terms were excluded if four or more of the math teachers marked 'no' for either incorrect definition or 'no' for a commonly used term. The researcher then excluded four additional terms because the term itself was used in the definition. This procedure resulted in 16 possible target vocabulary for the research study (see Appendix G).

\section{Word Card Set Screening Procedures}

Each participant took part in one screening session of the 16 potential vocabulary terms. The session consisted of one trial per vocabulary term in which the participants were asked to identify the correct term from a given definition. The participants responses were recorded as correct, incorrect or no response (see Appendix $\mathrm{H}$ for screening data sheet). The procedures used for the screening process included placing three distracter terms cards on the table in front of the participants. Second, the definition card was held up in front of the participant and read to them. Third, the researcher pointed to and labeled each of the term cards. The first response from the participant was recorded as correct, incorrect, or no response. If no response was given within five seconds a no response was recorded. Items identified correctly by each participant during their screening session were eliminated. 
Participant A and B answered eight definitions correctly. Participant $\mathrm{C}$ answered four definitions correctly. Participant $\mathrm{D}$ answered one definition correctly. Participants $\mathrm{E}$ and $\mathrm{F}$ did not answer any of the definitions correctly (see Appendix I for a list of the items answered correctly during screening).

Word sets. The words from each of the participants screening results that were answered correctly were used in a stratified randomization procedure where every $10^{\text {th }}$ word was selected until 5 target words were chosen. These 5 words became the targeted vocabulary for this research study (see Table 4 for each participant's target vocabulary list).

Seven of the terms were selected by only one participant. Four of the terms were used by two of the participants. Two of the terms were used by three of the participants. One of the terms was used by four of the participants, and one of the terms was used by five of the participants.

\section{Word Set Procedures}

The presentation order for the targeted vocabulary was randomized through the use of an online randomization program (Urbaniak \& Plous, 2010). Twenty 5-number sets of randomized numbers were used for the presentation order of the targeted vocabulary. This would provide a five day presentation rotation of the targeted vocabulary (see Appendix J). The targeted vocabulary was numbered in order from 1-5 alphabetically (see Table 4). Set \#1 through set \#4 formed day one presentation order. Set \#5 through set $\# 8$ formed day two presentation order. Sets \#9 through \#20 were paired in the exact same manner as the first two sets until five days of presentation order was established.

\section{Distracter Cards}


Table 4

Vocabulary Target Terms

Participants

\begin{tabular}{llllll}
\hline A & B & C & D & E & F \\
Angle & $\begin{array}{l}\text { Line of } \\
\text { symmetry }\end{array}$ & $\begin{array}{l}\text { Angle of } \\
\text { depression }\end{array}$ & Adjacent angles & Coplanar & Coplanar \\
Coplanar & Midpoint & Coplanar & Degree & $\begin{array}{l}\text { Irregular } \\
\text { polygon }\end{array}$ & $\begin{array}{l}\text { Irregular } \\
\text { Polygon }\end{array}$ \\
Midpoint & N-gon & Degree & Obtuse angle & N-gon & N-gon \\
Obtuse angle & Obtuse angle & Pi & Parallelogram & Obtuse angle & Obtuse angle \\
Sine & Transversal & Radius & Radius & Sine & Sine \\
\hline
\end{tabular}


Ten distracter cards were used in this study (see Table 5 for a list of distracter terms). The presentation order for the distracter cards was randomized through the use of an online randomization program (Urbaniak \& Plous, 2010). The distracter cards were numbered 6-15 alphabetically.

Each participant's distracter word list was created from the first 10 of the 11 remaining terms, alphabetized, not selected as targeted vocabulary from the original 16 potential terms were used as distracter terms. One of the terms was used by all six participants. Six of the terms were used by five of the participants. Three of the terms were used by four of the participants. Three of the terms were used by three of the participants. One of the terms was used by two of the participants and one of the terms was only used by one of the participants (see Table 5 for each participant's distracter term list).

The placement order for the targeted vocabulary terms and the distracter cards was randomized through the use of an online randomization program (Urbaniak \& Plous, 2010). The targeted vocabulary terms were labeled group 1 . The distracter cards, $6-10$, were label group 2. The distracter cards, 11-15, were labeled group 3. One hundred 3number sets of randomized numbers were used to determine the placement of each of the cards for one-week of instructional sessions (see Appendix K for group randomization chart). Times New Roman typeset using a 72 font in black and laminated for their protection. The first letter of each term was capitalized (see Appendix $\mathrm{C}$ for an example of this instructional material).

\section{Presentation Board}

The presentation board was constructed from $1 / 2$ inch foam board. The board was 12 
inches tall and 30 inches long. The board was covered front and back with black felt. To help stabilize the board, it was glued to a yard stick that was spray painted black (see Appendix L). The researcher constructed the presentation board.

\section{Measures}

\section{Independent Variable}

The independent variable was the constant time delay instructional intervention. Participants were given instruction on ten mathematical content area definitions.

\section{Dependent Variable}

The dependent variable was the percent correct of target word definitions. Percent correct was calculated by dividing the number of correct responses by five, the total number of trials in each session. Responses were marked correct if the participant initiated an answer either receptively or expressively within five seconds following the end of the reading of the target definition.

\section{Procedures}

\section{Baseline Sessions}

All baseline sessions were conducted by the experimenter. Four baseline sessions occurred prior to the beginning of the research study. Four baseline sessions were conducted to ensure a greater evidence of a stable baseline. Single-case design experts have recently stated that for studies to meet the standard of a single-case study the study

must have at least three baseline sessions (Kratochwill, Hitchcock, Horner, Levin, Odom, Rindskopf, \& Shadish, 2010). The five targeted vocabulary words were presented one time during each of the four sessions for a total of 20 trials. If there was fluctuation or an upward trend noted in the baseline, baseline sessions were continued until the data were 
stable and it is determined that the ability to document an effect following intervention was not compromised (Horner, Carr, Halle, McGee, Odom, \& Wolery, 2005). If a continued upward trend was noted after eight baseline sessions, then the math words used for the participant would be changed using mathematical vocabulary words from the word pool.

\section{Instructional Sessions}

Errorless Sessions. Following the initial baseline data collection phase, the first two participants began the errorless teaching phase. Group 1 participants entered the instructional phase in the order of A, B, C. Group 2 participants entered the treatment phase in the order of $\mathrm{D}, \mathrm{E}$, and $\mathrm{F}$. The researcher used a zero-second time delay for eight sessions. The researcher would simultaneously point to and state the correct term immediately following the stating of the last term. Therefore, the participant responded with $100 \%$ accuracy for two consecutive instructional sessions. Upon the completion of the errorless sessions the participants would then enter the 5-second delay sessions. The errorless sessions were conducted by the researcher.

Five Second Delay Sessions. Twenty sessions were conducted during each instructional session. Each targeted term was presented randomly four times during each session. Before the start of the session the participants were given the following directions. "I am going to place three term cards on the table in front of you. Then I will hold up a definition card and I will read it to you. I will point to and read the terms on each of the term cards. If you know the answer, touch the card or say the term. If you do not know the answer say, "I don't know" or say nothing."

An instructional trial included the presentation of a definition card and three term 
Table 5

Distracter Terms

\section{Participants}

\begin{tabular}{|c|c|c|c|c|c|c|}
\hline \multirow{11}{*}{ 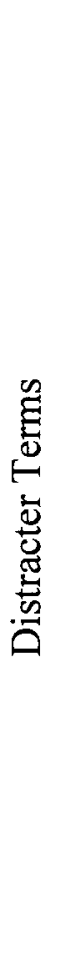 } & $\mathrm{A}$ & $\mathrm{B}$ & $\mathrm{C}$ & $\mathrm{D}$ & $\mathrm{E}$ & $\mathrm{F}$ \\
\hline & Adjacent angles & Adjacent angles & Adjacent angles & Angle & Adjacent angles & Adjacent Angles \\
\hline & Angle & $\begin{array}{l}\text { Angle of } \\
\text { depression }\end{array}$ & Angle & $\begin{array}{l}\text { Angle of } \\
\text { depression }\end{array}$ & Angle & Angle \\
\hline & Degree & Degree & Included side & Coplanar & $\begin{array}{l}\text { Angle of } \\
\text { depression }\end{array}$ & $\begin{array}{l}\text { Angle of } \\
\text { depression }\end{array}$ \\
\hline & Included side & Included side & Irregular polygon & Included side & Degree & Degree \\
\hline & Irregular polygon & Irregular polygon & Line of symmetry & Irregular polygon & Included side & Included side \\
\hline & Midpoint & Line of symmetry & Midpoint & Line of symmetry & Line of symmetry & Line of symmetry \\
\hline & Obtuse angle & $\mathrm{N}$-gon & $\mathrm{N}$-gon & Midpoint & Midpoint & Midpoint \\
\hline & Parallelogram & Parallelogram & Obtuse angle & $\mathrm{N}$-gon & Parallelogram & Parallelogram \\
\hline & $\mathrm{Pi}$ & $\mathrm{Pi}$ & Parallelogram & $\mathrm{Pi}$ & $\mathrm{Pi}$ & $\mathrm{Pi}$ \\
\hline & Sine & Radius & Sine & Sine & Radius & Radius \\
\hline
\end{tabular}


cards. Three term cards were placed on the work area in front of the students. One of the cards was the correct term card the other two cards were non-target geometry terms (see Table 5). The pairing of the cards and the cards placement on the table was established with the use of an online randomization program (Urbaniak \& Plous, 2010) (see Appendix $\mathrm{J} \& \mathrm{~K}$ for the randomization grid).

The term cards were placed in front of the participant on the table surface horizontally evenly spaced centered in front of the participant. The definition card was held up at chin level with the researcher's left hand. First, the researcher recited the definition. Second, the researcher with her right index finger touched and labeled each of the term cards moving right to left. The researcher moved her right hand to a neutral rest position when she had finished labeling the term cards. Third, the researcher began counting silently the five second delay (1 Mississippi, 2 Mississippi, ect.) waiting for the participant's response.

Criterion was achieved when $100 \%$ over three consecutive sessions. Instructional sessions were conducted by the researcher.

Maintenance Sessions. Once criterion was met, four probe sessions were collected on the current participant with four baseline sessions occurring with the remaining participants in the group. The maintenance sessions and the baseline sessions were aligned. The maintenance sessions followed the same format as the instructional sessions. This cycle continued until all members of Group 1 and Group 2 had entered the study. New participant probes and maintenance probes were aligned throughout the study. The researcher conducted the maintenance sessions.

\section{Data Collection}




\section{Vocabulary Term Cards}

The participant's first receptive response or verbal answer was what the instructor recorded for the purposes of this research study. The responses were recorded as correct, incorrect or no response (see Appendix $\mathrm{M}$ for data sheet). All of the correct responses were reinforced with verbal praise (e.g., "Great job, Great working!") and the researcher would say, "yes, a (state the term) is a (recite the definition)". Correct responses were defined as the participant initiating a response receptively through touch or verbally prior to the end of the five second delay and the selection of the correct term card. Incorrect responses received no consequences. Incorrect responses were defined as (1) not initiating a response either receptively though touch or verbally prior to the end of the five second delay, and (2) selecting the incorrect term card prior to the end of the five second delay. No response was defined as the participant not initiating movement toward the term cards within the five second delay.

If the student initiated an answer prior to the five seconds and was incorrect, the instructor would interrupt the selection and prompt the correct answer. The instructor removed the two incorrect terms from the table and placed the definition card on the table to the right of the term card. The instructor then pointed to and read the definition and term before moving to the next trial (see Table 6 for scripted teaching procedures).

Additional efficiency data were also collected and analyzed. Results were reported for the total number of sessions and trials, the total length of time, and the percent of errors each participant required to reach criterion.

\section{Generalization}


Generalization was the ability to perform skills across settings, across people, and across time (Alberto \& Troutman, 2006). Generalization probes were performed in all three conditions. Generalization probes were taken at the end of the research study's time allotment. The research study would end on the last day of the school calendar. The length of time between the last maintenance probe and the generalization probes would be contingent upon the mastery times of the participants. Generalization probes were taken in his/her classroom conducted by either his/her special education teacher of record or the paraprofessional assigned to his/her room. Generalization probes consisted of five multiple choice questions one for each of the targeted vocabulary (see Appendix N-P). Only targeted vocabulary terms were used in the field of three answer choices. The questions and answer choices were read to participants by either the teacher of record or the classroom paraprofessional.

\section{Internal validity}

Single subject research by design has limited internal validity concerns (Campbell \& Stanley, 1967; Horner, Carr, Halle, McGee, Odom, \& Wolery, 2005). The two types of internal validity that hold some concern are history effects and instrumentation. Instructional sessions were scheduled around scheduled school wide interruptions such as class bells and announcements. Unscheduled school wide interruptions during sessions were out of the control of the researcher. However, instrumentation effects were minimized with briefings between the researcher and the paraprofessional following each of the sessions to address any questions or confusions.

\section{Social validity}

Social validity was one of the core quality indicators established to evaluate the 
Table 6

Scripted Teacher Responses

Teacher Behavior

Student Behavior

Feedback

With-in 5 seconds. Student says or moves toward the correct answer.

Verbal praise is given. "Yes a is a "

Student says or moves toward the wrong answer

Interrupt and simultaneously point to the correct card and state the term. Remove the two incorrect term cards. Place the definition card on the table. Recite the definition and point to and read the term card.

No response is initiated by Simultaneously point to the student. the correct card and state the term. "A is a

scientific rigor of experimental, quasi experimental and single subject methodologies (Lane, Kalberg, Bruhn, Driscoll, Wehby, \& Elliott, 2009). Social validity was the degree to which society believes the treatment procedures selected are socially significant, socially acceptable and socially important (Lane et al., 2009). Social validity questions considered during all three phrases of a study: pre-, during, and post (Lane et al., 2009; Merchant, Renshaw, \& Young, 2006).

Vocabulary acquisition had social validity because of the importance that vocabulary plays in one's educational career. The use of mathematical vocabulary exposed students 
with moderate and severe disabilities to core content curriculum. The specific vocabulary terms selected for this research study were from a textbook accepted by the school district of the school where the research study takes place. Highly qualified math teachers verified (see Appendix E \& F) the vocabulary terms were accurate and representative of the core curriculum at the school where the research study took place (see Table 7 for verification results per term). Social validity was also demonstrated through the use of CTD a proven systematic evidence based research procedure accepted in the educational field and easily implemented by teachers and school staff (Horner et al., 2005).

\section{Inter-Rater reliability}

Reliability measures were taken on the dependent variable, correct vocabulary responses. Reliability measures were taken at least once a week for the duration of the research study. The reliability of the study describes the level of agreement among the observers. The reliability measure was calculated using the point-by-point or mean agreement procedure. The observer used an identical data sheet as the investigator (see Appendix M for data sheet). The point-by-point reliability procedure calculated reliability based on each occurrence of agreements among observers, mathematically represented by the following formula (Kazdin, 1982):

Agreements $\quad$ X $100=\%$ of Reliability

$$
\text { Agreements + Disagreements }
$$

Procedures for inter-rater reliability. The reliability observers were given a data sheet, a clipboard, and a pen. Each participant had his/her own data sheet. The interrater reliability data sheets were identical to the data sheet that the researcher used. The observer sat in a chair to the left of the researcher, approximately 2 to 4 feet away from 
the participant. The observer was perpendicular to the participants. The observer was silent throughout the session. The observer indicated "yes" on the data sheet if the participant, per the research guidelines, responded correctly. The observer indicated "no" on the data sheet if the participant, per the research guidelines, responded incorrectly. The observer indicated "no response" if the participant, per the research guidelines did not respond within the allotted time.

Observed Behavior $\quad$ X $100=\%$ of Procedural Reliability Planned Behaviors

Training. The inter-rater reliability observers were a paraprofessional and a certified teacher from one of the three community based instruction classrooms, at the same high school as the participants.

The observers received training from the experimenter. The observers were given two articles to read on constant time delay and had two training sessions with the experimenter. The articles include:

- Stevens, K. B., \& Lingo, A. S. (2005). Constant time delay: One way to provide positive behavioral support for students with emotional and behavioral disorders. Beyond Behavior, Spring, 10-21.

- Stevens, K. B., \& Schuster, J. W. (1988). Time delay: Systematic instruction for academic tasks. Remedial and Special Education, 9, 16-21.

During the first training session, the experimenter highlighted the important information from the above research. The experimenter gave an introduction to constant time delay and described the similarities and differences to the discrete trial teaching that occur daily in the classroom where the paraprofessional was assigned. The experimenter 
Table 7

Teacher Verification Results of Vocabulary Terms

\begin{tabular}{|c|c|c|c|}
\hline Term & $\begin{array}{l}\text { Not commonly } \\
\text { used }\end{array}$ & Term & used Not commonly \\
\hline Adjacent angles & 0 & Laws of detachment & 6 \\
\hline Alternate interior angles & 0 & Line of symmetry & 1 \\
\hline Angle & 0 & Midpoint & 0 \\
\hline Angle of depression & 1 & N-gon & 1 \\
\hline Apothem & 4 & Obtuse angle & 0 \\
\hline Circumscribe & 2 & Orthogonal drawing & 7 \\
\hline Composition of reflection & 5 & Parallelogram & 1 \\
\hline Conditional statement & 4 & $\mathrm{Pi}$ & 0 \\
\hline Congruent solids & 6 & Point of concurrency & 6 \\
\hline Coplanar & 1 & Proof of contradiction & 6 \\
\hline Counterexample & 4 & Radius & 1 \\
\hline Degree & 0 & Regular prism & 4 \\
\hline Direction & 5 & Right prism & 4 \\
\hline Exterior & 1 & Sector of a circle & 5 \\
\hline Geometric mean & 5 & Sine & 1 \\
\hline Included side & 1 & Tessellation & 4 \\
\hline Inscribed & 3 & Transversal & 1 \\
\hline Irregular polygon & 1 & Truth table & 7 \\
\hline
\end{tabular}

Note. Italicized items were excluded from the research project

also explained the parameters for the study. During the second training session, the 
experimenter demonstrated the 5 -second constant time delay teaching procedure. The experimenter and the paraprofessional role played the intervention session. The paraprofessional was given the opportunity to ask questions during and after each of the training sessions.

\section{Procedural Reliability}

Procedural reliability was collected on the researcher twice prior to the beginning of the screening sessions and at least once a week for the remainder of the research project. Procedural reliability assesses the accuracy and completeness of the research procedures (see Appendix Q for procedural reliability checklist). Procedural reliability was calculated by dividing the number of teacher behaviors observed by the number of planned teacher behaviors multiplied by 100 (Billingsley, White, \& Munson, 1980).

Procedures for Procedural Reliability. The procedural observers were given a data sheet, a clipboard, and a pen. Each participant had his/her own data sheet. The observer sat in a chair to the left of the researcher, approximately 2 to 4 feet away from the participant. The observer was perpendicular to the participants. The observer was silent throughout the session. The observer placed a check-mark in the appropriate column once the researcher completed the behavior. No check-marks were recorded if the researcher failed to follow the study parameters. Data was collected on all twenty sessions of targeted vocabulary during the instructional sessions. The procedural reliability total possible score was 123 .

Training. The procedural reliability observers were an assistant principal, a certified teacher and a paraprofessional. The participants were familiar with the observers. The observers were trained by the researcher. Observers were given a copy of 
the procedural reliability worksheet. The researcher explained the worksheet to the observers. The researcher walked through each of the eleven points on the worksheet with the observers. The researcher modeled each step of the instructional procedure showing what behavior was to be expected by the researcher during each of the instructional sessions. 


\section{CHAPTER IV}

\section{RESULTS AND DATA ANALYSIS}

The purpose of this chapter was to provide an in depth look at the results of the research study. First, information will be provided for Group 1 participants (verbal). Second, information will be provided for Group 2 participants (non-verbal).

\section{Participant Word Lists}

Based on the screening process of the targeted vocabulary words four of the six participants would have unique target word lists. The remaining two participants would share the same target word list. Fifteen of the sixteen original geometry terms, from the

screening process, were used in the research study. Eight of the terms were used in only one of the five word lists. Five of the terms were used in two of the five word lists. One term was used in three of the five word lists, and one term was used in four of the five word list (see Table 8).

Two of the terms were used as distracters in all five of the word lists. Six of the terms were used as distracters in four of the five word lists. Three of the terms were used as distracters in three of the word lists. Two of the terms were used as distracters in three of the word list, and two terms were used only once in a single word list (see Table 9).

\section{Results and Data Analysis of Group 1}

\section{Verbal Participants' Results}

Each instructional day consisted of four sessions of the five targeted vocabulary for 20 total trials of targeted vocabulary. The four sessions were delivered consecutively. 
Table 8

Term Word List

\begin{tabular}{|c|c|c|c|c|c|}
\hline Participant & A & B & $\mathrm{C}$ & $\mathrm{D}$ & $\mathrm{E} \& \mathrm{~F}$ \\
\hline Adjacent angles & & & & $\mathrm{X}$ & \\
\hline Angle & $\mathrm{X}$ & & & & \\
\hline Angle of depression & & & $\mathrm{X}$ & & \\
\hline Coplanar & $\mathrm{X}$ & & $\mathrm{X}$ & & $\mathrm{X}$ \\
\hline Degree & & & $\mathrm{X}$ & $\mathrm{X}$ & \\
\hline Irregular polygon & & & & & $\mathrm{X}$ \\
\hline Line of symmetry & & $\mathrm{X}$ & & & \\
\hline Midpoint & $\mathrm{X}$ & $\mathrm{X}$ & & & \\
\hline N-gon & & $\mathrm{X}$ & & & $\mathrm{X}$ \\
\hline Obtuse angle & $\mathrm{X}$ & $\mathrm{X}$ & & $\mathrm{X}$ & $X$ \\
\hline Parallelogram & & & & $\mathrm{X}$ & \\
\hline $\mathrm{Pi}$ & & & $\mathrm{X}$ & & \\
\hline Radius & & & $\mathrm{X}$ & $\mathrm{X}$ & \\
\hline Sine & $\mathrm{X}$ & & & & $\mathrm{X}$ \\
\hline Transversal & & $\mathrm{X}$ & & & \\
\hline
\end{tabular}

Participant A Verbal Group. Participant A was a male with mild moderate disabilities and speech language impairment. 
Screening. During the original screening process he correctly identified eight of the 16 terms. The targeted vocabulary terms for Participant A were angle, coplanar,

Table 9

Distracter Word Pairings

\begin{tabular}{|c|c|c|c|c|c|}
\hline Participant & $\mathrm{A}$ & $\mathrm{B}$ & $\mathrm{C}$ & $\mathrm{D}$ & $\mathrm{E}$ and $\mathrm{F}$ \\
\hline Adjacent angles & $\mathrm{X}$ & $\mathrm{X}$ & $\mathrm{X}$ & & $\mathrm{X}$ \\
\hline Angle & $\mathrm{X}$ & & $\mathrm{X}$ & $\mathrm{X}$ & $\mathrm{x}$ \\
\hline Angle of depression & & $\mathrm{X}$ & & $\mathrm{X}$ & $\mathrm{X}$ \\
\hline Coplanar & & & & $\mathrm{X}$ & \\
\hline Degree & $\mathrm{X}$ & $\mathrm{X}$ & & & $\mathrm{X}$ \\
\hline Included Side & $\mathrm{X}$ & $\mathrm{X}$ & $\mathrm{X}$ & $\mathrm{X}$ & $\mathrm{X}$ \\
\hline Irregular polygon & $\mathrm{X}$ & $\mathrm{X}$ & $\mathrm{X}$ & $\mathrm{X}$ & \\
\hline Line of symmetry & & $\mathrm{X}$ & $\mathrm{X}$ & $\mathrm{X}$ & $\mathrm{X}$ \\
\hline Midpoint & $\mathrm{X}$ & & $\mathrm{X}$ & $\mathrm{X}$ & $\mathrm{X}$ \\
\hline $\mathrm{N}$-gon & & $\mathrm{X}$ & $\mathrm{X}$ & $\mathrm{X}$ & \\
\hline Obtuse angle & $\mathrm{X}$ & & $X$ & & \\
\hline Parallelogram & $\mathrm{X}$ & $\mathrm{X}$ & $\mathrm{X}$ & & $\mathrm{x}$ \\
\hline $\mathrm{Pi}$ & $\mathrm{X}$ & $\mathrm{X}$ & & $\mathrm{X}$ & $\mathrm{x}$ \\
\hline Radius & & $\mathrm{X}$ & & & $\mathrm{x}$ \\
\hline Sine & $\mathrm{X}$ & & $\mathrm{X}$ & $\mathrm{X}$ & \\
\hline
\end{tabular}

midpoint, obtuse angle, and sine.

Baseline. Participant A's first baseline (sessions 1-4) produced results of 20 percent 
correct in all four sessions giving an mean percent correct score of 20 percent.

Instructional. Participant A had a total of 52 sessions of targeted vocabulary (baseline, errorless, 5-second delay, and maintenance). Participant A had eight sessions of errorless instruction (sessions 5-12) at 100 percent accuracy. The mean instructional time for a session ranged from 1:30 to 2:24 (Appendix R). The total instructional time for Participant A was 95:31 (1 hour 35 minutes and 31 seconds). Participant A's mean instructional time for a session was 1:50. The median instructional time for a session was 1:52 (See Table 10).

Participant A reached criteria with sessions 14-16 (see Figure 2). However due to an error by the researcher, Participant A continued in the instructional phase until session 40. The mean percent correct for the 24 sessions was $98 \%$. Participant $\mathrm{A}$ had an extended time in the instruction phase due an error on the part of the researcher. The researcher confused three sessions with three instructional days. The extended time did not adversely affect questions one and two of the research study. The effect of the extend time on the third research question is undeterminable.

The extended time spent in the instructional phase with Participant A due to the researcher's error did delay the start of the second and third verbal participant. However, Participant $\mathrm{B}$ and $\mathrm{C}$ were both able to obtain mastery of the targeted vocabulary. Mixed conclusions could be raised if the extended time in the instruction phase had any impact of the maintenance and generalization results for Participant A. Had Participant A's generalization and maintenance scores been at 100 percent one might have concluded that the results were impacted by the extended time. The fact that Participant A was not able to maintain mastery of the words gives indication that the magnitude of long-term 
learning could have been affected. Participant A's maintenance and generalization scores may have been lower if the error had not been made by the researcher.

Maintenance. Participant A scored 100 percent across all four sessions on the first probe session (sessions 41-44). The second probe sessions (sessions 45-48) had an mean percent correct score of 90 with the individual session scores of $80,80,100$, and 100 respectively. The third probe session (sessions 49-52) was again 100 percent across all four sessions (see Figure 2).

Generalization. Participant A's mean score of 56 percent across five generalization probes scored $60,100,40,40$, and 40 percent respectively. Generalization probes were conducted in the student's regular special education classroom with their teacher of record. Generalization probes consisted of five multiple-choice questions one for each of the targeted vocabulary (see Appendixes N-P). Only targeted vocabulary terms were used in the field of three answer choices. Either the teacher of record or the classroom paraprofessional read the questions and answer choices to participant $\mathrm{A}$.

Participant A was able to maintain mastery of two of the target vocabulary-sine and coplanar. The target vocabulary, obtuse angle, was maintained at 40 percent, and the target vocabulary of angle and midpoint were only maintained at only 20 percent. The five generalization probes were conducted across a span of 22 days. Generalization probes, for participant $A$, were initiated 53 days after he reached criteria.

Participant B Verbal Group. Participant B was a female with a functional mental disability and other health impairment disability. 
Table 10

Session Times

\begin{tabular}{lrrrrrr}
\hline Participants & A & B & C & D & E & F \\
\hline Mean & $1: 50$ & $2: 55$ & $1: 47$ & $2: 16$ & $2: 34$ & $2: 45$ \\
Median & $1: 52$ & $2: 55$ & $1: 50$ & $2: 14$ & $2: 36$ & $2: 46$ \\
Total (in minutes) & $95: 31$ & $210: 18$ & $57: 00$ & $461: 01$ & $337: 23$ & $231: 17$ \\
\hline
\end{tabular}

Screening. During the original screening process she correctly identified four of the 16 terms. The targeted vocabulary terms for participant B were line of symmetry, midpoint, n-gon, obtuse angle, and transversal.

Baseline. Participant B's first baseline sessions (1-4) produced results of 20, 0, 20, and 20 percent correct respectively. Participant's B second baseline session (5-8) produced result of $20,20,20$, and 20 percent respectively. Trend line data shows an upward trend that stabilizes and remains constant.

Instructional. Participant B had a total of 72 sessions of targeted vocabulary baseline, errorless, 5-second, and maintenance). Participant B had eight sessions (9-16) of errorless instruction at 100 percent accuracy. The mean instructional time for a session ranged from 2:10 to 3:38 (see Appendix R). The total instructional time for Participant B was 210:18 ( 3 hours 30 minutes and 18 seconds). Participant B's mean instructional time for a session was 2:55. The median instructional time for a session was 2:55 (See Table 10). The student's slow processing time and slow physical speed influenced the range of instructional time. If Participant B made any physical or verbal 
answering gesture prior to the end of five second delay she was allowed to answer based on the parameters of the study. For example, moving her hand toward the term cards or vocalizing an "umm" sound. Participant B reached criteria with sessions 62-64 (see Figure 2). Participant $B$ mean percent correct for the 48 instructional sessions (17-64) was 57 percent.

Maintenance. Participant B scored 100 percent across all four sessions on the first probe session. The second probe session had an mean percent correct score of 50 with the individual session's scores as 20,60,60, and 60 respectively (sessions 65-72) (see Figure 2).

Generalization. Participant B mean score was 44 percent across five generalization probes scoring 40,60,60,40, and 20 respectively. Generalization probes consisted of five multiple-choice questions one for each of the targeted vocabulary (see Appendixes N-P). Only targeted vocabulary terms were used in the field of three answer choices. Either the teacher of record or the classroom paraprofessional read the questions and answer choices to participant B

Participant B was able to maintain 80 percent mastery of one target vocabularyobtuse angle. The target vocabulary, n-gon and transversal were maintained at 60 percent, and the target vocabulary of line of symmetry was only maintained at 20 percent. Participant B was not able to generalize the target vocabulary midpoint and scored a zero percent across all five generalization probes. The five generalization probes were conducted across a span of 22 days. Generalization probes, for Participant B, were initiated 20 days after she reached criteria (See Figure 2).

Participant C Verbal Group. Participant $\mathrm{C}$ was a male with Autism. 
Screening. During the original screening process he correctly identified 8 of 16 geometry terms. However, the back and forth scanning movement with his hand over the three term cards suggested to the researcher that the participant was guessing. Participant C's original targeted vocabulary terms for this research study were angle of depression, coplanar, line of symmetry, n-gon, and radius.

Baseline. Participant C's original baseline results were a mean of 50 percent for the session. The scores for sessions $1-4$ were $60,60,60$, and 20 percent respectively. Trend line analysis of the first four baselines does show a downward trend (See Figure 1). However, due to the high scores of the first baseline a second baseline was conducted. High initial first scores would decrease the functional relationship that could be associated with the research study due to the small degree of learning that would occur in order to reach criteria. No procedural differences occurred during the first and second baseline.

The second baseline produced scores for sessions $5-8$ of $60,20,20$, and 60 percent respectively for a mean percent correct score of 40 percent (see Figure 1). Trend line analysis of the second set of baseline sessions showed a flat trend. However, there was 40 point variability between the 4 data points. The two high point were still at the 60 percent correct that could have affected the functional relationship between the learning and the teaching instruction. Based on the high screening and baseline results the researcher decided to alter the distracter term card presentation for the term 'angle of depression' and to deliver a third baseline.

The randomized list of paired distracter terms was altered for the third baseline. The alteration consisted of fashioning all of the term cards paired with 'angle of 
depression' to have the word 'angle' in them. Words that included 'angle' already paired with angle of depression from the randomized list continued in their same placement. Non 'angle' distracter terms were replaced with 'angle' terms alphabetically continuously throughout each of the five days target list (see Table11). The third baseline generated scores of 20,60, 0, and 40 percent respectively for sessions 9-12 (see Figure 1). The trend line analysis of the third set of baseline sessions was again a flat trend. While, the overall mean score was lower between the third and the second baseline a large variability still was prevalent in the data.

Based on the third baseline results the researcher decided to re-evaluate participant C's targeted vocabulay. The terms coplanar, n-gon and line of symmetry were initially excluded because the root word of each of the terms was a word in the definition; for example, the definition for $\mathrm{n}$-gon is a polygon with $\mathrm{n}$ sides. The three terms not included as targeted vocabulary from the screening process were degree, parallelogram, and pi. The term parallelogram was excluded based on the same criteria as coplanar and n-gon. Therefore, degree and pi were added to the target vocabulary replacing coplanar, n-gon and line of symmetry for participant C. Angle of depression was continued as a targeted word under the condition that all three distracter terms would continue to be terms that all contained the word 'angle'. Participant $\mathrm{C}$ needed a fifth target vocabulary word. One of the excluded terms would have to continue as a targeted vocabulary term. The decision to maintain coplanar above n-gon and line of symmetry was based on individual term scores from the three baselines. Participant $\mathrm{C}$ correctly identified coplanar 4 of 12 times or 33 percent of the time. Participant $\mathrm{C}$ correctly identified n-gon and line of symmetry 5 of 12 times or 42 percent of the time. Therefore, coplanar became the fifth targeted 
Figure 1

Baselines for Participant C
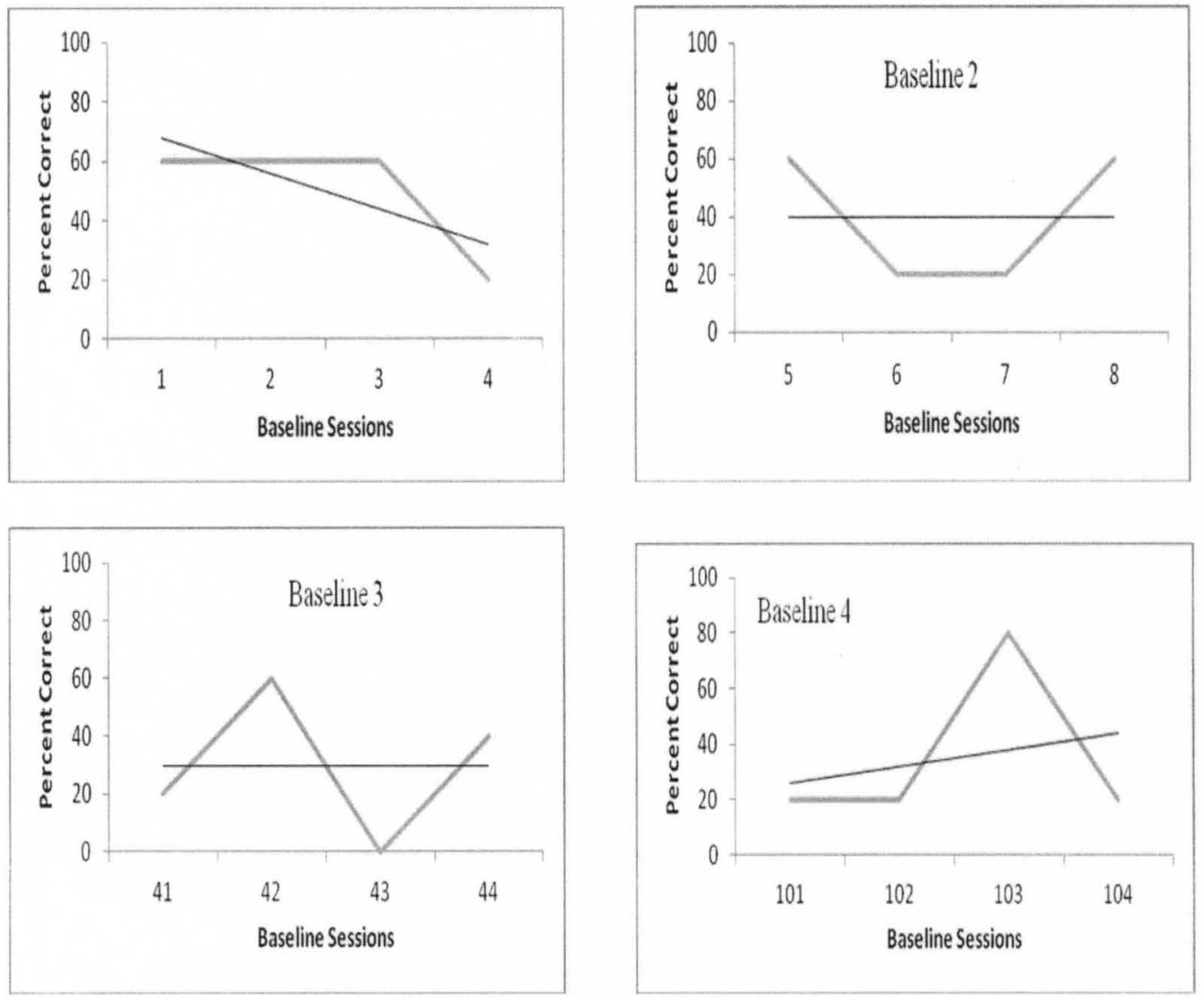

vocabulary.

A fourth baseline was conducted for the new list of target vocabulary terms angle of depression, coplanar, degree, angle of depression, pi, and radius. The two additional term choices paired with angle of depression continued to have the word 'angle' in them. The results of the forth baseline was $20,20,80$, and 20 percent resepectively for sessions 13 16 (see Figure 2). Trend data for the fourth set of baseline sessions showed an upward trend. However, the overall mean percent correct of 35. One score of the baseline appears to be an extreme outliner at 80 . Trend line data from the combined four baselines shows a sharpe downward trend. Due to the sharp downward trend and the 
Percent Correct

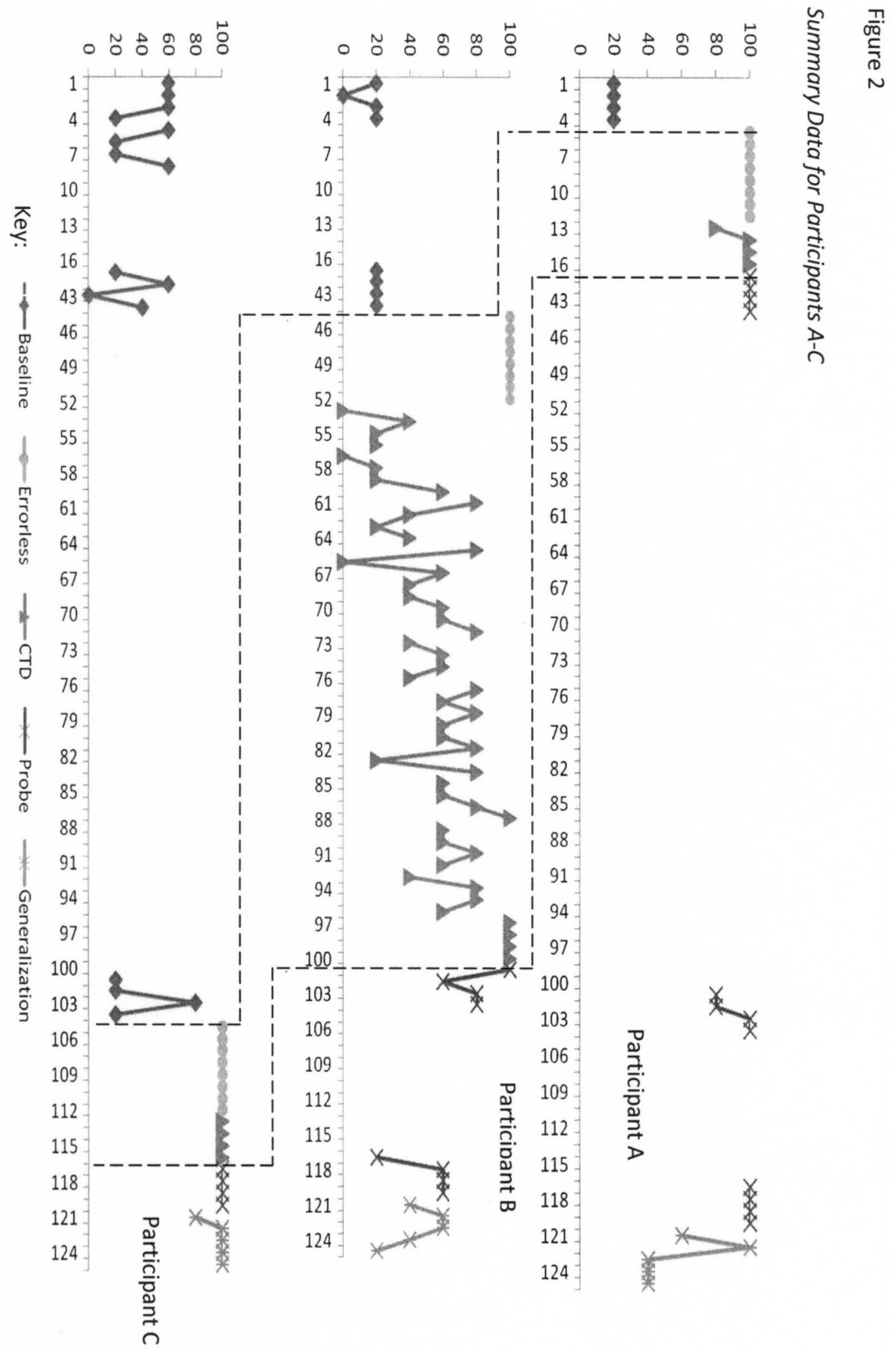


low percent correct scores of the fouth baseline the researcher decided to move forward with altered targeted vocabulary and altered distracter term card pairing for participant C.

Instructional. Participant $\mathrm{C}$ had a total of 32 sessions of targeted vocabulary (baseline, errorless, 5-second delay and maintenance). Participant $\mathrm{C}$ had eight sessions (sessions 17-24) of errorless instruction at 100 percent accuracy. The mean instructional time for a session ranged from 1:19 to 2:16 (see Appendix R). The total instructional time for Participant $\mathrm{C}$ was 57 minutes. Participant C's mean instructional

Table 11

Angle Terms Replaced for Participant C

Adjacent angles

Angle

Angle of depression

Obtuse angle

time for a session was 1:47. The median instructional time for a session was 1:50 (See Table 10). Participant $C$ reached criteria with 100 percent accuracy with sessions $25-27$.

Maintenance. Participant C scored 100 percent on all four session (29-32) of his first probe session (see Figure 1).

Generalization. Participant $\mathrm{C}$ mean score was 96 percent across five generalization probes scoring $80,100,100,100$, and 100 percent respectively (see Figure 1).

Generalization probes were conducted in the student's regular special education classroom with his teacher of record. Generalization probes consisted of five multiplechoice questions one for each of the targeted vocabulary (see Appendixes N-P). Only 
targeted vocabulary terms were used in the field of three answer choices. Either the teacher of record or the classroom paraprofessional read the questions and answer choices to Participant C.

Participant $\mathrm{C}$ was able to maintain mastery of four of the target vocabulary-angle of depression, degree, pi, and coplanar. The target vocabulary, radius was maintained at 80 percent. The five generalization probes were conducted across a span of 22 days. Generalization probes, for participant $\mathrm{C}$, were initiated 14 days after he reached criteria. Verbal Group Participants' Summary

All three of the verbal participants were able to reach criteria. The immediate acquisition time of criteria mastery for Participant $\mathrm{A}$ and $\mathrm{C}$ provides overwhelming support for errorless instruction. After being exposed to eight sessions of errorless instruction on their five targeted vocabulary Participants $\mathrm{A}$ and $\mathrm{C}$ were able to show mastery based on the parameters of the research study. The generalization probes speak more clearly too whether or not knowledge of the targeted vocabulary was truly acquired.

Participant A had an mean generalization score of 56 percent correct. The last three generalization probes had consistent scores of 40 percent with the exact same missed targeted vocabulary. One of the correct targeted terms' definitions contained the root of the term in the definition.

Participant B's results were complicated. Participant B had a mean generalization score of 44 percent correct with her last generalization probe being only 20 percent accurate. However, once the results of the generalization probes were analyzed one term displayed an mean maintenance of 80 percent and two terms showed an mean maintenance of 60 percent. Participant B's medical history is more complicated than the 
other two verbal participants. Participant B's seizure activity and delayed processing speed separates her among the verbal participants.

Participant C's mean generalization score was 96 percent correct. The mean generalization score would indicate that true learning of the targeted vocabulary had occurred. However, Participant $\mathrm{C}$ had had the shortest time between instructional sessions and generalization probes.

None of three verbal participants were assigned to the researcher's classroom. Each of the three verbal participants was in their second year at the researcher's school. Each of the participants and the researcher were familiar with each other and had routine interaction and communication. It is unclear as to whether this personal relationship between the research and the participants had any positive impact on the study. However, there was no negative impact from the personal relationships.

Retention of knowledge in the core content curriculum must be maintained overtime. The inability to maintain and add to new information in the core content curriculum will eventually create a exceedingly large gap between the material learned and covered by regular education students and the students with disabilities specifically in the content class that have scaffold learning.

None, of the verbal participants, displayed any inappropriate behaviors during the research study. The participants, while not over joyed to see the researcher when approached, always accompanied the researcher willingly to the research room. Other than a few yawns, engagement, participation and responses were proper.

\section{Results and Data Analysis of Group 2}

\section{Non-verbal Participants' Results}


Non-acquisition of the targeted vocabulary by the first non-verbal participant led the researcher to alter the procedures of the non-verbal group. The non-verbal participants' results became individual case studies. Participant $E$ entered the research study after Participant $\mathrm{D}$ had completed 72 sessions. Participant $\mathrm{F}$ entered the research study after Participant D had completed 132 sessions and Participant E had completed 56 sessions. Each instructional day consisted of four sessions of targeted vocabulary for a total for 20 trials. The four sessions were delivered consecutively. Probe data and generalization data were not collected on any of the non-verbal participants since the non-verbal participants were not able to reach the research study's criteria of mastery.

Participant D Non-Verbal Group. Participant D was a male with a functional mental disability. Participant $\mathrm{D}$ is non-verbal, but does have extremely limited vocal outputs. Participant D is Hispanic and moved to the United States during his elementary years. Participant D's mother communicates in Spanish and English to him in the home environment. Participant D's guardian who lives in the home also speaks a combination of English and Spanish to him in the home environment. Participant D will respond to certain English and Spanish terms in the classroom. Examples of Spanish commands that were given in the classroom were bano for bathroom, silencio for quite, and levantese for standup. During classroom instruction, Spanish terms are given when Participant D had not responded to the English counterpart. Participant D did not always respond to the Spanish term either.

Participant D's communication responses include vocalizations, gestures, facial expressions, actions, modified and approximate sign language, pointing, and showing objects. Participant D used two true signs of cookie and help, three modified signs of 
yes, help, and please, and one gesture for no. To communicate yes Participant D uses his right index finger to tap the right side of his temple. Help and please are both displayed by a fist making small circles on his chest. Participant D's no gesture was a back and forth waving motion with his wrist. For desired items Participant D will go and retrieve the actual item or a symbolic item such as cup if thirsty. Participant $D$ has a few phrases that he is able to verbalize such as "oh no, bye-bye, adios, time to go, and yeah". Participant $\mathrm{D}$ vocalizes these phrases randomly throughout each day. At times, these phrases are vocalized at appropriate times, but for the most part are verbal stims.

While Participant $\mathrm{D}$ would give yes and no responses he did not have a functional understanding of these two terms. Participant D responded more to tone and body language of the communication partner. Participant D would respond "yes" to any question posed to him in a sincere tone. For example, Participant D would respond to "yes" when asked would you like a Kit-Kat (his favorite candy bar) and can I throw away your backpack (his favorite item) you if delivered in the same sweet/affirmative tone.

Participant $\mathrm{D}$ also struggled with connecting verbal inquires and labels of objects with the real object. For example, Participant D will respond "yes" when asked if he would like to have an item and then when the item is presented to him refuse it. This could be a result of not having a functional relationship between the label for an item and the item itself or because he does not understand the content of the language.

Participant $\mathrm{D}$ had been conditioned to make a selection from items that are placed in front of him. Participant $\mathrm{D}$ had a strong background in discrete trial presentation and the response class associated with this type of instruction. Historically, Participant D was inconsistent in object identification when asked to choose a target item form an array of 2 
or 3 items. Participant D's accuracy improves if the function of the item is demonstrated with gestures along with the label of the item. Participant D's identification of pictures/photos was also inconsistent.

Screening. During the original screening process he correctly identified only one of the 16 terms. The targeted vocabulary terms for participant $\mathrm{D}$ were adjacent angles, degree, obtuse angle, parallelogram, and radius.

Baseline. Participant D's first baseline (sessions 1-4) produced results of 20, 20, 0, and 60 percent correct respectively with a mean score of 25 percent correct (See Figure 3). Participant D's first based line resulted in an upward trend. The 60 percent earned during the fourth baseline session of the first baseline group was best described as an outlier. Possible explanations for the outlier would be positional placement of the correct term card and guessing on the part of Participant $\mathrm{D}$. The results of the first baseline warranted a second baseline be conducted.

Figure 3

Baseline for Participant D

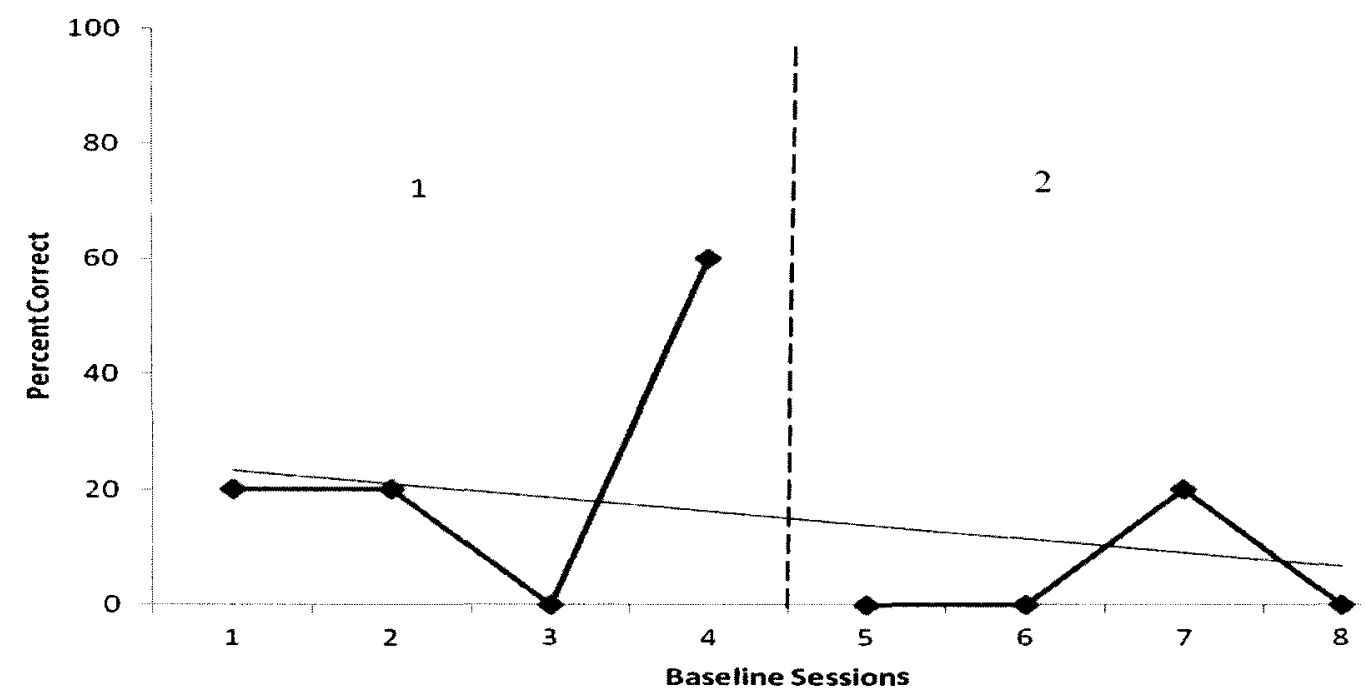


Participant D's second baseline (sessions 5-8) produced results of $0,0,20$, and 0 percent respectively with a mean score of 5 percent correct (See Figure 3). Trend line analysis of the second baseline also produced an upward trend. However, the low scores appear to show no learning. Therefore the two baselines were combined and analyzed. The combine baseline results for Participant D presented a downward trend (See Figure 3). The downward trend and a stable baseline made it possible for Participant $D$ to enter the instructional phase of the research study.

Instructional. Participant D had 51 days of instruction within 61 school days over 2 the course of 15 weeks. Participant D had a total of 204 instructional session of the targeted vocabulary (baseline, errorless, and 5-second delay). Participant D had eight sessions (9-16) of errorless instruction at 100 percent accuracy. The mean instructional time for a session ranged from 1:39 to 2:57 (see Appendix R). The total instructional time for Participant D was 461:01 (7 hours 41 minutes and 1 second). Participant D's mean instructional time for a session was 2:16. The median instructional time for a session was 2:14 (See Table 10).

Lack of progress by Participant D warranted several procedural changes. Term card placement was altered starting with session 53 and continued through session 64 . The terms were presented to Participant D vertically on the table centered in front of him. Term card one was on top, term card two was in the center, and term card three was on the bottom. Vertical placement of the term cards did not have any noticeable effect on Participant $\mathrm{D}$ therefore; in sessions $65-76$, the term cards were returned to the horizontal placement on the table in front of him. Continued lack of progress from Participant D resulted in sessions $77-88$ being returned to errorless teaching. A third and final 
adjustment was made to the term card placement following the return to errorless teaching. The term cards were placed on a solid black presentation board for sessions 89 to 204. The board was constructed from $1 / 2$ inch foam board. The board was 12 inches tall and 30 inches long. The board was covered front and back with black felt. To help stabilize the board, it was glued to a yardstick that was spray painted black (see Appendix L). The board was held on the table by three bookends.

Several alterations were made to the teaching procedures in an attempt to decrease impulsive choice making. In session 85 Participant $\mathrm{D}$ was moved to the side of the table where the researcher was seated. The researcher sat to the left of Participant D. The term card choices were placed on the presentation board left to right with the card in the left position being card one, the card in the middle being card two, and the term in the right position as being term three. The researcher held the definition card up in front of Participant $\mathrm{D}$ with the researcher's left hand. Once the definition card was read the research placed the card down on the table and the researcher's left hand was used to block choice making by Participant D's hands. The research's right hand was used to point to and label each of the term cards. Once the term cards were labeled the researcher placed her right hand on top of the researcher's left hand and counted one Mississippi, then the researcher removed both hands to allow Participant D to select an answer.

Participant D's demeanor in the sessions was cooperative and responsive. Participant $\mathrm{D}$ did not respond only 4 times in the over 1000 definition presentations. Participant $\mathrm{D}$ did seem to have a pattern or preference to his answer selections. Participant D most often selected either the middle term or the term on his right. 
Positional selection by participant $\mathrm{D}$ was evaluated by the researcher. Data for positional selection was collected on 168 of the 204 sessions (see figure 4). Sessions 124, 56-64, and 80-88 were excluded. The researcher did not take positional data on sessions 1 through 24 . Sessions 56-64 were sessions where the data term cards were positioned vertically on the table. Positional data was collected by the researcher for sessions 56-64, but was excluded so as to not cloud the results. Sessions $80-88$ were errorless teaching sessions and therefore Participant D did not make independent selections.

The positional data revealed the Participant D selected only one answer in the left term position in all of 168 sessions where data was collected (see figure 4). Fifty-eight percent of participant D's selections were in the right term position and 42 percent of Participant D's selections were in the center term position. In 36 of the 168 sessions or 21 percent of the time Participant D only selected the center position for all 5 trials and in 58 of the 168 sessions or 35 percent of the time Participant D only selected the right position for all 5 trials. The positional data reveals during each independent session Participant D typically would maintain a positional selection throughout the entire sessions.

Participant D did not reach the criteria set for this research study. The graphical results of Participant D's vocabulary acquisition show a semi-consistent level of achievement; however, Participant D's mean percent correct for the instructional sessions was 33 percent excluding the errorless sessions and the baseline sessions (see Figure 5). This percentage is equal to the 33 percent random chance associated with a field of three. Linear trend line analysis shows a flat trend line across the constant time delay 
Figure 4

Pattern Response Data for Participant D
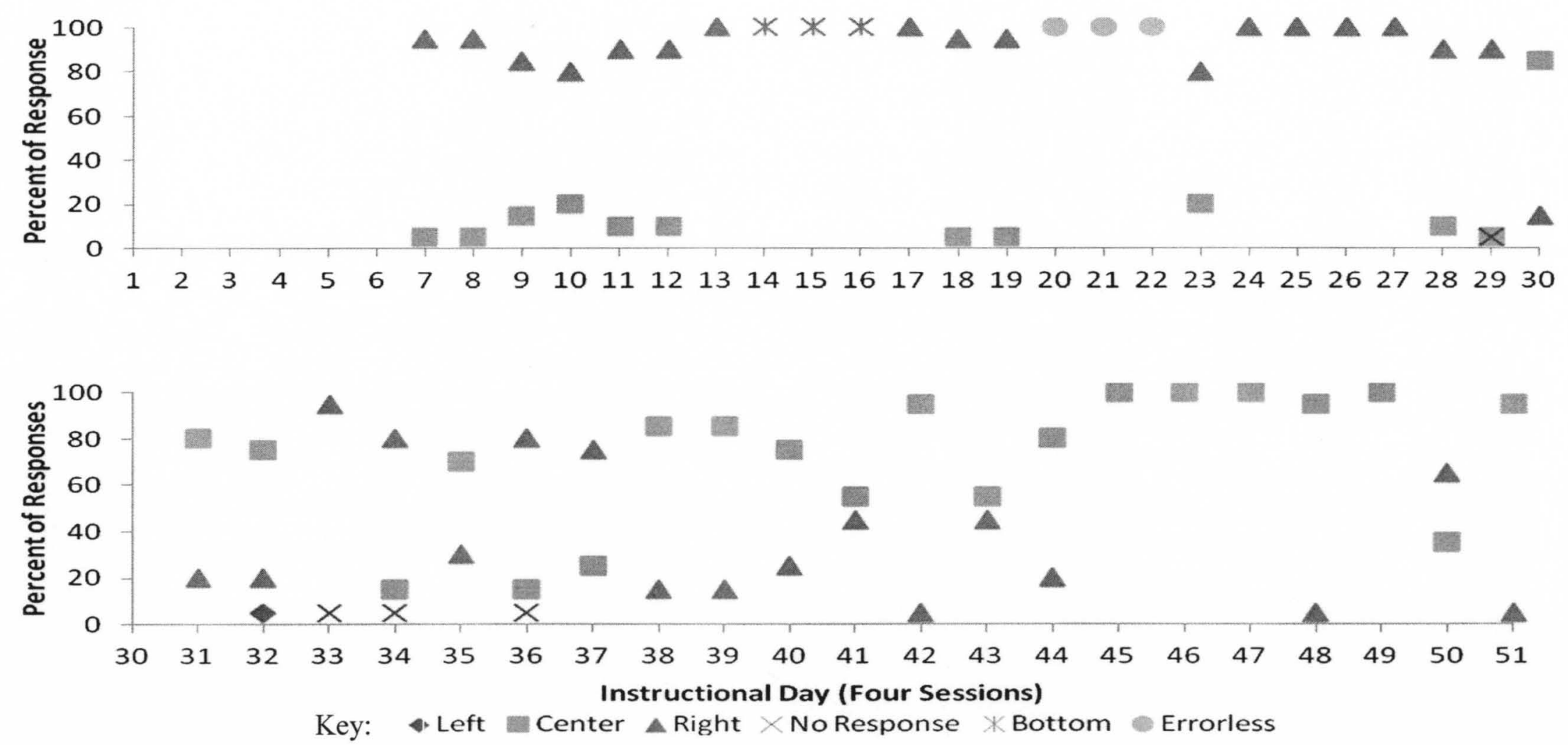
instructional sessions that appear to dip slightly at the end of the instructional period. The positional data along with the acquisition data confirms that the acquisition level of the targeted vocabulary to be a false positive.

Participant E Non-Verbal Group. Participant E was a male with a functional mental disability, Autism, and speech language impairment. Participant $\mathrm{E}$ is non-verbal. Participant E does not use any formal or informal sign language to communicate. The only vocalizations made by Participant $\mathrm{E}$ are humming noise at different pitches, adverse sounding screams, tongue clicking and laughs.

Participant $\mathrm{E}$ would go and retrieve items in the environment that he desired. If Participant $\mathrm{E}$ was unable to retrieve the item he moved away from it. When Participant E is upset and does not like or does not want to do what had been asked of him Participant E will smack and scream.

Participant E can follow simple single directions of actions familiar to him such as sit down or arms up. Participant E does not appear to be able to share joint attention with others in his environment. Participant E responds to very little environmental stimuli; however, he had begun to approach selected individual new to his environment to initiate a greeting.

Participant $\mathrm{E}$ had been conditioned to make a selection from items that are placed in front of him. Participant E will select a reinforcer (the actual item) from a field of two liked items. However, Participant E does not select a preferred item from a non-preferred item. Participant E's daily academic lessons include him receptively identifying items through the selection of picture cards. Pictured items are of frequently used and 
functional items in his environment, numbers 1-6 and yes/no symbols card of checkmarks and Xs.

Screening. During the original screening process he did not correctly identify any of the 16 terms. The targeted vocabulary terms for participant $\mathrm{E}$ were coplanar, irregular polygon, n-gon, obtuse angle, and sine.

Baseline. Participant $\mathrm{E}$ did not respond during his first baseline. Therefore his results for sessions $1-4$ were $0,0,0$, and 0 percent correct respectively. Participant's $\mathrm{E}$ second baseline (sessions 5-8) produced result of $0,0,40$, and 20 percent respectively for an mean score of 10 percent correct. The second baseline does show an upper trend, but the low mean percent correct rate led the researcher to initiate the instruction phase.

Instructional. Participant E had 33 instructional days within 36 school days over the course of 8 weeks. Participant E had a total of 132 sessions of the targeted vocabulary. Participant E had 12 sessions (9-20) of errorless instruction at 100 percent accuracy. Four additional sessions of errorless instruction was added to Participant E due to the low performance of Participant D. Participant $\mathrm{E}$ was also returned to errorless instruction for sessions 49 to 56 . The mean instructional time for a session ranged from 1:54 to 3:41 (see Appendix R). The total instructional time for Participant E was 337:23 (5 hours 37 minutes and 23 seconds). Participant E's mean instructional session time for a session was 2:34. The median instructional time for a session was 2:36 (See Table 10).

Participant $\mathrm{E}$ used a black presentation board for all of his instructional sessions. The board was constructed from $1 / 2$ inch foam board. The board was 12 inches tall and 30 inches long. The board was covered front and back with black felt. To help stabilize the 

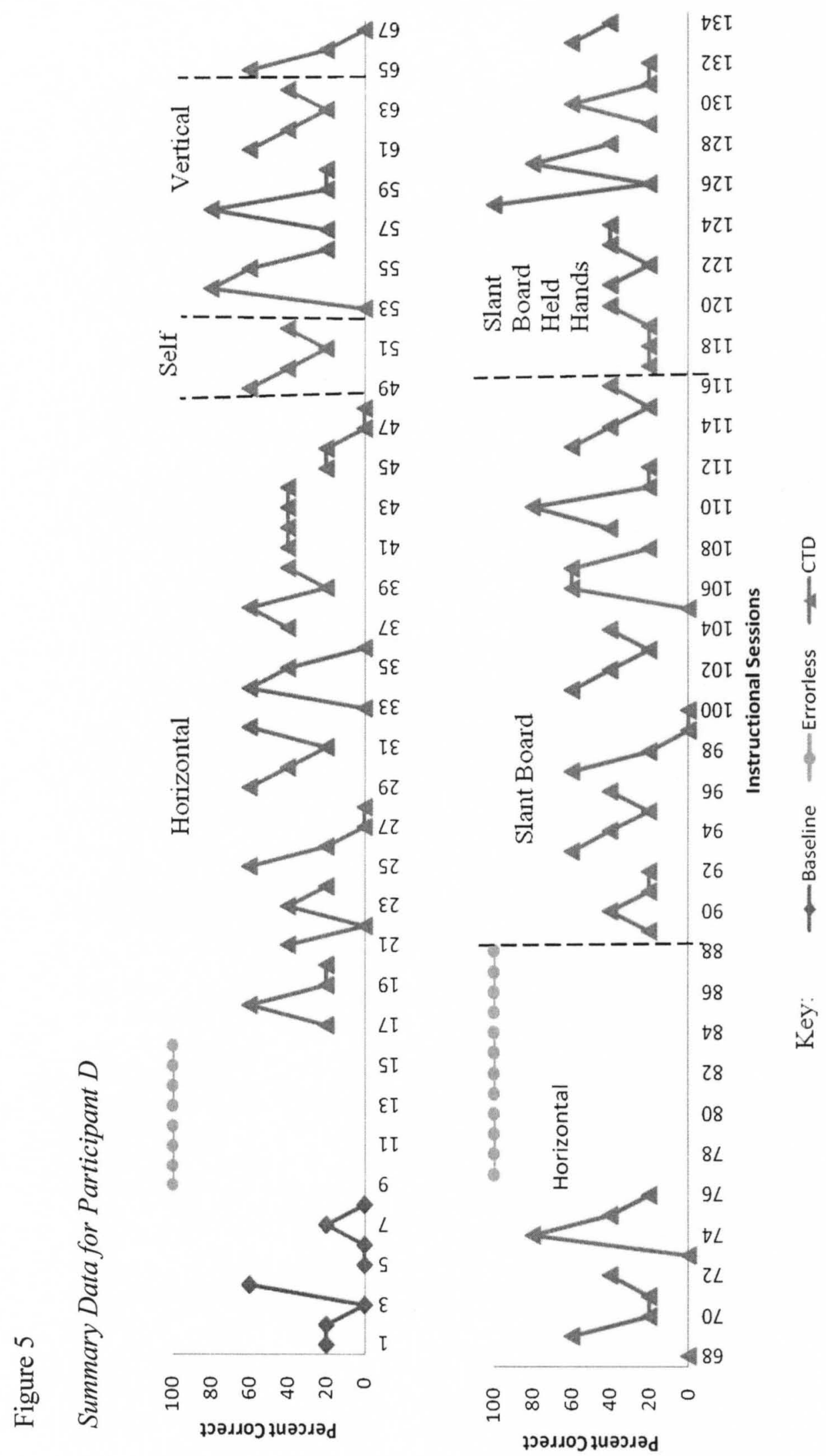

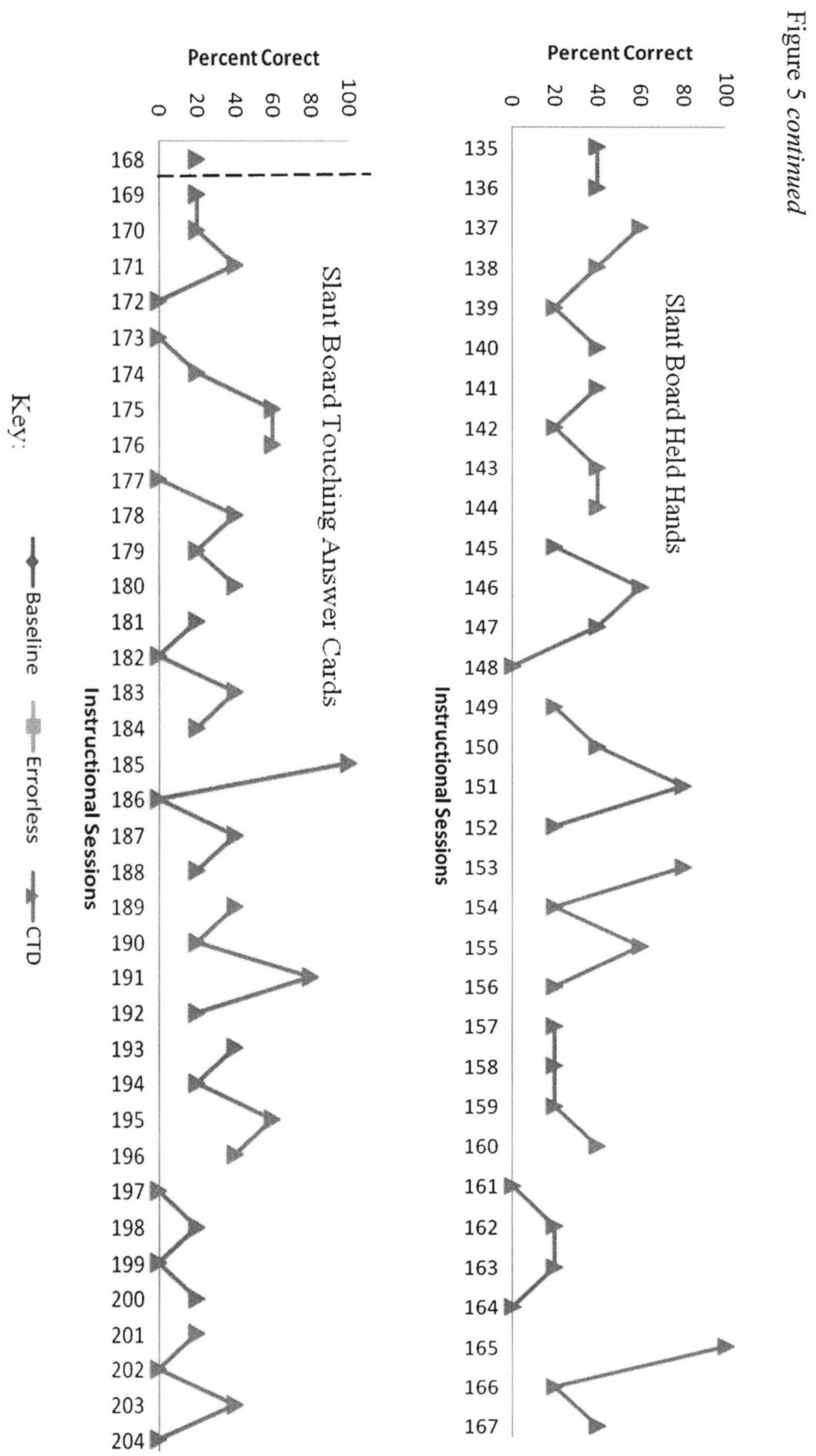
board, it was glued to a yardstick that was spray painted black (See Appendix L). The board was held on the table by three bookends.

Participant E sat on the same side of the table as the researcher for all his instructional sessions. The researcher sat to the left of Participant E. The term card choices were placed on the presentation board left to right with the card in the left position being card one, the card in the middle being card two, and the term in the right position as being term three. The researcher held the definition card up in front of Participant $\mathrm{E}$ with the researcher's left hand. Once the definition card was read the researcher placed the card down on the table. The research with her right hand took hold of Participant E's right wrist. The researcher then with hand-over-hand assistance used the participant's right hand to touch the three terms cards as the researcher labeled each of the term cards. Once the term cards had been labeled the researcher released Participant E's wrist. The researcher then began counting the 5-second delay. If Participant E did not make an answer choice; the researcher would again take Participant E's right wrist and hand -over-hand touch the correct term card while verbally labeling it.

Participant E's demeanor was positive during the instructional sessions. He would clap his hands, make noises, and laugh. He did not physically resist any of the handover-hand assistance during any of the instructional sessions. Even though Participant E did not answer with a high rate of consistency or accuracy he was engaged in the research sessions and he would reach out and touch the definition card as the researcher was reading it and reach out and touch the answer card during the correction part of the teaching procedure. Beginning with session 21 the researcher recorded touching behavior for Participant E. Participant E touched the definition card between $75-100$ 
Figure 6

Pattern of Participation Participant E

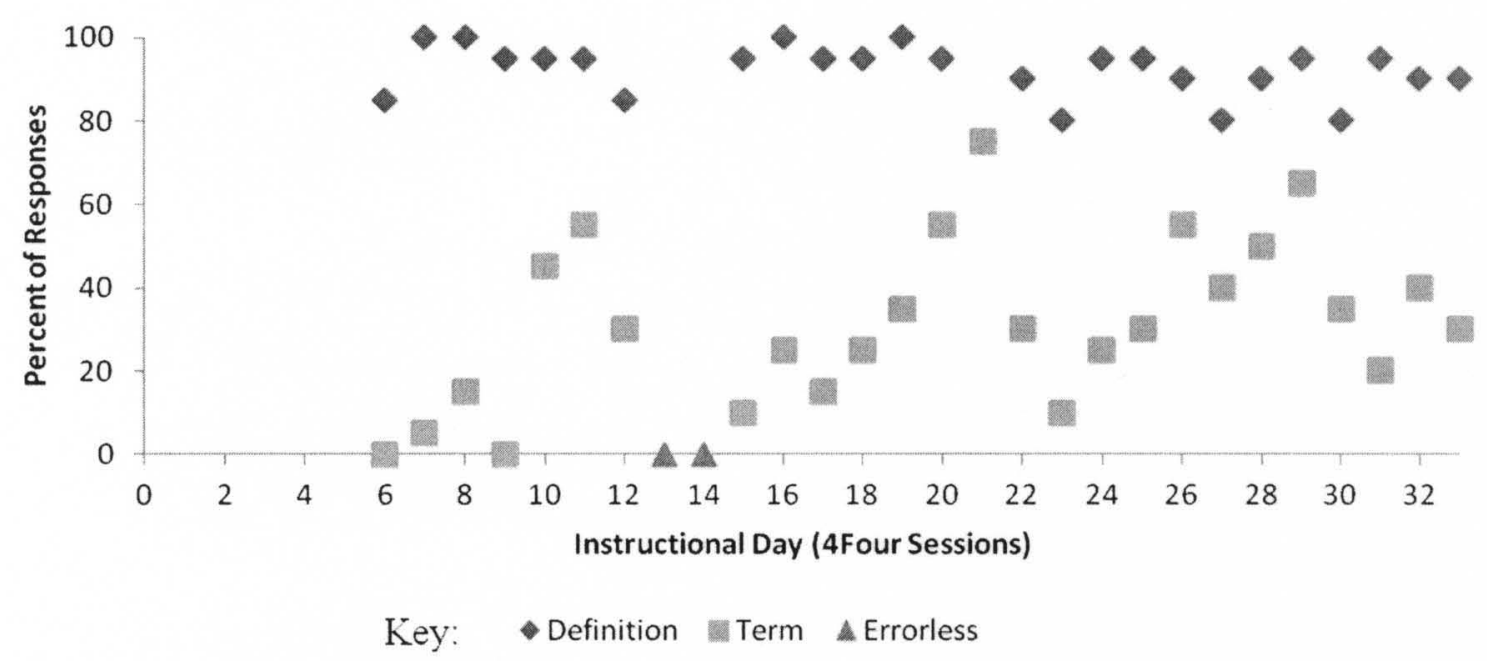

percent of the time during the 112 instructional sessions (see Figure 6). Participant E touched the answer card between 0 and 75 percent of the time during the 112 sessions (see Figure 6).

Participant $\mathrm{E}$ did not reach the criteria set for mastery for this research study. In 45 of the 112 of the instructional sessions (disregarding the 20 errorless sessions) Participant E did not make any answer choices making his mean non-response rate 40 percent. Participant E's mean correct percent was seven (see Figure 7). This percentage is far less than the 33 percent random chance associated with a field of three. Even though trend line analysis shows an upward trend at the end of the instructional period it is not possible to draw any acquisition conclusion for Participant E.

Participant F Non-Verbal Group. Participant F was a female with multiple disabilities including functional mental disability, orthopedic impairment, other health impairment disability, and speech language impairment. Participant $\mathrm{F}$ is non-verbal. Participant F vocalized single pitched sounds, cries, and laughs. 
Participant F had a "yes" head shake that was fairly consistent when Participant F was asked about items of want either for nourishment or body positioning. Participant F used non-response or rejection to indicate "no" to questions. This behavior might be characterized as hiding her eyes or looking away. Within the last year, in the school setting, the concept of responding "yes" to the identification of an item was initiated. For example, Participant $\mathrm{F}$ was shown a photograph of her mother and asked, "is this your mom". Participant F mean percentage of responding to this task was only 45 .

When Participant $\mathrm{F}$ was in need she would cry in order to obtain the attention of her caregivers. Caregivers use environmental cues such as dropped reinforcers or contorted body placement to determine what Participant $\mathrm{F}$ is in need of. Caregivers often must cycle through several actions or questions in order to determine the need of Participant $F$.

Participant $\mathrm{F}$ did seem to have a limited or selected ability for joint attention. Participant $\mathrm{F}$ often responds to environment events appropriately such as laughing when something funny had been said or done.

Like Participants D and E, Participant F has developed the response class of responding to discrete presentation of material. However, Participant $F$ was not as consistent with responding in the classroom setting as the other two non-verbal participants.

Screening. During the original screening process she did not correctly identify any of the 16 terms. The targeted vocabulary terms for participant $\mathrm{F}$ were coplanar, irregular polygon, n-gon, obtuse angle, and sine.

Baseline. Participant F's first baseline (sessions 1-4) produced results of 0, 0, 0, and 0 percent correct respectively with an mean score of 0 percent correct. Participant F only 
made one selection during sessions 1-4. Participant F's selection was incorrect. Participant's F second baseline (sessions 5-8) produces result of 20, 0, 20, and 0 percent correct respectively with an mean score of 10 percent correct. The first baseline shows a flat trend line and the second baseline shows a downward trend line. Participant F had 12 baseline sessions over 3 instructional days 1, 16 and 44 days prior to the beginning of her instructional period.

Instructional. Participant F had 19 instructional days within 21 school days over the course of 5 weeks. Participant F had a total of 84 sessions of the targeted vocabulary. Participant F had 12 sets over three sessions of errorless instruction at 100 percent accuracy. The researcher decided to add an additional session of errorless instruction because of the lack of progress made by the two on-going non-verbal participants. The mean instructional time for a session ranged from 1:48 to $3: .38$ (see Appendix R). The total instructional time for Participant F was 231:17 (3 hours 51 minutes and 17 seconds). Participant F's mean session time for a session was $2: 45$. The median instructional time for a session was 2:46 (See Table 10).

Participant F had a wide range of session times. Participant F's physical condition impacted the researcher's delivery of hand-over-hand assistance to Participant F. Participant $F$ would tighten her arm muscles and pull against the researcher. The strength of both of the researcher's arms was required at times to be able to physically manipulate Participant F's arm. Participant F would look at the researcher, the ceiling lights, or the presentation board. The only vocalization that Participant F made during the instructional sessions was laughter. Participant F's demeanor appeared content, but uninterested and matter of fact during most of the instructional sessions. However, 

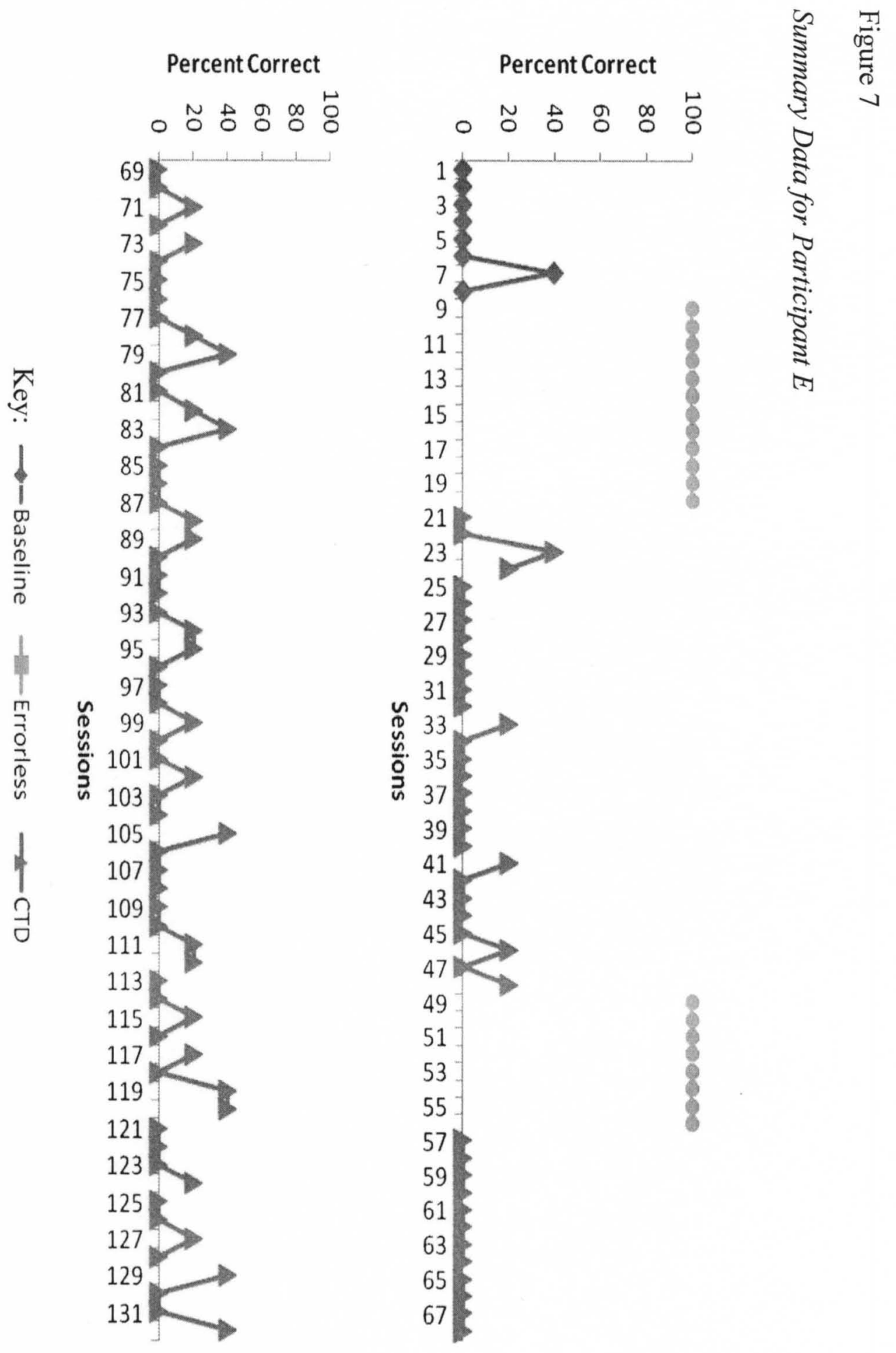
Participant F did not whine or cry during any of the instructional sessions even though both of these were in her behavior repertoire when she was displeased. Participant F used a black presentation board for all of his instructional sessions. The board was constructed from $1 / 2$ inch foam board. The board was 12 inches tall and 30 inches long. The board was covered front and back with black felt. To help stabilize the board, it was glued to a yardstick that was spray painted black (See Appendix L). The board was held on the table by three bookends.

Participant F sat on the same side of the table as the researcher. The researcher sat to the left of Participant F. The term card choices were placed on the presentation board left to right with the card in the left position being card one, the card in the middle being card two, and the term in the right position as being term three. The researcher held the definition card up in front of Participant F with the researcher's left hand. Once the definition card was read the researcher placed the card down on the table. The research with her right and left hands as needed took hold of Participant F's left wrist and elbow if needed. The researcher then with hand-over-hand assistance used the participant's left hand to touch the three terms cards as the researcher labeled each of the term cards. Once the term cards had been labeled the researcher returned Participant F's arm to a neutral position. The researcher then began counting the 5-second delay. If Participant $\mathrm{F}$ did not make an answer choice, the researcher would again take Participant F's left wrist and elbow if needed and hand-over-hand touch the correct term card while verbally labeling it.

Participant $\mathrm{F}$ did not reach the criteria set for mastery for this research study. In 54 of the 72 of the instructional sessions (disregarding the errorless sessions) Participant $F$ 
had a 100 percent non-response rate (see Figure 8). Participant F's mean non-response rate in the 72 instructional sessions was only 75 percent (see Figure 8). Percent F's mean correct percent was two percent (see Figure 9). This percentage is far less than the 33 percent random chance associated with a field of three. Trend line analysis shows a continuous downward trend across the instructional sessions (see Figure 9). The mean low correct rate of two percent would indicate that Participant F did not acquire any targeted vocabulary during the research study. However, this conclusion was clouded by the extremely low response rate. Refusal to respond, while discouraging, cannot be interpreted as a direct correlation to lack of knowledge.

\section{Non-verbal Participants' Summary}

The researcher had an extensive knowledge of the non-verbal participants as the researcher was also the non-verbal participants' teacher of record. All three non-verbal participants were members of the researcher's classroom. In reviewing the results of this study the researcher was able to add firsthand knowledge of behaviors, learning styles and student responses that add insight into the behaviors of the participants. It is felt that the researcher's knowledge and relationship with the participant did not change the outcome, but added clarification to what otherwise would have been complete unknown variables had another researcher presided over the study.

Participants D and E were completing their second year in the researcher's

classroom. Participant $\mathrm{F}$ was finishing her first year in the researcher's classroom. All three of the participant's academic programming consisted of discrete trial presentation of material. 
Figure 8

Pattern of Response Rate for Participant F

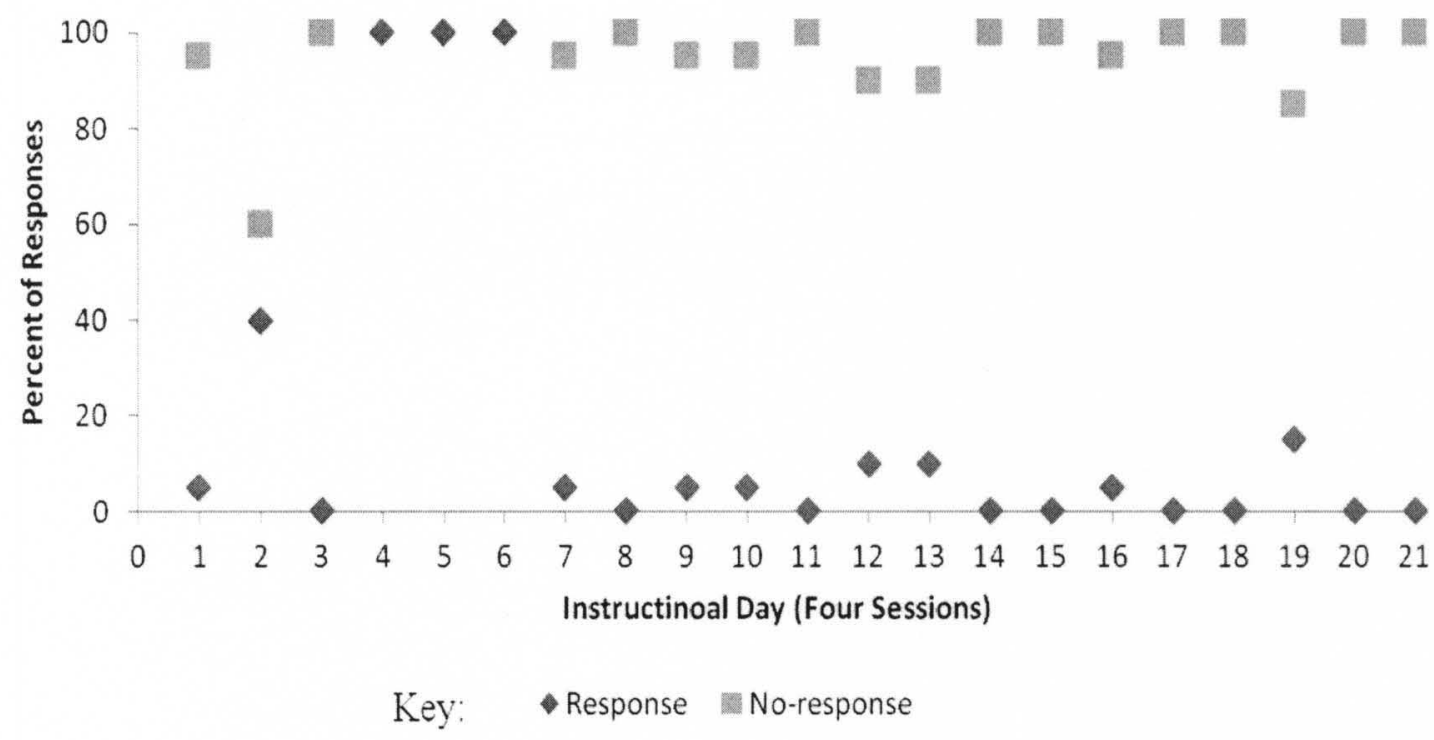

Participant D's discrete trial material was presented in a horizontal tabletop orientation in the classroom setting. This was the same format in which the content vocabulary was originally presented. While not all of Participant D's academic material was presented in a field of three he had had exposure and experience with a field of three. Participant D did display a tendency to indicate answers that were on his right or center at higher rates of response then the left hand position. However, Participant D also displayed the ability to scan the array of three and to make accurate selections.

Behaviorally, during the research sessions, Participant D was engaged and responsive. He remained seated, made eye contact with the researcher and made answer choices. Participant D has a pleasing personality and while he does not comprehend most of material presented to him he does follow rote routines. The pattern of response represented in the rote procedures involved in the selection of an answer was not a 
Figure 9

Summary Data for Participant F
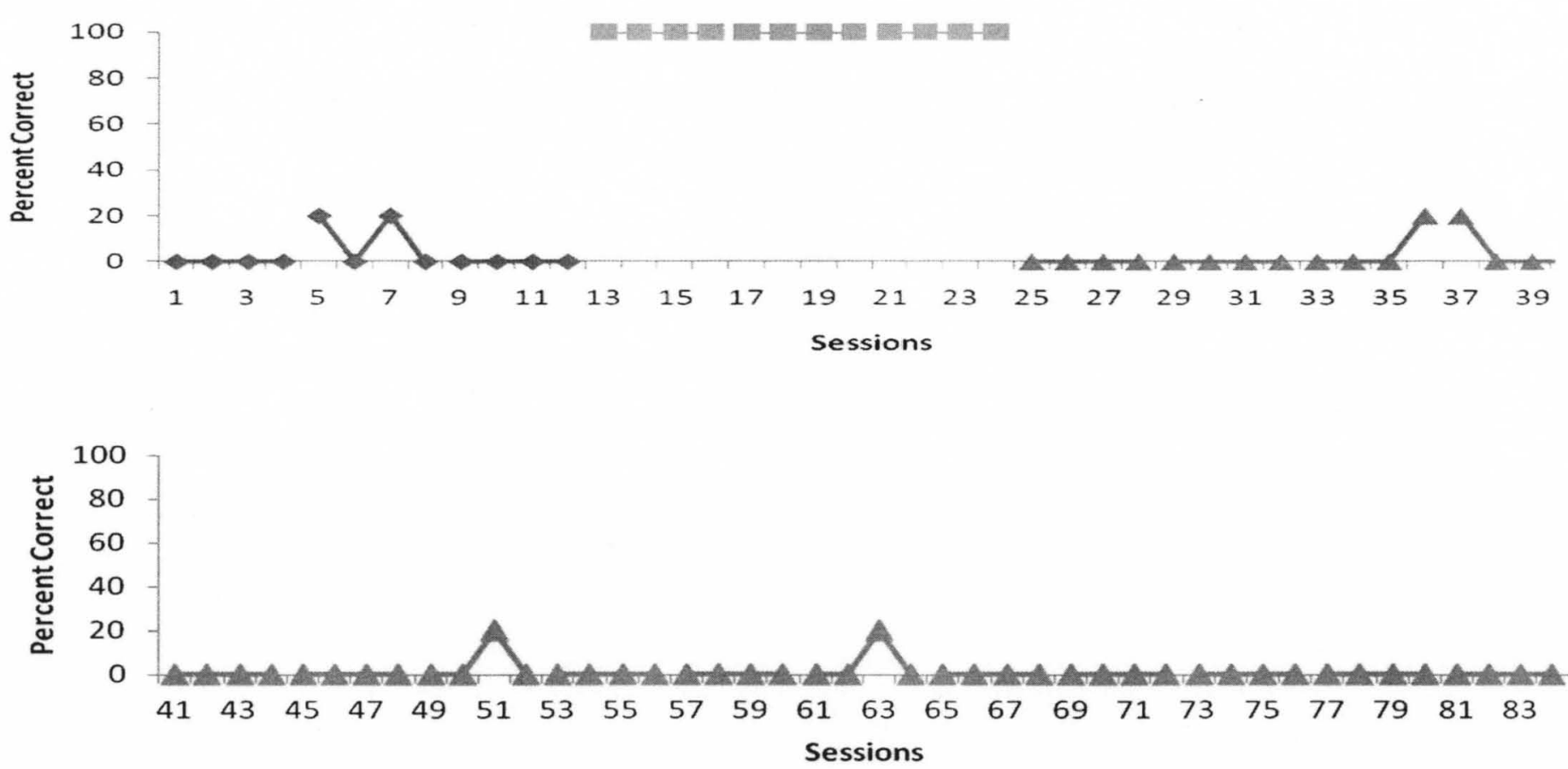

Key: $\rightarrow$ Baseline $\rightarrow$ Errorless 
challenging skill for Participant D.

Participant E's discrete trial material in the classroom was present in a vertical orientation in a field of two. Participant E's programming procedures in the classroom were vertically based due to his inability to pick-up, grasp, and release 3-D and 2-D items. Participant E developed the ability to grasp 3-D objects during his first school year with the researcher, but he still struggles with grasping 2-D items. When successful at grasping 2-D items it was done with the palm and not the fingers. These two factors combined with the alternate delivery system, the presentation board, having been initiated with Participant $D$ was why the researcher began Participant E's responses in the vertical and not the horizontal orientation.

Behaviorally, during the research sessions Participant $\mathrm{E}$ was responding to and interacting with the researcher. Participant $\mathrm{E}$ does respond with vocal indications of discontentment and slapping when engaging in activities not to his liking. Throughout each of the instructional sessions, Participant $E$ did not engage in any level of negative behaviors or responses to the researcher.

All but one of Participant F's discrete trial materials in the classroom was present in a vertical orientation in a field of two. A field of three was requested by the parents of Participant $\mathrm{F}$ to be done with one academic task as indication of knowledge growth. While expanding the field of selection for items decreases the impact the chance to the data collection, multiple field selection becomes more of a visual scanning exercise than proof of higher thinking. Participant F's limited body movement's impacts her ability to make selections when the selection field was expanded to three. In the researcher study, her range of motion was extended to its max. In the classroom setting, the researcher 
watches all of Participant F's upper extremity motions when making selections. The movement of Participant F's shoulder was a strong indicator towards the intent of Participant's E selection. Participant $\mathrm{F}$ had to rotate her shoulder to make a cross midline selection.

Participant F's limited mobility and classroom exposure to vertical presentation of material and the initiation of the alternate delivery system, the presentation board, with Participant D was why the researcher began Participant F's responses in the vertical and not the horizontal orientation.

Behaviorally, Participant $\mathrm{F}$ has a history of several behavioral responses when uninterested or discontented with activities in the school setting. One response was to place her fist to her eye and bow her head. A second response would be to put her fingers in her mouth and tilt head back and position her eyes to the ceiling. A third, the most adverse reaction, was screaming and crying. A forth behavioral response engaged in by Participant $\mathrm{F}$ was tightening of the muscles in her mobile arm. As the researcher moved Participant's F arm while reading the answer choices, Participant F would contract her muscles randomly. At times, the researcher would have to use both of her arms to have the strength to physically manipulate Participant F's arm. While, Participant F made very few responses during the research study she never engaged in crying and screaming behavior or the fist to the eye behavior. Attempts to put her fingers in her mouth were blocked by the researcher. This blocking behavior by the researcher never triggered additional negative responses from Participant $\mathrm{F}$.

While, Participants $\mathrm{E}$ and $\mathrm{F}$ were not able to show any acquisition of learned vocabulary one cannot conclude that they did not absorb any of the information that had 
been presented to them. As with any academic or functional skill, participants have to be able and willing to display proof of knowledge. Verbal individuals have two means of relaying this information to others through either receptive or expressive means. It is difficult for any professional to ascertain true cognitive abilities on individuals locked in silence. Evaluative materials require both receptive and expressive output on the part of the individual. Until modern medicine could translate brain activity into responses that could indicate learned knowledge and skills--teachers, parents, and other professionals will be left to infer and guess intent and means based on behavioral output.

\section{Reliability}

\section{Procedural Reliability}

The research study consisted of 420 separate instructional sessions across the six participants. The research study was conducted across 65 school days in 15 calendar weeks. Procedural reliability was collected during 99 instructional sessions (23.57\%) The observer placed a check-mark in the appropriate column once the researcher completed the behavior. No check-marks were recorded if the researcher failed to follow the study procedures. Procedural reliability mean for four sessions ranged from 91 percent to 100 percent. The mean procedural agreement was 99.6 percent.

\section{Inter-rater Agreement}

The research study consisted of 420 separate instructional sessions across the six participants. The research study was conducted across 65 school days in 15 calendar weeks. Inter-rater agreement was collected during 68 instructional sessions (16.19\%) of the instructional sessions across all six participants. The observer indicated "yes" on the data sheet if the participant, per the research guidelines, responded correctly. The 
observer indicated "no" on the data sheet if the participant, per the research guidelines, responded incorrectly. The observer indicated "no response" if the participant, per the research guidelines did not respond within the allotted time. Inter-rate agreement mean for four sessions between observers ranged from 95 percent to 100 percent. The mean inter-rater agreement was 99.7 percent. 


\section{CHAPTER V}

\section{DISCUSSION}

This chapter begins with an overview of the study's purpose, population and methodology. Discussion, conclusions and implications for practice follow the summary of results for each question. The chapter concludes with an examination of the study's limitations and suggestions for further research.

\section{Overview of Purpose}

The purpose of this study was to determine if students with moderate and severe disabilities could acquire core content vocabulary using constant time delay procedures. The participants were six $10^{\text {th }}$ graders who through their IEP were assigned eligibility to participate in the Kentucky state alternate assessment. All six of the students spent the majority of their day in a special class. The six participants were enrolled in one of the three community based instruction (CBI) classrooms in a rural high school.

Four males and two females participated in the study. Five were Caucasian and one participant was Hispanic. One of the participants qualified for the federal free lunch program based on their family's income. The participants were divided into two groups: verbal and non-verbal. Group 1 consisted of the verbal participants and group two consisted of the non-verbal participants.

A multiple probe design (Horner \& Baer, 1978; Murphy \& Bryan, 1980) across behaviors (vocabulary) with replication across participants was used to assess the effectiveness of constant time delay on the acquisition of mathematical core content 
vocabulary by $10^{\text {th }}$ graders with moderate and severe disabilities. Data were analyzed for each participant in regards to the mean percent correct for the vocabulary terms as a whole. Data were analyzed to determine the increase of knowledge for each individual vocabulary term through generalization for Group 1 the verbal participants. Group 2 (non-verbal) data were analyzed in terms of number of trials on a case study basis. This was conducted as a result of the lack of students' ability to reach a criterion level of the vocabulary terms.

\section{Discussion of Results}

Goal 1. Confirm that the evidence based research teaching strategy; constant time delay could be used to teach core content skills to students with moderate and severe disabilities.

In light of the findings, the answer to this goal was mixed. Group 1, the verbal participants displayed a functional relationship between constant time delay and acquisition of mathematical content vocabulary. However, the results for stability of long-term learning did not appear to be remarkable. For example, the participants, as a group, were able to maintain acquisition of 87 percent of their respective targeted vocabulary. It should be noted, however, that Participant B's maintenance score was 65 percent. It should also be noted that while Participant $\mathrm{C}$ had a perfect score of 100 percent he had also just concluded his instructional phase.

Regarding the generalizability of the math vocabulary terms the participants, as a group, had a generalization mean score of 65 percent of their respective targeted vocabulary. Based on these findings, the objective of Goal 1 was met for Group 1 (verbal) although it appeared that there was a higher maintenance rate of acquisition, than 
the ability to generalize or use the terms in different contexts. This somewhat low rate of generalization would have significant implications in the classroom. For example, once the student learned the vocabulary words, they would not be able to use the words in other contexts, thus limiting the effectiveness of the original gained knowledge.

The results and responses for Group 2, the nonverbal group, were complex. Group 2, participants did not display a functional relationship between constant time delay and acquisition of mathematical content vocabulary. The data indicated that no acquisition of targeted vocabulary were obtained by two of the participants and unsupported acquisition of the targeted vocabulary by the third participant as his acquisition rate appeared to be no greater then random chance for a field of three. While these results seem to support that Goal 1 was not achieved by the participants who were non-verbal, further analysis of the data were warranted. For example, the low acquisition rates for two of the participants appeared to be due to non-responsiveness by the participants. Nonresponsive behavior might not be directly viewed as representative of unlearned behavior.

Several strategies were used to increase response rate. For example, teaching procedures were changed throughout the study in order to determine if environmental factors were impacting the participants' non-responsive behaviors. It is note worthy that the behaviors the participants did engage in during the instructions sessions did not include negative behaviors. The participants appeared to be content and engaged in the presentation of the material. At no time did the participants resist or protest the researcher's use of hand-over-hand prompting techniques. It did not appear to the researcher, that the participants' non-response rate was a result of the participants not understanding that they were to make a selection with the known behavioral response of 
touching a card. Each of the participants had discrete selection as part of their daily instruction in their classroom. Therefore, each subject appeared to have the requisite skills to follow the CTD instructional procedures. However, the amount of language used in the instruction process was more involved than the participants had previous experience. Typical instructional delivery in the classroom was three to five words in length for the participants.

Goal 2. Encourage other researchers and teachers to attempt other academic skills from the general education core content curriculum in moderate and severe classrooms.

The success of this goal is not readily known. However, the results of this study do not appear to be a promising approach to teach students who are nonverbal with moderate and severe disabilities core content vocabulary words using constant time delay procedures.

\section{Discussion of Research Question Results}

Research question 1. What are the effects of Constant Time Delay on the acquisition of core content math vocabulary by $10^{\text {th }}$ graders with moderate and severe disabilities?

The results were mixed. Two separate groups participated in this study. All the students in the study had been diagnosed with moderate and severe learning disabilities. A distinctive characteristic dividing the participants was their expressive language statuses. Group 1, Participant A-C, contained two males and one female who all had recognizable verbal outputs to novel listeners. Group 2, Participants D-F, also contained two males and one female who were non-verbal with no functional commutative vocal output. The three verbal participants (A-C) were able to reach criteria. 
The three non-verbal participants (D-F) were not able to reach criteria. Several factors might have contributed to the non-acquisition of the targeted vocabulary by the non-verbal participants. The location of the research study, materials, number of intervention sessions, reinforcement schedule, time delay length, time of day, content, and response modes might have impacted the participants' results.

Research environment. For example, the location was different than their normal classroom. This environmental change could have triggered any number of internal sensory responses in the participants that were undetected by the researcher.

Regarding the research materials, the cards were larger than the participants used in their daily learning environment. The larger size of the material might have impacted their visual screening and scanning abilities. However, each of the non-verbal participants had normal vision acuity

Intervention sessions. The number of intervention sessions might have been too short. Intervention sessions were halted because the school year ended. While Participant D had 204 instructional sessions, it is unknown if acquisition of the vocabulary words might have been obtained in more sessions with these participants. There is little research that delves into the length/number of instructional trials that might be needed to reach criterion based on one's disability in obtaining core content vocabulary definitions.

Reinforcement schedule. A continuous reinforcement schedule was used during the research study. A continuous reinforcement schedule provides reinforcement after every correct response. It should be noted that continuous reinforcement schedules can be useful for teaching new behaviors, when the goal is to emphasize the "relationship 
between a discriminative stimulus and an associated response" (Alberto \& Troutman, $1999 ; 2006)$. In this study, praise was used as the reinforcement. There was consideration of using secondary reinforcers paired with the primary reinforcers to help increase the response rate of the participants. However, it was determined based on what reinforcers were used in the classroom, that this might not be effective strategy. Therefore, it is unknown whether adding such reinforcers would have had any impact on the rate of response. It should be noted that reinforcement based solely on the act of responding might have impacted Participants $\mathrm{E}$ and $\mathrm{F}$ rate of response. Participant $\mathrm{E}$ had a non-response rate of 40 percent. Participant $F$ had a non-response rate of 75 percent. Although the reinforcement aspect of this study appeared to be limitation, the notion that increasing the participants' response rate would not guarantee correctness of response. Just as with the increase of the schedule of reinforcement the additional tangible reinforcers would not guarantee correctness of the increase responses.

Length of time delay. The length of the time delay might have influenced the acquisition rate of the non-verbal participants. Longer processing time might have led to increase responses by Participants E and F, but it would not guarantee that the increased responses would be correct. Participant $\mathrm{D}$ responded immediately after the presentation of the material; therefore, additional delay length would not have impacted this participant. Using progressive time delay where the length of time changes throughout the intervention might have been a better instructional procedure to use with these participants. Progressive time delay consists of "gradually fading the controlling prompt by increasing the interval between the presentation of the stimulus and the delivery of the 
controlling response prompt" (Wolery, et al., 1992). However, the use of this procedure was beyond the scope of this research study.

Time of day. The time of day might have impacted the attention span or interest of the participants. All instructional sessions for this study were conducted in the afternoon between 1 and 3 p.m. While, the three non-verbal participants typically do the majority of their academic work before noon, all of the non-verbal participants have been known to complete academic tasks in the afternoon hours when needed. Morning instructional times might have impacted the acquisition results for the non-verbal participants.

Content. Perhaps one of the areas that might have impacted the results for the nonverbal participants in Group 2 was the idea that the mathematical content might have been too abstract or foreign. Mathematical vocabulary could be so difficult to learn from a lack of exposure to the vocabulary terms in everyday life (Monroe \& Orme, 2002). Mathematical texts were difficult to read and demand higher processing and comprehension skills (Reehm \& Long, 1996). Mathematical texts were also noted by researcher to be the most difficult content material to read (Schell, 1982). In content classroom vocabulary terms are essential for the development of conceptual framework (Blachowicz, Fisher, \& Watts-Taffe, 2005). When students do not know the vocabulary found in text, comprehension of the text will be reduced (Pikulski \& Templeton, 2004).

Response modes. Participants' receptive and expressive language skills might have had a large impact on the results of this study. The non-verbal participants did not possess the ability to give a verbal response; therefore, a receptive answer mode was determined to be the best method of response. Although Group 1 participants had the ability to verbally say the terms in a manner in which could have been understood by the 
researcher it was determined that all participants would be required to only give a receptive response (e.g. pointing to the answer). This was used as a way to equalize response modes for both groups.

Communication competence factors. Perhaps an important aspect of this research study was the inclusion of students who were non-verbal. One consideration regarding the ability to communication revolves around one's communicative competency.

Towles-Reeves, Kearns, Kleinert and Kleinert (2009) investigated the learning characteristics of the students who qualified for state alternate assessments. These participants would be individuals classified as having moderate and severe disabilities. The researchers found that the participants could be classified in one of two subgroups, symbolic and pre-symbolic (Towles-Reeves et al., 2009). The group classifications were based on verbal expressiveness (Towles-Reeves et al., 2009). In their review, $63-74 \%$ of the participants' primarily communicated expressively referred to as symbolic language; $17-26 \%$ communicated through gestures, pictures, objects, or pointing referred to as emerging symbolic language; and 8-11\% communicated through cries, facial expressions, and changes in muscle tone considered to be a pre-symbolic level of communication (Towles-Reeves et al., 2009). This $8-11 \%$ would be individuals classified as non-verbal and would be the most severely cognitively challenged.

Their study also looked at correlation between expressiveness and reading and math levels (Towles-Reeves et al., 2009). A statistically significant correlation was found to exist between the level of expressive language and reading and math levels (TowlesReeves et al., 2009). Students classified as having symbolic or emerging symbolic language had functional reading and math skills (Towles-Reeves et al., 2009). By 
definition, academic content is symbolic content that grows in complexity and becomes more abstract through each grade (Towles-Reeves et al., 2009).

A guiding question for researchers to ask in future studies. Do pre-symbolic moderate to severe communicators have the ability to respond to symbolic content

This study was designed to pair higher level academic skills with the most cognitively challenged participants. This study asked participants to learn the definitions for content vocabulary, a highly symbolic task. Hughes and Fredrick (2006) asked participants to write a target term next to a definition using constant time delay. The participants were successful, but all of the participants were verbal and IQ ranged from 90-106.

Throughout the delivery and the writing of this research study the researcher has found one additional study (McDonnell, Johnson, Polychronis, \& Risen, 2002) where students with moderate and severe disabilities were taught definitions. The two participants in the study had IQ's that were reported as 50 and 55 and the participants were verbal (McDonnell, Johnson, Polychronis, \& Risen, 2002).

Participant characteristics in previous studies. In light of the results of Group 2 the non-verbal participants, the researcher decided to take a second look at the characteristics of participants in the most recent review of literature where constant time delay instruction was used to determine the communication competence of the participants. Dogoe and Banda (2009) complied a review of research of constant time delay and functional tasks from 1996 to 2007 . Two additional reviews of constant time delay teaching procedures and its effectiveness preceded this review. Wolery, Holcombe, Cybriwsky, Doyle, Schuster, Ault and Gast (1992) reviewed constant time delay and 
discrete tasks from 1978 to 1992 and Schuster, Morse, Ault, Doyle, and Crawford (1998) reviewed studies that used constant time delay and chained tasks.

The Dogoe and Banda (2009) study reviewed eleven studies. The reported cognitive and verbal abilities of the participants in the 11 studies were reviewed. Four of the 11 studies in the review did not list cognitive abilities for the participants (Bozkurt \& Gursel, 2005; Fiscus et al., 2002; Yilmaz et al., 2005; \& Zhang et al., 2000). Low cognitive abilities of participants were reported in six of the studies that were reviewed (Dipipi-Hoy \& Jitendra, 2004; Graves et al., 2005; Morse \& Schuster, 2000; Stonecipher et al., 1999; Wall \& Gast, 1999; \& Zhang et al., 2004). The verbal abilities of the participants in one study could not be determined (Zhang et al., 2004). Nine of the studies revealed that the participants had either expressive symbolic language or emerging symbolic language (Bozkurt \& Gursel, 2005; Dipipi-Hoy \& Jitendra, 2004; Fiscus et al., 2002; Graves et al., 2005; Morse \& Schuster, 2000; Stonecipher et al., 1999; Wall \& Gast, 1999; Yilmaz et al., 2005; \& Zhang et al., 2000 . Only one article referenced a single participant where cognitive ability was not unobtainable from a standardized assessment and where that participant was non-verbal (Wall et al., 1999). The other three participants in the study had low cognitive abilities and emerging symbolic language (Wall et al., 1999).

The results from the 11 studies continued to support the use of constant time delay as effective instructional strategy to instruct individuals with moderate and severe disabilities functional tasks (Dogoe \& Banda, 2009).

An additional perspective could be gained by looking at the differences in the participants in Group 2 of the current study and the participants from the literature 
review. Group 2 participants in the current study were considered to have low cognitive abilities and were identified as functioning within the moderate and severe range of functioning.

Group 2's findings open a new avenue of exploration for instruction and research. Further research might need to focus on participant characteristics beyond educational classifications. Cognitive ability and the level of communicative responses, presymbolic, emerging symbolic and symbolic could have profound results on the appropriateness and effectiveness of instructional strategies.

Research question 2. What are the effects of constant time delay on the maintenance of acquired mathematical vocabulary by $10^{\text {th }}$ graders with moderate and severe disabilities?

Maintenance data was only collected on Group 1, Participants A-C (verbal participants). Participant A had three maintenance probes. Participant A scored 100 percent on 10 of the 12 maintenance sessions (sessions 41-52). Participant A's mean percent correct for the 12 maintenance sessions were 97 percent. Participant B had two maintenance probes (sessions 65-72). Participant B scored 100 percent during one of the eight maintenance sessions. Participant B mean percent correct for the maintenance sessions was 65 percent. Participant $\mathrm{C}$ had one maintenance probe (sessions 29-32). Participant $\mathrm{C}$ scored 100 percent in all four the maintenance sessions.

The maintenance probes provided insight into the depth at which the learned material was maintained. Maintenance of acquired material is an essential component of learning. This would be especially true of scaffold and foundational skills that make up core content curriculum. Individuals with moderate and severe disabilities not only have 
to be able to acquire core content curriculum they would also have to be able to maintain, add to, and build upon their learned knowledge. Acquisition of this knowledge would also have to be acquired at rates commensurate with their peers in order to fulfill the same educational expectations as their peers.

While Participant C's maintenance results are impressive his probe was delivered only one day after he reached criteria. Participant A had the most notable results as he maintained knowledge with a mean score of 97 percent that was maintained between four days and 41 days post instruction.

Maintenance data was not collected for Group 2, Participants D-F (non-verbal group). Participants D-F did not reach criteria for the researcher study and therefore did not enter into the maintenance phase of the research study.

Research Question 3. What are the effects of constant time delay on the generalization of acquired mathematical vocabulary by $10^{\text {th }}$ graders with moderate and severe disabilities?

Generalization probes consisted of five multiple-choice questions one for each of the targeted vocabulary. Only targeted vocabulary terms were used in the field of three answer choices. Either the teacher of record or the classroom paraprofessional read the questions and pointed to and read the answer choices to the participants. Participant A and $\mathrm{C}$ circled the letter $(\mathrm{a}, \mathrm{b}, \mathrm{c})$ associated with their answer choice. Participant $\mathrm{B}$ pointed to her answer choice on the generalization worksheet and the staff member assisting her with the activity circled the answers choice indicated by the participant.

Participant A had a generalization mean score of 56 percent correct. Participant A's five generalization scores were $60,100,40,40$, and 40 . Participant A answered two 
target vocabulary, sine and coplanar, correctly on all five generalization probes.

Participant A had a mean score of 80 percent correct on two target vocabulary, angle and midpoint. The final target vocabulary word, obtuse angle had a mean maintenance score of 60 percent correct in the generalization probes.

Participant B had a generalization mean score of 44 percent correct. Participant B's five generalization scores were $40,60,60,40$, and 20 percent correct. While the mean generalization percent correct show a downward trend or regression; further analysis of the data revealed that Participant B was able to generalize one of the five target vocabulary terms, obtuse angle at 80 percent correct over the five probes. Participant B was able to show a mean generalization of two target vocabulary, n-gon and transversal at 60 percent correct across the five generalization probes. Participant $B$ was only able to generalize the two remaining target vocabulary line of symmetry and midpoint at 20 and 0 percent correct, respectively across the five generalization probes.

Participant C's had a generalization mean score of 96 percent correct. Participant C's five generalization scores were $80,100,100,100$, and 100 respectively. Participant C was able to generalize four of the five targeted vocabulary at 100 percent across the five generalization probes. The four targeted vocabulary was angle of depression, degree, pi, and coplanar. The fifth targeted vocabulary, radius, was only missed once in the five generalization probes.

Generalization probes provide evidence to the breath at which learned material can be expanded. Students must be able to access learned knowledge in multiple formats; for example, listing verses selecting or defining verses using in a sentence. Participant A and B combined generalization scores were quite different than each specific vocabulary term 
generalization score. Both participants had low generalization mean scores, but each had individual terms generalize at 80 percent correct.

Generalization data was not collected on Group 2, Participants D-F, (non-verbal group). Participants D-F did not reach criteria for the researcher study and therefore did not enter into the generalization phase of the research study.

\section{Implications of Findings}

The results from this research study produced several implications worth noting. These included implications relate to the findings, the empirical knowledge base, practice, pre-requisite skills, the field, and future research.

Based on the findings of this study, it appears that the three verbal individuals with moderate and severe disabilities, individuals with intelligence scores between 40 and 64, were able to acquire limited core content vocabulary. These participants' communication competency would be considered at the symbolic level. The findings provided additional avenues for scientific research to continue.

The findings also indicated that individuals with moderate and severe disabilities who are nonverbal at the pre-symbolic level of communication competency might have difficulty learning core content information. These results have several implications for practice and future research. For example, the inability to reach the research goals by the non-verbal participants was possibly the result of individual factors. Factors such as vision, hearing, speech, modality, behaviors, and verbal status all contribute to the functioning level of each individual. Additionally, the need to pre-train participants in how to respond using CTD prior to baseline might have been a factor.

\section{Implication Related to Empirical Knowledge Base}


The results of this study might be best viewed in what has been found in previous research studies and if the present results are comparable or provide additional insight to what is known about constant time delay and, core content vocabulary acquisition in terms of definition identification..

In 2003 Bryant et al. conducted a review of literature of vocabulary intervention with students with learning disabilities. Bryant (2003) and associates found research in this field to be limited. One might conclude from their review that a variety of vocabulary interventions could help to improve vocabulary knowledge with students with LD across content. The parameters of this study included that the students had to be middle or high school aged which is the same as the participants used in the current study. Participants also had to be identified as having a learning disability (Bryant et al., 2003). This review looked at six research articles. Four of the six studies listed at least normal intelligence or normal intelligence in their descriptions of their participants. The fifth article only refers to the participants as mild and the sixth did not indicate an overall functioning level of the participants. The review found that depending on the purpose of the vocabulary instruction the methods of instruction used in the study were successful in improving vocabulary knowledge.

Another large review of the literature as it pertained to vocabulary and students with learning disabilities were conducted in 2004 by Jitendra, Edwards, Sacks, and Jacobson (see Table 1). These researchers reviewed 19 studies (Jitendra et al., 2004). The conclusions of the review found several effective and efficient research based methods that were available for vocabulary instruction (Jitendra et al., 2004). Here again, one must take a close look at the population of the studies in the review. Only one of the 19 
studies reported the cognitive ability of the participants as being below normal (Jitendra et al., 2004). Three of the studies did not indicate the cognitive ability of the participants. However, the most telling information comes from the remaining 15 studies. The reported intelligence scores of the participants in these studies range from 70-115 with the majority of the studies reporting cognitive ability means to be in the 90 s (Jitendra et al., 2004). The overall results of the study found that vocabulary instruction for students with learning disabilities can lead to increased word knowledge (Jitendra et al., 2004). Therefore, there is evidence that constant time delay and vocabulary instruction has been found to be with children with learning disabilities. However, there is little empirical evidence that CTD and vocabulary instruction (e.g. word definitions) with children with moderate/severe disabilities. Furthermore, there does not appear to be data regarding one's communication competency and the use of CTD and learning word definitions. This result of this study provides a glimpse at whether one's communication competency level affects one's ability to learn core content mathematic vocabulary. This area of research was beyond the scope of this study. Further research that specifically addresses communication competency would be subject worth more investigation.

\section{Implications for Practice}

The Common Core State Standards (CCS) were developed to ensure that all students are prepared for educational or professional avenues in the twenty-first century (CCSI, 2011). The CCS were meant to provide a roadmap for educators to use for planning a year-long academic journey. Teachers then use their individual experience and personalities to inspire their students to make connections and forge lifelong educational foundations. Educators and parents must combine to find the relevancy of 
the CCS and the future educational and professional opportunities for students with moderate and severe disabilities. A balance must be found between functional and academic curriculum spurred through inclusion, content and assessment mandates.

This research study continued to validate the use of constant time delay with students with moderate and severe disabilities who are verbal. The fact that this study was not successful with the non-verbal participants with core content vocabulary does not diminish the years of positive results other researchers have obtained with moderate and severe participants with functional skills or other academic skills. However, there needs to be more replications of this study to determine what factors affect an individual with moderate and severe disabilities to learn core content vocabulary/definitions using constant time delay procedures. Although there is an empirical base for using constant time delay for students of various disabilities, further research that investigates various factors that might impede student learning with individuals who are non-verbal with moderate and severe disabilities appears to be warranted.

\section{Implications for Pre-requisite Skills}

Future researchers should consider two pre-requisite skills for moderate and severe participants in core content research studies. The first, pre-requisite skill that should be considered is the participant's ability to deliver a response appropriate for the target skills. This might include only verbal response or a combination of both verbal and receptive responses. The second pre-requisite skill includes the participant's ability to respond to the material based on the level of communication competency the participant, symbolic, emerging, symbolic, or pre-symbolic. Participants might need to be excluded based on their communication competency. The last consideration would be for a 
researcher to determine if the participants have an understanding of the materials and what type of response the participant is expected to give. Modeling or practice responses of non-related material might be used to show that the participant understood what response was being expected of them.

\section{Implications for the Field}

This research study continued to validate the use of constant time delay with students with moderate and severe disabilities who are verbal. This translates to the continued need for teacher training in the use of constant time delay instructional procedures. Secondary teaching environments need to continue to educate the next generation of teachers in the craft of discrete presentations and the systematic instruction. Teachers also need to have the ability to mold discrete presentation and systematic instruction with continued rigor to fit the complex needs of all the students.

Professional development opportunities are numerous. Context expects are needed to help teachers who work with children with moderate and severe disabilities, to modify and adapt curriculum topics into discrete skills. Special education teachers would also need professionals available to help them imbed the systematic instruction of the discrete skills into daily instructional times.

The institutions of higher education (IHE) and the district level professionals should consider adding additional time and training on exploring the differences of instruction for the verbal and non-verbal moderate and severe students. Response class, behavioral control, teaching procedures, assessment procedures, materials, inclusion strategies, and parent relations are different.

\section{Implications for Future Research}


This research study was designed to expand the current available research on participants with moderate and severe disabilities and academic skills. Research for decades have paired moderate and severe participants with functional skills and learning disabled participants with academic skills.

The generalization of the findings from this research study can only be supported or refuted through replication. The crisscross pairing of moderate and severe participants with academic skills lends itself to additional research. The possibilities are endless for future research in the crisscross pairing when looking at expanding knowledge of the most severely cognitively challenged students with academic tasks instead of functional tasks which historically have been done.

The following examples illustrate how future replication and expansion of this research study could occur. For example, research could specifically focus on, the verbal status of participants. Furthermore, research studies might investigate how the degree of language acquisition impacts acquisition rates, mastery times, generalization, and maintenance over time. Studies could also focus on whether verbal or manual language communication modes impact academic learning by individuals with moderate and severe disabilities.

Additional research inquires could specifically focus on the delivery of response. For example, the non-verbal participants in this research study used a vertical presentation rather than a horizontal presentation. Researchers might investigate if visual planes (horizontal or vertical) impacts student achievement.

Researchers could specifically focus on, the use of adapted response mechanisms or assistive technology output devices. For example, Participant F's limited body control 
might have been a contributing factor in her non-response rate. It is unknown if another method of response would have yielded better results. Another consideration regarding the use of assistive technology would be the amount of time the participant would need in order to respond to the prompt. Further investigation into the need for additional response time when using adapted response devices such as but not limited to eye gaze, switch/scanning inputs or voice output devices appears to be warranted.

Other studies could focus on whether the selection field has a significant impact on the acquisition results. Reducing the selection to a field of two draws random change considerations into the analysis of the data. However, a multi-tier research approach could be used to decrease the impact of chance on the results.

Research could be further expanded through the use of different core content areas. Core content material would have a near endless supply of category specific vocabulary, formulas, and facts necessary for mastery of the core curriculum.

Lastly, research could investigate the addition of pictures or manipulative, such as geo-boards or 3-D models, as part of constant time delay procedures with core content vocabulary words. The addition of these items along with textual cards might make the terminology more concrete or meaningful to the participant.

\section{Limitations}

Generalization to the population in the field of moderate and severe disabilities is difficult to achieve. Individuals with moderate and severe disabilities might be similar in regards to their IQ range, but contain a vast number of other contributing characteristics that belong uniquely to each individual. These individual characteristics make it difficult to form large homogeneous groups. In this research study there was a distinct difference 
in the performance of the verbal group and the non-verbal group. The following limitations of this study could have impacted the overall research findings.

\section{Setting Limitations}

One limitation of the study that might have had an impact on the participants was the setting change for the research study, especially for the non-verbal participants. The researcher does not believe the setting impacted the verbal participants based on their lack of inquiry of the new location or about the location itself. The verbal participants were also able to achieve mastery leading to the assumption that the setting did not appear to impact their learning. The setting could have contributed to the speed of acquisition, but its impacts would have been minimal due to the short length of time it took the verbal participants reached criteria.

Two of the non-verbal participants were somewhat familiar with the research location because they received speech language services in this room. It is unknown whether their responses or least their willingness to respond might not have been higher had the research study been conducted in their normal classroom where the pattern of instruction and the expectation of responding had already been established

\section{Time Limitations}

The research study ended with the academic school year. The research study was carried out over the course of 15 calendar weeks. The first non-verbal participant to enter the study received intervention services the entire 13 calendar weeks with the other two non-verbal participants receiving intervention services for 8 weeks and 5 weeks respectively. One must consider, what impact two more week or 15 more weeks would 
have had on the outcome of the study and the acquisition levels for the non-verbal participants.

Another consideration regarding the amount of time to complete the study would have been to implement two studies. One study would have been with Group 1, verbal participants, and the other study would have been with Group 2, non-verbal participants. Both studies could have been implemented at the same time using a multiple baseline design. By conducting the research in this manner, the number of days for implementing the study would have been greater for Group 2 .

\section{Generalization Limitations}

The results of this study might not be generalized. Multiple replications of this study are needed in order to make statements regarding the effectiveness of CTD procedures to learn mathematical definitions. Multiple replications would focus on the participants who were verbal. Although the results of this study regarding participants who are non-verbal are interesting, there are too many factors that might have interfered with the study's results and generalizability. Therefore, study refinements would need to be made regarding participants who were non-verbal. Such refinements include identifying the participants' communication competency abilities. Furthermore, if participants had pre-symbolic communication levels, then a determination whether they had the understanding of how to respond using CTD procedures would need to be made. A refinement of pre-training participants in CTD procedures using alternate materials might have eliminated the notion that the results were based on the participants' lack of understanding what was required of them.

\section{Procedural Study Limitations}


Participant A remained in the instructional phrase for 24 sessions longer than was required for this researcher study. Researcher error accounted for this mistake. The researcher confused three consecutive sessions with three consecutive days (12 consecutive sessions) before criteria was met. This error delayed the start for Participant $\mathrm{B}$ and therefore delayed the start of Participant $\mathrm{C}$. Participant $\mathrm{B}$ and $\mathrm{C}$ were both able to reach criteria and therefore did not comprise the results of the study.

Participant $\mathrm{C}$ had an initial high first baseline results with sessions score of 60,60 , 60 , and 20 . The researcher analyzed these results as being too high and therefore learning results would be comprised based on the small degree of learning that would need to take place. However, if the researcher had analyzed the baseline results as showing a downward trend the eventual need to change targeted vocabulary for Participant $\mathrm{C}$ might have been avoided. The immediate repetition of the second baseline could have likely resulted in learning taking place and once again might have been what spurred the need to change targeted vocabulary.

\section{Subject Pre-requisite Skills Limitations}

One of the limitations of this study concerned the language ability of the participants. In reflection, the researcher might have delved into the communication competency of the participants and conducted a study with only verbal, symbolic level individuals using constant time delay procedures. The addition of individuals who were non-verbal added another dimension to this study that was not initially considered. Therefore, it is unknown whether the participants who were non-verbal had the prerequisite skills to make meaningful responses. Careful consideration of subject prerequisite skills is an important factor that potentially impacts the fidelity of results. If 
it was determined that participants did not have the prerequisite skills, the option of pretraining response skills to the students prior to the implementation of the study might have been conducted. This appears to be the case regarding the results of the participants who were non-verbal. In retrospect, it appears that Group 2 (non-verbal) participants might not have had the prerequisite skills to make meaningful responses. Therefore, pretraining the students on how to response using CTD should have been conducted in order to rule out how this factor might have impeded the overall results. However, this limitation provided a better understanding regarding the importance of including communication competency levels as a requirement for participation in future studies.

\section{Conclusion}

Constant time delay teaching procedure appears to have been an effective technique with the participants with moderate and severe disabilities who were verbal. However, it is unclear if this type of procedure was effect for individuals who were non-verbal in this study.

The fact that spoken language accounts for a larger portion of our understanding of language (Greer, Smith, \& Erwin, 1996) could account for the difficulties that the nonverbal participants had with vocabulary acquisition in this study. The participant's inability to produce spoken language might be an indication that these individuals would not be able to acquire abstract mathematical terms. However, without additional instruction, and perhaps in different core content subject matter, a solid conclusion cannot be made regarding the potential learning of these three participants using constant time delay with core content mathematical vocabulary word definitions. 


\section{REFERENCES}

Adams, T. L., Thangata, F., \& King, C. (2005). "Weigh to go!" Exploring mathematical language. Mathematics Teaching in the Middle School, 10, 444-448.

Alberto, P. A., \& Troutman, A. C. (1999). Differential reinforcement: Stimulus control and shaping. In A. C. Davis (Ed.), Applied behavior analysis for teachers (pp. 333368). Upper Saddle River, NJ: Merrill.

Alberto, P. A., \& Troutman, A. C. (2006). Applied behavior analysis for teachers $\left(7^{\text {th }}\right.$ Ed.). Upper Saddle River, NJ: Pearson Education.

Aleman, S. R. (1991). Education of the Handicapped Act Amendments of 1990, P.L. 101-476: A summary. CRS report to Congress.

Armbruster, B. B., \& Nagy, W. E. (1992). Vocabulary in content area lessons. The Reading Teacher, 45, 550-551.

Asselin, M. (2002). Vocabulary instruction. Teacher Librarian, 29, 57-60.

Ault, M. J., Wolery, M., Gast, D. 1., Doyle, P. M., \& Eizenstat, V. (1988). Comparison of response prompting procedures in teaching numeral identification to autistic subjects. Journal of Autism and Developmental Disorders, 18, 627-636.

Baer, D. M., Wolf, M. M., \& Risley, T. R. (1968). Some current dimensions of applied behavior analysis. Journal of Applied Behavior Analysis, 1, 91-97.

Billingsley, F. F., White, O. R., \& Munson, R. (1980). Procedural reliability: A rationale and an example. Behavior Assessment, 2, 229-241.

Blachowicz, C. L. Z., Fisher, P. J. L., Ogle, D., \& Watts-Taffe, S. (2006). Vocabulary: 
Questions from the classroom. Reading Research Quarterly, 41, 524-539.

Boyd, C. J., Cummins, J., Malloy, C., Carter, J., \& Flores, A. (2005). Geometry. New York: Glencoe McGraw Hill.

Bozkurt, F., \& Gursel, O. (2005). Effectiveness of constant time delay on teaching snack and drink preparation skills to children with mental retardation. Education and Training in Developmental Disabilities, 40, 390-400.

Bromley, K. (2007). Nine things every teacher should know about words and vocabulary instruction. Journal of Adolescent \& Adult Literacy, 50, 528-537.

Browder, D., Ahlgrim-Delzell, L., Spooner, F., Mimn, P. J., \& Baker, J. N. (2009). Using time delay to teach literacy to students with severe developmental disabilities. Exceptional Children, 75, 343-364.

Browder, D. M., \& Cooper-Duffy, K. (2003). Evidence-based practices for students with severe disabilities and the requirement for accountability in "No Child Left Behind". The Journal of Special Education, 37, 157-163.

Browder, D. M., Morris, W. W., \& Snell, M. E. (1981). Using time delay to teach manual signs to a severely retarded student. Education and Training of the Mentally Retarded, 16, 252-258.

Browder, D. M., Spooner, F., Algozzine, R., Ahlgrim-Delzell, L., Flowers, C., \& Karvonen, M. (2003). What we know and need to know about alternate assessment. Exceptional Children, 70, 45-61.

Browder, D. M., Wakeman, S. Y., Spooner, F., Ahlgrim-Delzell, L., \& Algozzine, B. (2006). Research on reading instruction for individuals with significant cognitive disabilities. Exceptional Children, 72, 392-408. 
Browder, D. M., \& Xin, Y. P. (1998). A meta-analysis and review of sight word research and its implications for teaching functional reading to individuals with moderate and severe disabilities. The Journal of Special Education, 32, 130-153.

Brown, C. L. (2007). Supporting English language learners in content-reading. Reading Improvement, 44, 32-39.

Bryant, D. P., Goodwin, M., Bryant, B. R., \& Higgins, K. (2003). Vocabulary instruction for students with learning disabilities: A review of the research. Learning Disability Quarterly, 26, 117-128.

Burke, J. (2003). The place and purpose of vocabulary instruction. In L. Bridges, (Ed), The English Teacher's Companion: A Complete Guide to Classroom, Curriculum, and the Profession (pp.102-123). Portsmouth, NH: Heinemann.

Campbell, D. T., \& Stanley, J. C. (1966). Experimental and quasi-experimental designs for research. Chicago: Rand McNally.

Carmichael, S. B., Wilson, W. S., Martino, G., Finn, C. E., Jr., Porter-Magee, K., \& Winkler, A. M. (2010). Review of the draft K-12 common core standards. Thomas Fordham Institute.

Casey, S. D. (2008). A comparison of within- and across- session progressive time delay procedures for teaching sight words to individuals with cognitive delays. Behavior Analyst Today, 9, 162-171.

Chandler, W., Schuster, J. W., \& Stevens, K. B. (1993). Teaching employment skills to adolescents with mild and moderate disabilities using a constant time delay procedure. Education and Training in Mental Retardation, June, 155-168.

Cohen, E. T., Heller, K. W., Alberto, P., \& Fredrick, L. D. (2008). Using a three-step 
decoding strategy with constant time delay to teach word reading to students with mild and moderate mental retardation. Focus on Autism and Other Developmental Disabilities, 23, 67-78.

Collins, B. C., Evans, A., Creech-Galloway, C., Karl, J., \& Miller, A. (2007).

Comparison of the acquisition and maintenance of teaching functional and core content sight words in special and general education settings. Focus on Autism and Other Developmental Disabilities, 22, 220-233.

Collins, B. C., Hager, K. L., \& Galloway, C. C. (2011). Addition of functional content during core content instruction with students with moderate disabilities. Education and Training in Autism and Developmental Disabilities, 46, 22-39.

Common Core Standards Initiative. (2011). Common Core. Retrieved from: www.corestandards.org

Cortiella, C., \& National Center for Learning Disabilities, I. Y. (2006). IDEA Parent Guide: A Comprehensive Guide to Your Rights and Responsibilities under the Individuals with Disabilities Education Act (IDEA 2004). National Center for Learning Disabilities.

Council for Exceptional Children. (2010). K-12 common core state standards for the instruction of students. Retrieved from: www.cec.sped.org Crutchfield, M. D., (2003). What do the CEC standards mean to me? Teaching Exceptional Children, 35, 40-45.

David, J. L., (2010). Closing the vocabulary gap. Educational Leadership, March, 85-86. Dipipi-Hoy, C., \& Jitendra, A. (2004). A parent delivered intervention to teach purchasing skills to young adults with disabilities. The Journal of Special Education, 
$38,144-157$.

Dogoe, M., \& Banda, D. R. (2009). Review of recent research using constant time delay to teach chained tasks to persons with developmental disabilities. Education an Training in Developmental Disabilities, 44, 177-186.

Elliott, S. N., Compton, E., \& Roach, A. T. (2007). Building validity evidence for scores on a state-wide alternate assessment: A contrasting groups, Multimethod approach. Educational Measurement; Issues and Practice, 26, 30-43.

Elliott, S. N., \& Roach, A. T. (2007). Alternate assessments of students with significant disabilities: Alternative approaches, Common technical challenges. Applied Measurement in Education, 20,301-333.

Fiscus, R. S., Schuster, J. W. , Morsem T. E., \& Collins, B. C. (2002). Teaching elementary students with cognitive disabilities food preparation skills while embedding instructive feedback in the prompt and consequence event. Education and Training in Mental Retardation and Developmental Disabilities, 37, 55-69.

Fisher, D., \& Frey, N. (2004). Improving Adolescent Literacy: Strategies at Work. New Jersey: Pearson.

Flanigan, K., \& Greenwood, S. C. (2007). Effective content vocabulary instruction in the middle: Matching students, purposes, words, and strategies. Journal of Adolescent \& Adult Literacy, 51, 226-238.

Fuchs, D., Fuchs, L. S., \& Stecker, P. M. (2010). The "blurring" of special education in a new continuum of general education placements and services. Exceptional Children, $76(3), 301-323$.

Gong, B., \& Marion, S., National Center on Educational Outcomes, M. N., Council of Chief State School Officers, W. C., \& National Association of State Directors of 
Special Education, W. C. (2006). Dealing with Flexibility in Assessments for Students with Significant Cognitive Disabilities. Synthesis Report 60. National Center on Educational Outcomes, University of Minnesota,

Graves, T. B., Collins, B. C., Schuster, J. W., \& Kleinert, H. (2005). Using video prompting to teach cooking skills to secondary students with moderate disabilities. Education and Training in Developmental Disabilities, 40, 34-46.

Graves, M. F., \& Prenn, M. C. (1986). Costs and benefits of various methods of teaching vocabulary. Journal of Reading, 596-602.

Greenwood, S. C. (2002). Making words matter: Vocabulary study in the content areas. Clearing House, 75, 258-263.

Greer, M., Smith, R. S., \& Erwin, L. (1996). Standards for the English Lange Arts. Retrieved from http://www.ncte.org/library/NCTEFiles/Resources/Books/Sample/ StandardsDoc.pdf

Handen, B. L., \& Zane, T. (1987). Delayed prompting: A review of procedural variations and results. Research in Developmental Disabilities, 8, 307-330.

Hardman, M. L., \& Dawson, S. (2008). The impact of federal public policy on curriculum and instruction for students with disabilities in the general classroom. Preventing School Failure, 52, 5-11.

Harmon, J. M., Hedrick, W. B., \& Wood, K. D. (2005). Research on vocabulary instruction in the content areas: Implications for struggling readers. Reading \& Writing Quarterly, 21, 261-280.

Harris, T. L., Hodges, R. E., \& International Reading Association, N. E. (1995). The Literacy Dictionary: The Vocabulary of Reading and Writing. 
Horner, R. D., \& Baer, D. M. (1978). Multiple-probe technique: A variation of the multiple baseline. Journal of Applied Behavior Analysis, 11, 189-196.

Horner, R. H., Carr, E. G., Halle, J., McGee, G., Odom, S., \& Wolery, M. (2005). The use of single-subject research to identify evidence-based practice in special education. Exceptional Children, 71, 165-179.

Hughes, T. A., \& Fredrick, L. D. (2006). Teaching vocabulary with students with learning disabilities using classwide peer tutoring and constant time delay. Journal of Behavioral Education, 15, 1-23.

Jalongo, M. R., \& Sobolak, M. J. (2010). Supporting young children's vocabulary growth: The challenges, the benefits, and evidence-based strategies. Early Childhood Education Journal, 38, 421-429.

Jimenez, B. A., Browser, D. M., \& Courtade, G.R. (2009). An exploratory study of selfdirected science concept learning by students with moderate intellectual disabilities. Research and Practice for Persons with Severe Disabilities, 34, 33-46.

Jitendra, A. K., Edwards, L. L., Sacks, G., \& Jacobson, L. A. (2004). What research says about vocabulary instruction for student with learning disabilities. Exceptional Children, 70, 299-322.

Johnson, E. S., \& Arnold, N. (2007). Examining an alternate assessment. Journal of Disability Policy Studies, 18, 23-31.

Kazdin, A. E. (1982). Single-case research designs: Methods for clinical and applied settings. New York: Oxford University Press.

Kennedy, C. H. (2005). Single-case designs for educational research. Boston: Pearson Education, Inc. 
Kester Phillips, D. C., Foote, C. J., \& Harper, L. J. (2008). Strategies for effective vocabulary instruction. Reading Improvement, 45, 62-68.

Kidd, D. H., Madsen, A.L., \& Lamb, C. E. (1993). Mathematics vocabulary: Performance of residential deaf students. School Science and Mathematics, 93. 418-421.

Kieffer, M. J., \& Lesaux, N. K. (2007). Breaking down words to build meaning: Morphology, vocabulary, and reading comprehension in the urban classroom. The Reading Teacher, 6, 134-144.

Kleinert, H. L., \& Kearns, J. F. (2010). Alternate assessment for students with significant cognitive disabilities: An educator's guide. Baltimore, MD: Paul H. Brookes Publishing.

Kleinert, H. L., Quenemoen, R. F., \& Thurlow, M. (2010). An introduction to alternate assessments: Historical foundations, essential parameters, and guiding principles. In H. L. Kleinert \& J. Farmer-Kearns (Eds.), Alternate assessment for students with significant cognitive disabilities: An educator's guide (pp. 3-18). Baltimore, MD: Paul H. Brookes Publishing.

Knight, M. G., Ross, D. E., Taylor, R. L., \& Ramasamy, R. (2003). Constant time delay and interspersal of known items to teach sight words to students with mental retardation and learning disabilities. Education and Training in Developmental Disabilities, 38, 179-191.

Koscinski, S. T., \& Gast, D. L. (1993). Use of constant time delay in teaching multiplication facts to students with learning disabilities. Journal of Learning Disabilities, 26, 533-544, 567.

Kratochwill, T. R., Hitchcock, J., Horner, R. H., Levin, J. R., Odom, S. L., Rindskopf, D. 
M. \& Shadish, W. R. (2010). Single-case designs technical documentation. Retrieved from What Works Clearinghouse website:

http://ies.ed.gov/ncee/wwc/pdf/wwc_scd.pdf.

Kurt, O., \& Tekin-Ftar, E. (2008). A comparison of constant time delay and simultaneous prompting within embedded instruction on teaching leisure skills to children with autism. Topics in Early Childhood Special Education, 28, 53-64.

Lane, K. L., Kalberg, J. R., Bruhn, A. L., Driscoll, S. A., Wehby, J. J., \& Elliott, S. N. (2009). Assessing social validity of school-wide positive behavior support plans: Evidence for the reliability and structure of the primary intervention rating scale. School Psychology Review, 38, 135-144.

Lee, H., \& Herner-Patnode, L. M. (2007). Teaching mathematics vocabulary to diverse groups. Intervention in School and Clinic, 43, 121-126.

Linn, R. L. (2000). Assessments and accountability. ERIC/AE Digest, ED447220.

Marion, S. F., \& Pellegrino, J. W. (2006). A validity framework for evaluating the technical quality of alternate assessments. Educational Measurements: Issues and Practice, 25, 47-57.

Manzo, A. V., Manzo, U. C., \& Thomas, M. M. (2006). Rationale for systematic vocabulary development: Antidote for state mandates. Journal of Adolescent $\&$ Adult Literacy, 49, 610-619.

Mastropieri, M. A., Scruggs, T. E., \& Graetz, J. E. (2003). Reading comprehension instruction for secondary students: Challenges for struggling students and teachers. Learning Disability Quarterly, 26, 103-116.

McDonnell, J., Johnson, J.W., Polychronis, \& Risen, T. (2002). Effects of embedded 
instruction on students with moderate disabilities enrolled in general education classes. Education and Training in Mental Retardation and Developmental Disabilities, 37, 363-377.

Merchant, M., Renshaw, T., \& Young, E. (2006). Using single-subject research in the practice of school psychology. NASP Communiqué, 35, 1-6.

Miller, L. D., (1993). Making the connection with language. The Arithmetic Teacher, 40, 311-316.

Misulis, K. (1999). Making vocabulary development manageable in content instruction. Contemporary Education, 70, 25-29.

Monroe, E. E. (1998). Using graphic organizers to teach vocabulary: Does available research inform mathematics instruction? Education, 118, 538-540, 572.

Monroe, E. E., \& Orme, M. P. (2002). Developing mathematical vocabulary. Preventing School Failure, 46, 139-142.

Moore, D. W., \& Hinchman, K. A. (2006). Connections beyond the Classroom. In A. M. Ramos, K. Shannon (Eds), Teaching Adolescents Who Struggle with Reading: Practical Strategies (pp. 129-150). Boston: Pearson

Morse, T. E., \& Schuster, J. W. (2000). Teaching elementary students with moderate intellectual disabilities how to shop for groceries. Exceptional Children, 66, 273-288.

Murphy, R.J., \& Bryan, A. J. (1980). Multiple baseline and multiple probe designs: Practical alternatives for special education assessment and evaluation. Journal of Special Education, 14, 325-335.

National Council for Teacher of English. (2011). Supporting teachers in the time of core standards. Retrieved from: www.ncte.org 
National Council of Teacher of Mathematics. (1989). Table of standards and expectations. Retrieved from: www.nctm.org

No Child Left Behind: A parents guide. (2003). Washington, DC: U.S. Department of Education. Retrieved July 4, 2010 from http://www2.ed.gov/parents/academic/involve/nclbguide/parentsguide.pdf Oldfield, C. (1996). The language of mathematics. Mathematics in School, November, $22-23$.

Orlich, D. C. (2011). Educational standards---Caveat emptor. Kappa Delta Pi Record, 47, $52-57$.

Ouellette, G. P. (2006). What's meaning got to do with it: The role of vocabulary in word reading and reading comprehension. Journal of Educational Psychology, 98, 554566.

Perner, D. E. (2007). No Child Left Behind: Issues of assessing students with the most significant cognitive disabilities. Education and Training in Developmental Disabilities, 42, 243-251.

Pearson, P. D., Hiebert, E. H., \& Kamil, M. L. (2007). Vocabulary assessment: What we know and what we need to learn. Reading Research Quarterly, 42, 282-296.

Phillips, V., Wong, C. (2010). Tying together the common core of standards, instruction, and assessments. Phi Delta Kappan, 91, 37-42.

Pikulski, J. J., \& Templeton, S. (2004). Teaching and developing vocabulary: Key to long-term reading success. Current Research in Reading/Language Arts. Retrieved from www.eduplace.org

Popham, W.J. (2009). Assessment literacy for teachers: Faddish or fundamental?. Theory 
Into Practice, 48, 4-11.

Porter, A., McMaken, J., Hwang, J., \& Yang, R. (2011). Common core standards: The new U. S. intended curriculum. Educational Researcher, 40, 103-116.

Quenemoen, R. F., Lehr, C. A., Thurlow, M. L., \& Massanari, C. B. (2001). Students with disabilities in standards-based assessment and accountability systems: Emerging issues, strategies, and recommendations (Synthesis Report 37). Minneaplois, MN: University of Minnesota, national Center on Educational Outcomes.

Reehm, S. P., \& Long, S. A. (1996). Reading in the mathematics classroom. Middle School Journal, May, 35-41.

Roach, A. T., Elliott, S. N., \& Berdt, S. (2007). Teacher perceptions and the consequential validity of an alternate assessment for students with significant cognitive disabilities. Journal of Disability Policy Studies, 18, 168-175.

Roach, A. T., Elliott, S. N., \& Webb, N. L. (2005). Alignment of an alternate assessment with state academic standards: Evidence for the content validity of the Wisconsin alternate assessment. The Journal of Special Education, 38, 218-231.

Rubenstein, R.N., \& Thompson, D. R. (2002). Understanding and support children's mathematical vocabulary development. Teaching Children Mathematics, 9, 107-112.

Rupley, W. H., Logan, J. W., \& Nichols, W. D. (1989/1999). Vocabulary instruction in a balanced reading program. The Reading Teacher, 52, 336-346.

Schell, V. J. (1982). Learning partners: Reading and mathematics. The Reading Teacher, $35,544-548$.

Schuster, J. W., Morse, T. E., Ault, M. J., Doyle, P. M., Crawford, M. R., \& Wolery, M. (1998). Constant time delay with chained tasks: A review of the literature. Education 
and Treatment of Children, 21,74-107.

Schuster, J. W., Stevens, K. B., \& Doak, P. K. (1990). Using constant time delay to teach word definitions. The Journal of Special Education, 24, 306-318.

Spencer, B. H., \& Guillaume, A. M. (2006). Integrating curriculum through the learning cycle: Content-based reading and vocabulary instruction. The Reading Teacher, 60, 206-219.

Stahl, S. A., \& Fairbanks, M. M. (1986). The effects of vocabulary instruction: A modelbased meta-analysis. Review of Educational Research, 56, 72-110.

Stevens, K. B., \& Lingo, A. S. (2005). Constant time delay: One way to provide positive behavioral support for students with emotional and behavioral disorders. Beyond Behavior, Spring, 10-15.

Stevens, K.B., \& Schuster, J.W. (1987). Effects of a constant time delay procedure on the written spelling performance of a learning disabled student. Learning Disability Quarterly, 10, 9-16.

Stevens, K. B., \& Schuster, J. W. (1988). Time delay: Systematic instruction for academic tasks. Remedial and Special Education, 9, 16-21.

Stiggins, R. (2004). New assessment beliefs for a new school mission. Phi Delta Kappan, September, 22-27.

Stonecipher, E. L., Schuster, J. W., Collins, B. C., \& Grisham-Brown, J. (1999). Teaching gift wrapping skills in a quadruple instructional arrangement using constant time delay. Journal of Developmental and Physical Disabilities, 11, 139-157.

Taylor, D. B., Mraz, M., Nichols, W. D., Rickelman, R. J., \& Wood, K. D. (2009). Using explicit instruction to promote vocabulary learning for struggling readers. Reading 
and Writing Quarterly, 25, 205-220.

Thelen, J. N., (1986). Vocabulary instruction and meaningful learning. Journal of Reading, April, 603-609.

Thompson, D. R., \& Rubenstein, R. N. (2000). Learning mathematics vocabulary: Potential pitfalls and instructional strategies. The Mathematics Teacher, 93, 568-574.

Touchette, P.E. (1971). Transfer of stimulus control: Measuring the moment of transfer. Journal of the Experimental Analysis of Behavior, 15, 347-354.

Towles-Reeves, E., Kearns, J., Kleinert, H., \& Kleinert, J. (2009). An analysis of the learning characteristics of students taking alternate assessment based on alternate achievement standards. The Journal of Special Education, 42, 241-254.

Towles-Reeves, E.,\& Kleinert, H (2006). The impact of one state's alternate assessment upon instruction and IEP development. Rural Special Education Quarterly, 25(3), 3139 ,

Towles-Reeves, E., Kleinert, H., \& Muhomba, M. (2009). Alternate Assessment: Have we learned anything new? Exceptional Children, 75, 233-252.

Urbaniak, G. C., \& Plous, S. (2010). Research Randomizer (Version 3.0) [Computer software].Retrieved from http://www.randomizer.org on November 2, 2010.

Wakeman, S. Y., Browder, D. M., Meier, I., \& McColl, A. (2007). The implications of No Child Left Behind for student with developmental disabilities. Mental Retardation and Developmental Disabilities Research Reviews, 13, 143-150.

Walker, G. (2008). Constant and progressive time delay procedures for teaching children with autism: A literature review. Journal of Autism and Developmental Disorders, 38, 261-275. 
Wall, M. F., \& Gast, D. L. (1999). Acquisition of incidental information during instruction for a response-chain skill. Research in Developmental Disabilities, 20, 31 50.

Wall, M. E., Gast, D. L., \& Royston, P.A. (1999). Leisure skills instruction for adolescents with severe or profound developmental disabilities. Journal of developmental and Physical Disabilities, 11, 193-219.

Webster's New World Dictionary, Third College Edition (1988). V.Neufeldt, \& D.B. Guralnik (Eds.), p. 362.

Williams, D. M., \& Collins, B. C. (1994). Teaching multiplication facts to students with learning disabilities: Teacher-selected versus student-selected material prompts within the delay procedure. Journal of Learning Disabilities, 27, 589-597.

Wolery, M., Holcombe, A., Cybriwsky, C., Doyle, P. M., Schuster, J. W., Ault, M. J., \& Gast, D. L. (1992). Constant time delay with discrete responses: A review of effectiveness and demographic, procedural, and methodological parameters. Research in Developmental Disabilities, 13, 239-266.

Yilmaz, T. Birkan, B., Konukman, F., \& Erkan, M. (2005). Using constant time delay procedure to teach aquatic play skills to children with autism. Education and Training in Developmental Disabilities, 40, 171-182.

Zhang, J., Cote, B., Chem, S., \& Lui, J. (2004). The effect of a constant time delay skill. Physical Educator, 61, 63-74.

Zhang, J., Gast, D. L., Horvat, M., \& Dattilo, J. (2000). Effect of a constant time delay procedure on motor skill completion durations. Education and Training in Mental Retardation and Developmental Disabilities, 35, 317-325. 
Appendix A

Parental Consent Document 
Parental Consent Document

\title{
Acquisition of Mathematical Vocabulary using Constant Time Delay with
}

\section{Individuals}

\author{
with Moderate and Severe Disabilities
}

IRB Assigned Number:

Investigator (s) name and address:

\section{Connie Morrison}

1475 Bonnie Brae Drive

Shelbyville, KY 40065

502-633-3501-Home

502-220-0238-Cell

Connie.morrison@insightbb.com
Dr. Debra Bauder

Department of Teaching and Learning

College of Education and Human Development

University of Louisville

Louisville, KY 40292

$502-852-0564$

dkbaud01@1ouisville.edu

Site(s) where study is to be conducted: Study participants' high school in a special education classroom.

Phone number for parents or subjects to call for questions: Connie Morrison 502-2200238 or Dr. Debra Bauder 502-852-0564 


\section{Introduction and Background Information}

Your child is invited to participate in a research study. The study is being conducted by Connie Morrison, Doctoral Candidate in the College of Education and Human Development at the University of Louisville. The study will take place at the participants' high school. Approximately seven subjects will be invited to participate.

\section{Purpose}

The purpose of this study is to determine if constant time delay teaching strategy can be used to teach core content mathematical vocabulary to students with moderate and severe disabilities. Constant time delay instruction involves the use of a systematic prompting procedure. Constant time delay has been found to be effective with students with moderate and severe disabilities with functional tasks and with students with learning disabilities with academic skills.

\section{Procedures}

In this study, your child will be asked to learn $510^{\text {th }}$ grade geometry vocabulary terms. The researcher will use constant time delay instruction. The study should last 6-9 weeks. Your child will be instructor one-to-one in am empty special education classroom. Sessions should last 10-20 minutes. Three terms cards will be placed on a table in front of your child. A definition card will be held up in front of them and read to them and then the terms cards on the table will be labeled for them. Your child will be asked to indicate either receptively through touch or vocally which term matches the definition. Each vocabulary term will be asked twice per instructional session. The researcher, paraprofessional, and the University of Louisville are the only people who will have 
access to your child's results. If the study is published, your child's name will not be made public.

\section{Potential Risks}

There are no foreseeable risks, although there may be unforeseen risks.

\section{Benefits}

The possible benefit of this study is increased vocabulary knowledge. The information collected may not benefit your child directly. The information learned in this study may be helpful to others who experience difficulty with core content curriculum.

\section{Compensation}

You and your child will not be compensated for your time, inconvenience, or expenses for you participation in this study.

\section{Confidentiality}

Total privacy cannot be guaranteed. Your privacy will be protected to the extent permitted by law. If the results from this study are published, your child's name will not be made public. While unlikely, the following may look at the study records: The University of Louisville Institutional Review Board and the Human Subjects Protection Program Office, the Office for Human Research Protections (OHRP), and the Office of Civil Rights.

The participants' data sheets will be housed in a locked cabinet in the investigator's classroom.

\section{Conflict of Interest}

This study does not involve a conflict of interest.

\section{Voluntary Participation}


Taking part in this study is voluntary. You ma chose not to take part at all. If you decide to be in this study you may stop taking part at any time. If you decide not to be in this study or if you stop taking part at any time, you will not lose any benefits for which you may qualify.

\section{Research Subject's Rights, Questions, Concerns, and Complaints}

If you have any concerns or complaints about the study or the study staff, you have four options.

You may contact the investigator at 502-220-0238. You may contact the principal investigator at the University of Louisville at 502-852-0564. If you have any questions about your rights as a study subject, questions, concerns or complaints, you may call the Human Subjects Protection Program Office (HSPPO) 502-852-5188. You may discuss any questions about your rights as a subject, in secret, with a member of the Institutional Review Board (IRB) or the HSPPO staff. The IRB is an independent committee composed of members of the University community, staff of the institutions, as well as lay member if the community not connected with these institutions.

The IRB has reviewed this study.

If you want to speak to a person outside the University, you may call 1-877-852-1167.

You will be given the chance to talk about any questions, concerns or complaints in secret. This is a 24 hour hot line answered by people who do not work at the University of Louisville. 
This paper tells you what will happen during the study if you choose to take part. Your signature means that this study has been discussed with you, that your questions have been answered, and that you will take part in the study. This informed consent document is not a contract. You are not giving up any legal rights by signing this informed consent document. You will be given a signed copy of his paper to keep for your records.

Signature of Subject/Legal Representative Date Signed

Signature of Person Explaining the Consent Form Date Signed

(if other than the Investigator)

Signature of Investigator

Date Signed 
Appendix B

Internal Review Board Approval Letter 


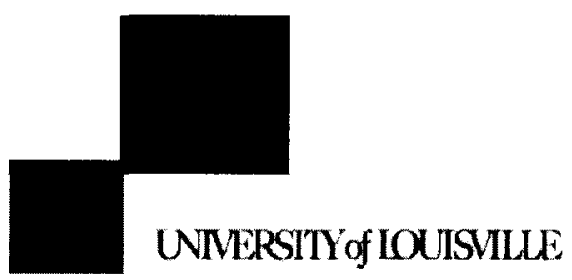

INSTITUTIONAL REVIEW BOARDS

University of Lauisville

MedCenter One, Suite 200

501 E. Broadway

Louisville, Kentucky $40202-1798$

Office: $\quad 502-852-5188$

Fax: $\quad 502-852-2164$

To: $\quad$ Bauder, Debra

From: $\quad$ The University of Louisville Institutional Review Board (IRB)

Date: $\quad$ Tuesday. December 21, 2010

Subject: IRB Correspondence

Tracking \#: 10.0652

Title: $\quad$ Acquistion of Mathematical Vocabulary using Constant Time Delay with Individuals with Moderate and Severe Disabilities

This study was reviewed on $12 / 19 / 2010$ and determined by the chair of the Institutional Review Board that the study is exempt according to 45 CFR 46.101(b) under category (1) Research conducted in established or commonly accepted educational settings, involving normal educational practices, such as (i) research on regular and special education instructional strategies, or (ii) research on the effectiveness of or the comparison among instructional techniques, curricula, or classroom management methods. The study is exempt only if information that could identify subjects is not recorded.

Since this study has been found to be exempt. no additional reporting. such as submission of Progress Reports for continuation reviews, is needed. If your research focus or activities change. please submit a Study Amendment Request Form to the IRB for review to ensure that the study still meets exempt status. Best wishes for a successful study. Please send all inquires and electronic revised/requested items to our office email address at hsppofc:louisville.edu.

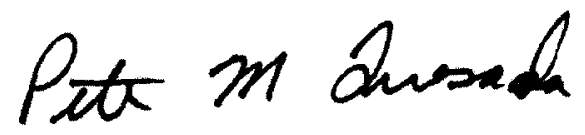

Board Designee: Quesada, Peter

Letter Sent By: Peek, Tamara, 12/21/2010 11:24 AM 
Appendix C

Instructional Material 


\section{Angle of depression}

A line that intersects two or more lines in a plane at different points. 
Appendix D

Original Geometry Terms and Definitions 


\begin{tabular}{|c|c|}
\hline Adjacent angles & $\begin{array}{l}\text { Two angles that lie in the same plane with a common vertex and } \\
\text { common side. }\end{array}$ \\
\hline $\begin{array}{l}\text { Alternate interior } \\
\text { angles }\end{array}$ & $\begin{array}{l}\text { In the figure above, transversal } t \text { intersects lines } 1 \text { and } \mathrm{m} . \quad 1 \text { and } 7, \\
\text { and } 2 \text { and } 8 \text { are alternate interior angles. }\end{array}$ \\
\hline Angle & The intersection of two non-collinear rays at a common endpoint. \\
\hline $\begin{array}{l}\text { Angle of } \\
\text { depression }\end{array}$ & $\begin{array}{l}\text { The angle between the line of sight and the horizontal when an } \\
\text { observer looks downward. }\end{array}$ \\
\hline Apothem & $\begin{array}{l}\text { A segment that is drawn from the center of a regular polygon } \\
\text { perpendicular to a side of the polygon. }\end{array}$ \\
\hline Axis & $\begin{array}{l}\text { In a cylinder, the segment with endpoints that are the centers of the } \\
\text { bases. }\end{array}$ \\
\hline Centroid & The point of concurrency of the medians of a triangle. \\
\hline Circumscribe & $\begin{array}{l}\text { A circle is circumscribed about a polygon if the circle contains all of } \\
\text { the vertices of the polygon }\end{array}$ \\
\hline $\begin{array}{l}\text { Composition of } \\
\text { reflection }\end{array}$ & Successive reflections in parallel lines. \\
\hline $\begin{array}{l}\text { Conditional } \\
\text { statement }\end{array}$ & A st \\
\hline Congruent solids & $\begin{array}{l}\text { Two solids are congruent if all of the following conditions are met } \\
\text { (1) the corresponding angles are congruent (2) corresponding edges } \\
\text { are congruent (3) corresponding faces are congruent (4) the volumes } \\
\text { are congruent }\end{array}$ \\
\hline Construction & $\begin{array}{l}\text { A method of creating geometric figures without the benefit of } \\
\text { measuring tools. }\end{array}$ \\
\hline Coplanar & Points that lie in the same plane \\
\hline Counterexample & An example used to show that a given statement is not always true. \\
\hline Degree & A unit of measure used in measuring angles and arcs. \\
\hline Direction & $\begin{array}{l}\text { The measure of the angle that a vector forms with the positive } \mathrm{x} \text {-axis } \\
\text { or any other horizontal line. }\end{array}$ \\
\hline Exterior & $\begin{array}{l}\text { A point is in the exterior of an angle if it is neither on the angle nor } \\
\text { in the interior of the angel. }\end{array}$ \\
\hline Geometric mean & $\begin{array}{l}\text { For any positive numbers } a \text { and } b \text {, the positive number } x \text { such } a / x= \\
x / b \text {. }\end{array}$ \\
\hline Hemisphere & $\begin{array}{l}\text { One of the two congruent parts into which a great circle separates a } \\
\text { sphere. }\end{array}$ \\
\hline Included side & The side of a triangle that is a side of each of two angles. \\
\hline Inscribed & $\begin{array}{l}\text { A polygon is inscribed in a circle if each of its vertices lie on the } \\
\text { circle. }\end{array}$ \\
\hline Irregular polygon & A polygon that is not regular. \\
\hline Kite & $\begin{array}{l}\text { A quadrilateral with exactly two distinct pairs of adjacent congruent } \\
\text { sides. }\end{array}$ \\
\hline $\begin{array}{l}\text { Laws of } \\
\text { detachment }\end{array}$ & conditional and $\mathrm{p}$ is true, the $\mathrm{q}$ is also true. \\
\hline
\end{tabular}




\begin{tabular}{|c|c|}
\hline Line of symmetry & $\begin{array}{l}\text { A line that can be drawn through a plane figure so that the figure on } \\
\text { one side is the reflection image of the figure on the opposite side. }\end{array}$ \\
\hline Magnitude & The length of a vector. \\
\hline Midpoint & The point halfway between the endpoints of a segment. \\
\hline N-gon & A polygon with $\mathrm{n}$ sides. \\
\hline Obtuse angle & An angle with degree measure greater than 90 and less than 180 . \\
\hline $\begin{array}{l}\text { Orthogonal } \\
\text { drawing }\end{array}$ & $\begin{array}{l}\text { The two-dimensional top view, left view, front view, and right view } \\
\text { of a three-dimensional object. }\end{array}$ \\
\hline Parallelogram & A quadrilateral with parallel opposite sides. \\
\hline $\mathrm{Pi}$ & $\begin{array}{l}\text { An irrational number represented by the ratio of the circumference } \\
\text { of a circle to the diameter of the circle. }\end{array}$ \\
\hline $\begin{array}{l}\text { Point of } \\
\text { concurrency }\end{array}$ & The point of intersection of concurrent lines \\
\hline Polyhedrons & Closed three-dimensional figures made up of flat polygonal regions. \\
\hline $\begin{array}{l}\text { Proof of } \\
\text { contradiction }\end{array}$ & $\begin{array}{l}\text { An indirect proof in which one assumes that the statement to be } \\
\text { provided is false. }\end{array}$ \\
\hline Radius & $\begin{array}{l}\text { In a circle, any segment with endpoints that are the center of the } \\
\text { circle and a point on the circle. }\end{array}$ \\
\hline Rectangle & A quadrilateral with four right angles. \\
\hline Regular prism & A right prism with bases that are regular polygons. \\
\hline Resultant & The sum of tow vectors. \\
\hline Right prism & A prism with lateral edges that are also altitudes. \\
\hline Scalar & A constant multiplied by a vector. \\
\hline Sector of a circle & $\begin{array}{l}\text { A region of a circle bounded by a central angle and its intercepted } \\
\text { arc. }\end{array}$ \\
\hline Semicircle & An arc that measures 180 . \\
\hline Sine & $\begin{array}{l}\text { For an acute angle of a right triangle, the ratio of the measure of the } \\
\text { leg opposite the acute angle to the measure of the hypotenuse. }\end{array}$ \\
\hline Space & A boundless three-dimensional set of all points. \\
\hline Statement & Any sentence that is either true or false, but not both. \\
\hline Tessellation & $\begin{array}{l}\text { A pattern that covers a plane by transforming the same figure or set } \\
\text { of figures so that there are not overlapping or empty spaces. }\end{array}$ \\
\hline Transversal & A line that intersects two or more lines in a plane at different points. \\
\hline Truth table & $\begin{array}{l}\text { A table used as a convenient method for organizing the truth values } \\
\text { of statements. }\end{array}$ \\
\hline Vector & $\begin{array}{l}\text { A directed segment representing a quantity that has both magnitude, } \\
\text { or length, and direction. }\end{array}$ \\
\hline
\end{tabular}


Appendix E

Initial Teacher Surveys for Targeted Vocabulary 
Below is a table of a list of mathematical terms. Mark yes or no, in the third column, if the term is a Geometry term.

Mark yes or no, in the fourth column, if the Geometry term is addressed in a $10^{\text {th }}$ grade Geometry class.

\begin{tabular}{|c|c|c|c|}
\hline Term & Definition & Geometry Term & $\begin{array}{l}\text { Commonly } \\
\text { Used Term }\end{array}$ \\
\hline Angle & The intersection of two non-collinear rays at a common endpoint. & $\begin{array}{l}\square \text { Yes } \\
\square \text { No }\end{array}$ & $\begin{array}{l}\square \text { Yes } \\
\square \text { No }\end{array}$ \\
\hline Axis & In a cylinder, the segment with endpoints that are the centers of the & $\begin{array}{l}\square \text { Yes } \\
\square \text { No }\end{array}$ & $\begin{array}{l}\square \text { Yes } \\
\square \text { No }\end{array}$ \\
\hline Centroid & The point of concurrency of the medians of a triangle. & $\begin{array}{l}\square \text { Yes } \\
\square \text { No }\end{array}$ & $\begin{array}{l}\square \text { Yes } \\
\square \text { No }\end{array}$ \\
\hline Construction & A method of creating geometric figures without the benefit of & $\begin{array}{l}\square \text { Yes } \\
\square \text { No }\end{array}$ & $\begin{array}{l}\square \text { Yes } \\
\square \text { No }\end{array}$ \\
\hline Coplanar & Points that lie in the same plane & $\begin{array}{l}\square \text { Yes } \\
\square \text { No }\end{array}$ & $\begin{array}{l}\square \text { Yes } \\
\square \text { No }\end{array}$ \\
\hline Degree & A unit of measure used in measuring angles and arcs. & $\begin{array}{l}\square \text { Yes } \\
\square \text { No }\end{array}$ & $\begin{array}{l}\square \text { Yes } \\
\square \text { No }\end{array}$ \\
\hline Hemisphere & One of the two congruent parts into which a great circle separates a & $\begin{array}{l}\square \text { Yes } \\
\square \text { No }\end{array}$ & $\begin{array}{l}\square \text { Yes } \\
\square \text { No }\end{array}$ \\
\hline Kite & A quadrilateral with exactly two distinct pairs of adjacent congruent & $\begin{array}{l}\square \text { Yes } \\
\square \mathrm{No}\end{array}$ & $\begin{array}{l}\square \text { Yes } \\
\square \text { No }\end{array}$ \\
\hline Magnitude & The length of a vector. & $\begin{array}{l}\square \text { Yes } \\
\square \text { No }\end{array}$ & $\begin{array}{l}\square \text { Yes } \\
\square \text { No }\end{array}$ \\
\hline Midpoint & The point halfway between the endpoints of a segment. & $\begin{array}{l}\square \text { Yes } \\
\square \text { No }\end{array}$ & $\begin{array}{l}\square \text { Yes } \\
\square \text { No }\end{array}$ \\
\hline N-gon & A polygon with $\mathrm{n}$ sides. & $\begin{array}{l}\square \text { Yes } \\
\square \text { No }\end{array}$ & $\begin{array}{l}\square \text { Yes } \\
\square \text { No }\end{array}$ \\
\hline Parallelogram & A quadrilateral with parallel opposite sides. & $\begin{array}{l}\square \text { Yes } \\
\square \text { No }\end{array}$ & $\begin{array}{l}\square \text { Yes } \\
\square \text { No }\end{array}$ \\
\hline
\end{tabular}




\begin{tabular}{|c|l|l|l|}
\hline Polyhedrons & Closed three-dimensional figures made up of flat polygonal regions. & $\begin{array}{l}\square \text { Yes } \\
\square \text { No }\end{array}$ & $\begin{array}{l}\square \text { Yes } \\
\square \text { No }\end{array}$ \\
\hline Rectangle & A quadrilateral with four right angles. & $\begin{array}{l}\square \text { Yes } \\
\text { No }\end{array}$ & $\begin{array}{l}\square \text { Yes } \\
\square \text { No }\end{array}$ \\
\hline Resultant & The sum of tow vectors. & $\begin{array}{l}\square \text { Yes } \\
\square \text { No }\end{array}$ & $\begin{array}{l}\square \text { Yes } \\
\square \text { No }\end{array}$ \\
\hline Scalar & A constant multiplied by a vector. & $\begin{array}{l}\square \text { Yes } \\
\square \text { No }\end{array}$ & $\begin{array}{l}\square \text { Yes } \\
\square \text { No }\end{array}$ \\
\hline Semicircle & An arc that measures 180. & $\square$ Yes \\
$\square$ No & $\begin{array}{l}\square \text { Yes } \\
\square \text { No }\end{array}$ \\
\hline Space & A boundless three-dimensional set of all points. & $\begin{array}{l}\square \text { Yes } \\
\square \text { No }\end{array}$ & $\begin{array}{l}\square \text { Yes } \\
\square \text { No }\end{array}$ \\
\hline Statement & Any sentence that is either true or false, but not both. & $\begin{array}{l}\square \text { Yes } \\
\square \text { No }\end{array}$ & $\begin{array}{l}\square \text { Yes } \\
\square \text { No }\end{array}$ \\
\hline Transversal & A line that intersects two or more lines in a plane at different points. & $\begin{array}{l}\square \text { Yes } \\
\square \text { No }\end{array}$ & $\begin{array}{l}\square \text { Yes } \\
\square \text { No }\end{array}$ \\
\hline Vector & A directed segment representing a quantity that has both magnitude, or & $\begin{array}{l}\square \text { Yes } \\
\square \text { No }\end{array}$ & $\begin{array}{l}\square \text { Yes } \\
\square \text { No }\end{array}$ \\
\hline
\end{tabular}


Appendix F

Second Set of Teacher Surveys for Targeted Vocabulary 
Below is a table of a list of mathematical terms. Mark yes or no, in the third column, if the term is a Geometry term. Mark yes or no, in the fourth column, if the Geometry term is addressed in a $10^{\text {th }}$ grade Geometry class.

\begin{tabular}{|c|c|c|c|}
\hline Term & Definition & Geometry Term & $\begin{array}{l}\text { Commonly } \\
\text { Used Term }\end{array}$ \\
\hline Adjacent angles & $\begin{array}{l}\text { Two angles that lie in the same plane with a common vertex and } \\
\text { common side. }\end{array}$ & $\begin{array}{l}\square \text { Yes } \\
\square \text { No }\end{array}$ & $\begin{array}{l}\square \text { Yes } \\
\square \text { No }\end{array}$ \\
\hline $\begin{array}{l}\text { Alternate } \\
\text { interior angles }\end{array}$ & $\begin{array}{l}\text { In the figure above, transversal t intersects lines } I \text { and } \mathrm{m} . \quad 1 \text { and } 7 \text {, and } \\
2 \text { and } 8 \text { are alternate interior angles. }\end{array}$ & $\begin{array}{l}\square \text { Yes } \\
\square \text { No }\end{array}$ & $\begin{array}{l}\square \text { Yes } \\
\square \text { No }\end{array}$ \\
\hline Angle & The intersection of two non-collinear rays at a common endpoint. & $\begin{array}{l}\square \text { Yes } \\
\square \text { No }\end{array}$ & $\begin{array}{l}\square \text { Yes } \\
\square \text { No }\end{array}$ \\
\hline $\begin{array}{l}\text { Angle of } \\
\text { depression }\end{array}$ & $\begin{array}{l}\text { The angle between the line of sight and the horizontal when an observer } \\
\text { looks downward. }\end{array}$ & $\begin{array}{l}\square \text { Yes } \\
\square \text { No }\end{array}$ & $\begin{array}{l}\square \text { Yes } \\
\square \text { No }\end{array}$ \\
\hline Apothem & $\begin{array}{l}\text { A segment that is drawn from the center of a regular polygon } \\
\text { perpendicular to a side of the polygon. }\end{array}$ & $\begin{array}{l}\square \text { Yes } \\
\square \text { No }\end{array}$ & $\begin{array}{l}\square \text { Yes } \\
\square \text { No }\end{array}$ \\
\hline Circumscribe & $\begin{array}{l}\text { A circle is circumscribed about a polygon if the circle contains all of the } \\
\text { vertices of the polygon }\end{array}$ & $\begin{array}{l}\square \text { Yes } \\
\square \text { No }\end{array}$ & $\begin{array}{l}\square \text { Yes } \\
\square \text { No }\end{array}$ \\
\hline $\begin{array}{l}\text { Composition of } \\
\text { reflection }\end{array}$ & Successive reflections in parallel lines. & $\begin{array}{l}\square \text { Yes } \\
\square \text { No }\end{array}$ & $\begin{array}{l}\square \text { Yes } \\
\square \text { No }\end{array}$ \\
\hline $\begin{array}{l}\text { Conditional } \\
\text { statement }\end{array}$ & A statement that can be written in if-then form. & $\begin{array}{l}\square \text { Yes } \\
\square \text { No }\end{array}$ & $\begin{array}{l}\square \text { Yes } \\
\square \text { No }\end{array}$ \\
\hline $\begin{array}{l}\text { Congruent } \\
\text { solids }\end{array}$ & $\begin{array}{l}\text { Two solids are congruent if all of the following conditions are met (1) } \\
\text { the corresponding angles are congruent (2) corresponding edges are } \\
\text { congruent (3) corresponding faces are congruent (4) the volumes are }\end{array}$ & $\begin{array}{l}\square \text { Yes } \\
\square \text { No }\end{array}$ & $\begin{array}{l}\square \text { Yes } \\
\square \text { No }\end{array}$ \\
\hline Coplanar & Points that lie in the same plane & $\begin{array}{l}\square \text { Yes } \\
\square \text { No }\end{array}$ & $\begin{array}{l}\square \text { Yes } \\
\square \text { No }\end{array}$ \\
\hline
\end{tabular}




\begin{tabular}{|c|c|c|c|}
\hline Counterexample & An example used to show that a given statement is not always true. & $\begin{array}{l}\square \text { Yes } \\
\square \text { No }\end{array}$ & $\begin{array}{l}\square \text { Yes } \\
\square \text { No }\end{array}$ \\
\hline Degree & A unit of measure used in measuring angles and arcs. & $\begin{array}{l}\square \text { Yes } \\
\square \text { No }\end{array}$ & $\begin{array}{l}\square \text { Yes } \\
\square \text { No }\end{array}$ \\
\hline Direction & $\begin{array}{l}\text { The measure of the angle that a vector forms with the positive } \mathrm{x} \text {-axis or } \\
\text { any other horizontal line. }\end{array}$ & $\begin{array}{l}\square \text { Yes } \\
\square \text { No }\end{array}$ & $\begin{array}{l}\square \text { Yes } \\
\square \text { No }\end{array}$ \\
\hline Exterior & $\begin{array}{l}\text { A point is in the exterior of an angle if it is neither on the angle nor in } \\
\text { the interior of the angel. }\end{array}$ & $\begin{array}{l}\square \text { Yes } \\
\square \text { No }\end{array}$ & $\begin{array}{l}\square \text { Yes } \\
\square \text { No }\end{array}$ \\
\hline $\begin{array}{l}\text { Geometric } \\
\text { mean }\end{array}$ & For any positive numbers $a$ and $b$, the positive number $x$ such $a / x=x / b$. & $\begin{array}{l}\square \text { Yes } \\
\square \text { No }\end{array}$ & $\begin{array}{l}\square \text { Yes } \\
\square \text { No }\end{array}$ \\
\hline Included side & The side of a triangle that is a side of each of two angles. & $\begin{array}{l}\square \text { Yes } \\
\square \text { No }\end{array}$ & $\begin{array}{l}\square \text { Yes } \\
\square \text { No }\end{array}$ \\
\hline Inscribed & A polygon is inscribed in a circle if each of its vertices lie on the circle. & $\begin{array}{l}\square \text { Yes } \\
\square \text { No }\end{array}$ & $\begin{array}{l}\square \text { Yes } \\
\square \text { No }\end{array}$ \\
\hline $\begin{array}{l}\text { Irregular } \\
\text { polygon }\end{array}$ & A polygon that is not regular. & $\begin{array}{l}\square \text { Yes } \\
\square \text { No }\end{array}$ & $\begin{array}{l}\square \text { Yes } \\
\square \text { No }\end{array}$ \\
\hline $\begin{array}{l}\text { Laws of } \\
\text { detachment }\end{array}$ & If $p \rightarrow q$ is a true conditional and $p$ is true, the $q$ is also true. & $\begin{array}{l}\square \text { Yes } \\
\square \text { No }\end{array}$ & $\begin{array}{l}\square \text { Yes } \\
\square \text { No }\end{array}$ \\
\hline $\begin{array}{l}\text { Line of } \\
\text { symmetry }\end{array}$ & $\begin{array}{l}\text { A line that can be drawn through a plane figure so that the figure on one } \\
\text { side is the reflection image of the figure on the opposite side. }\end{array}$ & $\begin{array}{l}\square \text { Yes } \\
\square \text { No }\end{array}$ & $\begin{array}{l}\square \text { Yes } \\
\square \text { No }\end{array}$ \\
\hline Midpoint & The point halfway between the endpoints of a segment. & $\begin{array}{l}\square \text { Yes } \\
\square \text { No }\end{array}$ & $\begin{array}{l}\square \text { Yes } \\
\square \mathrm{No}\end{array}$ \\
\hline N-gon & A polygon with $\mathrm{n}$ sides. & $\begin{array}{l}\square \text { Yes } \\
\square \text { No }\end{array}$ & $\begin{array}{l}\square \text { Yes } \\
\square \text { No }\end{array}$ \\
\hline
\end{tabular}




\begin{tabular}{|c|c|c|c|}
\hline Obtuse angle & An angle with degree measure greater than 90 and less than 180 . & $\begin{array}{l}\square \text { Yes } \\
\square \text { No }\end{array}$ & \begin{tabular}{|l}
$\square$ Yes \\
$\square$ No
\end{tabular} \\
\hline $\begin{array}{l}\text { Orthogonal } \\
\text { drawing }\end{array}$ & $\begin{array}{l}\text { The two-dimensional top view, left view, front view, and right view of a } \\
\text { three-dimensional object. }\end{array}$ & $\begin{array}{l}\square \text { Yes } \\
\square \text { No }\end{array}$ & $\begin{array}{l}\square \text { Yes } \\
\square \text { No }\end{array}$ \\
\hline Parallelogram & \begin{tabular}{|l} 
A quadrilateral with parallel opposite sides. \\
\end{tabular} & $\begin{array}{l}\square \text { Yes } \\
\square \text { No }\end{array}$ & $\begin{array}{l}\square \text { Yes } \\
\square \text { No }\end{array}$ \\
\hline $\mathrm{Pi}$ & $\begin{array}{l}\text { An irrational number represented by the ratio of the circumference of a } \\
\text { circle to the diameter of the circle. }\end{array}$ & $\begin{array}{l}\square \text { Yes } \\
\square \text { No }\end{array}$ & $\begin{array}{l}\square \text { Yes } \\
\square \text { No }\end{array}$ \\
\hline $\begin{array}{l}\text { Point of } \\
\text { concurrency }\end{array}$ & The point of intersection of concurrent lines & $\begin{array}{l}\square \text { Yes } \\
\square \text { No }\end{array}$ & $\begin{array}{l}\square \text { Yes } \\
\square \text { No }\end{array}$ \\
\hline $\begin{array}{l}\text { Proof of } \\
\text { contradiction }\end{array}$ & $\begin{array}{l}\text { An indirect proof in which one assumes that the statement to be } \\
\text { provided is false. }\end{array}$ & $\begin{array}{l}\square \text { Yes } \\
\square \text { No }\end{array}$ & $\begin{array}{l}\square \text { Yes } \\
\square \text { No }\end{array}$ \\
\hline Radius & $\begin{array}{l}\text { In a circle, any segment with endpoints that are the center of the circle } \\
\text { and a point on the circle. }\end{array}$ & $\begin{array}{l}\square \text { Yes } \\
\square \text { No }\end{array}$ & $\begin{array}{l}\square \text { Yes } \\
\square \text { No }\end{array}$ \\
\hline Regular prism & A right prism with bases that are regular polygons. & $\begin{array}{l}\square \text { Yes } \\
\square \text { No }\end{array}$ & $\begin{array}{l}\square \text { Yes } \\
\square \text { No }\end{array}$ \\
\hline Right prism & A prism with lateral edges that are also altitudes. & $\begin{array}{l}\square \text { Yes } \\
\square \text { No }\end{array}$ & \begin{tabular}{|l}
$\square$ Yes \\
$\square$ No
\end{tabular} \\
\hline $\begin{array}{l}\text { Sector of a } \\
\text { circle }\end{array}$ & A region of a circle bounded by a central angle and its intercepted arc. & $\begin{array}{l}\square \text { Yes } \\
\square \text { No }\end{array}$ & $\begin{array}{l}\square \text { Yes } \\
\square \text { No }\end{array}$ \\
\hline Sine & $\begin{array}{l}\text { For an acute angle of a right triangle, the ratio of the measure of the leg } \\
\text { opposite the acute angle to the measure of the hypotenuse. }\end{array}$ & $\begin{array}{l}\square \text { Yes } \\
\square \text { No }\end{array}$ & $\begin{array}{l}\square \text { Yes } \\
\square \text { No }\end{array}$ \\
\hline
\end{tabular}




\begin{tabular}{|l|l|l|l|}
\hline Tessellation & $\begin{array}{l}\text { A pattern that covers a plane by transforming the same figure or set of } \\
\text { figures so that there are not overlapping or empty spaces. }\end{array}$ & $\begin{array}{l}\square \text { Yes } \\
\square \text { No } \\
\square \text { No }\end{array}$ \\
\hline Transversal & A line that intersects two or more lines in a plane at different points. & $\begin{array}{l}\square \text { Yes } \\
\square \text { No }\end{array}$ & $\begin{array}{l}\square \text { Yes } \\
\square \text { No }\end{array}$ \\
\hline Truth table & $\begin{array}{l}\text { A table used as a convenient method for organizing the truth values of } \\
\text { statements. }\end{array}$ & $\begin{array}{l}\square \text { Yes } \\
\square \text { No }\end{array}$ & $\begin{array}{l}\square \text { Yes } \\
\square \text { No }\end{array}$ \\
\hline
\end{tabular}


Appendix G

Target Vocabulary 


\section{Term Definition}

\begin{tabular}{|c|c|}
\hline Adjacent angles & $\begin{array}{l}\text { Two angles that lie in the same plane with a common vertex and } \\
\text { common side. }\end{array}$ \\
\hline Angle & The intersection of two non-collinear rays at a common endpoint. \\
\hline Angle of depression & $\begin{array}{l}\text { The angle between the line of sight and the horizontal when an } \\
\text { observer looks downward. }\end{array}$ \\
\hline Coplanar & Points that lie in the same plane \\
\hline Degree & A unit of measure used in measuring angles and arcs. \\
\hline Included side & The side of a triangle that is a side of each of two angles. \\
\hline Irregular polygon & A polygon that is not regular. \\
\hline Line of symmetry & $\begin{array}{l}\text { A line that can be drawn through a plane figure so that the figure } \\
\text { on one side is the reflection image of the figure on the opposite }\end{array}$ \\
\hline Midpoint & The point halfway between the endpoints of a segment. \\
\hline N-gon & A polygon with $\mathrm{n}$ sides. \\
\hline Obtuse angle & An angle with degree measure greater than 90 and less than 180 . \\
\hline Parallelogram & A quadrilateral with parallel opposite sides. \\
\hline $\mathrm{Pi}$ & $\begin{array}{l}\text { An irrational number represented by the ratio of the circumference } \\
\text { of a circle to the diameter of the circle. }\end{array}$ \\
\hline Radius & $\begin{array}{l}\text { In a circle, any segment with endpoints that are the center of the } \\
\text { circle and a point on the circle. }\end{array}$ \\
\hline Sine & $\begin{array}{l}\text { For an acute angle of a right triangle, the ratio of the measure of } \\
\text { the leg opposite the acute angle to the measure of the hypotenuse. }\end{array}$ \\
\hline Transversal & $\begin{array}{l}\text { A line that intersects two or more lines in a plane at different } \\
\text { points. }\end{array}$ \\
\hline
\end{tabular}


Appendix $\mathrm{H}$

Screening Data Sheet

Screening Data Sheet

Participant: 
Date:

Time:

\begin{tabular}{|l|l|l|l|}
\hline \multicolumn{1}{|c|}{ Target Vocabulary } & Correct & Incorrect & No Response \\
\hline 1. Adjacent angles & & & \\
\hline 2. Angle & & & \\
\hline 3. Angle of depression & & & \\
\hline 4. Coplanar & & & \\
\hline 5. Degree & & & \\
\hline 6. Included side & & & \\
\hline 7. Irregular polygon & & & \\
\hline 8. Line of symmetry & & & \\
\hline 9. Midpoint & & & \\
\hline 10. N-gon & & & \\
\hline 11. Obtuse angle & & & \\
\hline 12. Parallelogram & & & \\
\hline 13. Pi & & & \\
\hline 14. Radius & & & \\
\hline 15. Sine & & & \\
\hline 16. Transversal & & & \\
\hline Total 3 of + / & & & \\
\hline Percent & & & \\
\hline
\end{tabular}


Appendix I

Screening Results 
Target Vocabulary

\section{Participants}

\begin{tabular}{|l|c|c|c|c|c|c|}
\hline & A & B & C & D & E & F \\
\hline 1. Adjacent angles & $\sqrt{ }$ & & $\sqrt{ }$ & & & \\
\hline 2. Angle & & & $\sqrt{ }$ & & & \\
\hline 3. Angle of depression & $\sqrt{ }$ & $\sqrt{ }$ & & & & \\
\hline 4. Coplanar & & & & & & \\
\hline 5. Degree & $\sqrt{ }$ & & & & & \\
\hline 6. Included side & $\sqrt{ }$ & & $\sqrt{ }$ & & & \\
\hline 7. Irregular polygon & & & $\sqrt{ }$ & $\sqrt{ }$ & & \\
\hline 8. Line of symmetry & $\sqrt{ }$ & & & & & \\
\hline 9. Midpoint & $\sqrt{ }$ & & & & & \\
\hline 10. N-gon & & & $\sqrt{ }$ & & & \\
\hline 11. Obtuse angle & $\sqrt{ }$ & & & & & \\
\hline 12. Parallelogram & & $\sqrt{ }$ & & & & \\
\hline 13. Pi & & $\sqrt{ }$ & & & & \\
\hline 14. Radius & & $\sqrt{ }$ & $\sqrt{ }$ & & & \\
\hline 15. Sine & $\sqrt{ }$ & & $\sqrt{ }$ & & & \\
\hline 16. Transversal & & 25 & 50 & 6 & 0 & 0 \\
\hline Total Correct & & 8 & 1 & 0 & 0 \\
\hline Percent Correct & & & & & \\
\hline
\end{tabular}


Appendix $\mathrm{J}$

Randomization Placement Chart for Target Vocabulary 


\begin{tabular}{|c|c|c|c|c|}
\hline Day 1 & Day 2 & Day 3 & Day 4 & Day 5 \\
\hline 3 & 4 & 3 & 2 & 1 \\
\hline 1 & 1 & 2 & 3 & 5 \\
\hline 4 & 3 & 4 & 1 & 4 \\
\hline 5 & 2 & 5 & 4 & 2 \\
\hline 2 & 5 & 1 & 5 & 3 \\
\hline 5 & 2 & 1 & 1 & 5 \\
\hline 3 & 3 & 5 & 5 & 2 \\
\hline 2 & 5 & 3 & 4 & 3 \\
\hline 4 & 1 & 2 & 3 & 4 \\
\hline 1 & 4 & 4 & 2 & 1 \\
\hline 1 & 4 & 3 & 3 & 5 \\
\hline 2 & 1 & 1 & 2 & 2 \\
\hline 3 & 2 & 4 & 5 & 3 \\
\hline 4 & 3 & 5 & 4 & 1 \\
\hline 5 & 5 & 2 & 1 & 4 \\
\hline 1 & 3 & 4 & 1 & 2 \\
\hline 3 & 2 & 5 & 4 & 1 \\
\hline 5 & 4 & 2 & 3 & 4 \\
\hline 4 & 1 & 1 & 5 & 3 \\
\hline 2 & 5 & 3 & 2 & 5 \\
\hline
\end{tabular}




\section{Appendix K \\ Randomization Chart for Card Placement}




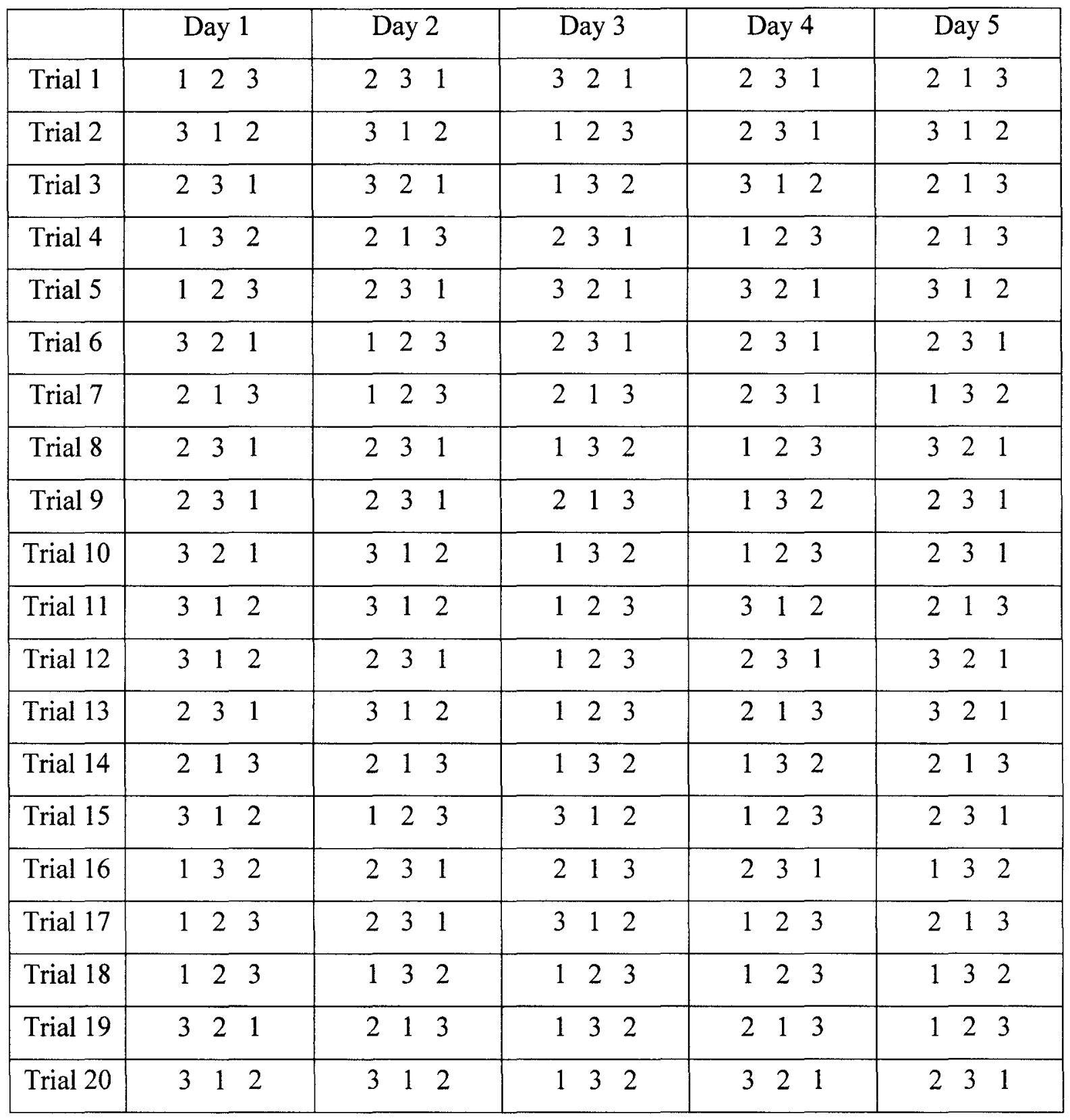


Appendix L

Presentation Board 


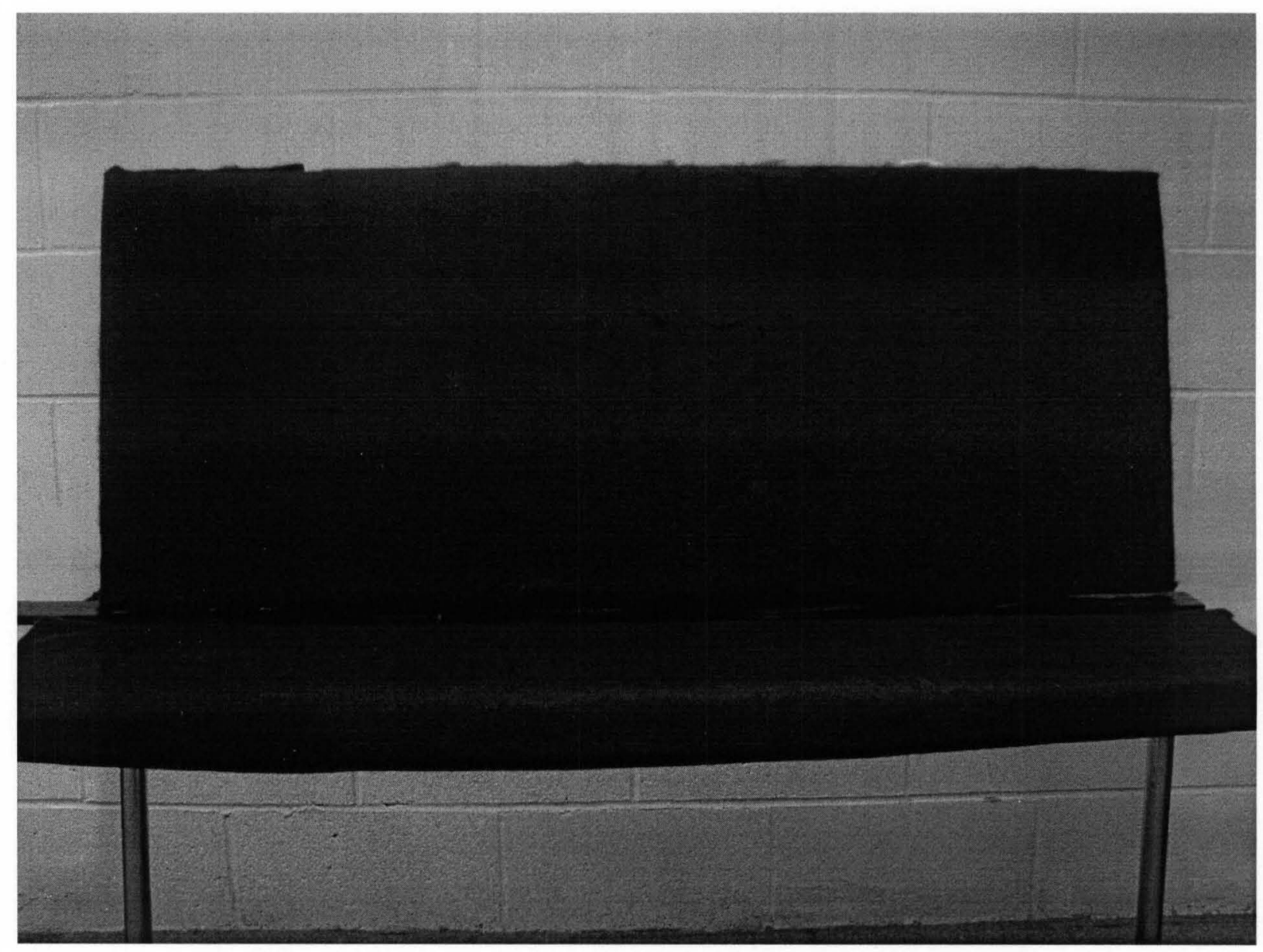


Appendix M

Data Sheet 
Time Delay Data Sheet

Participant:

Instruction/Probe Date:

Time:

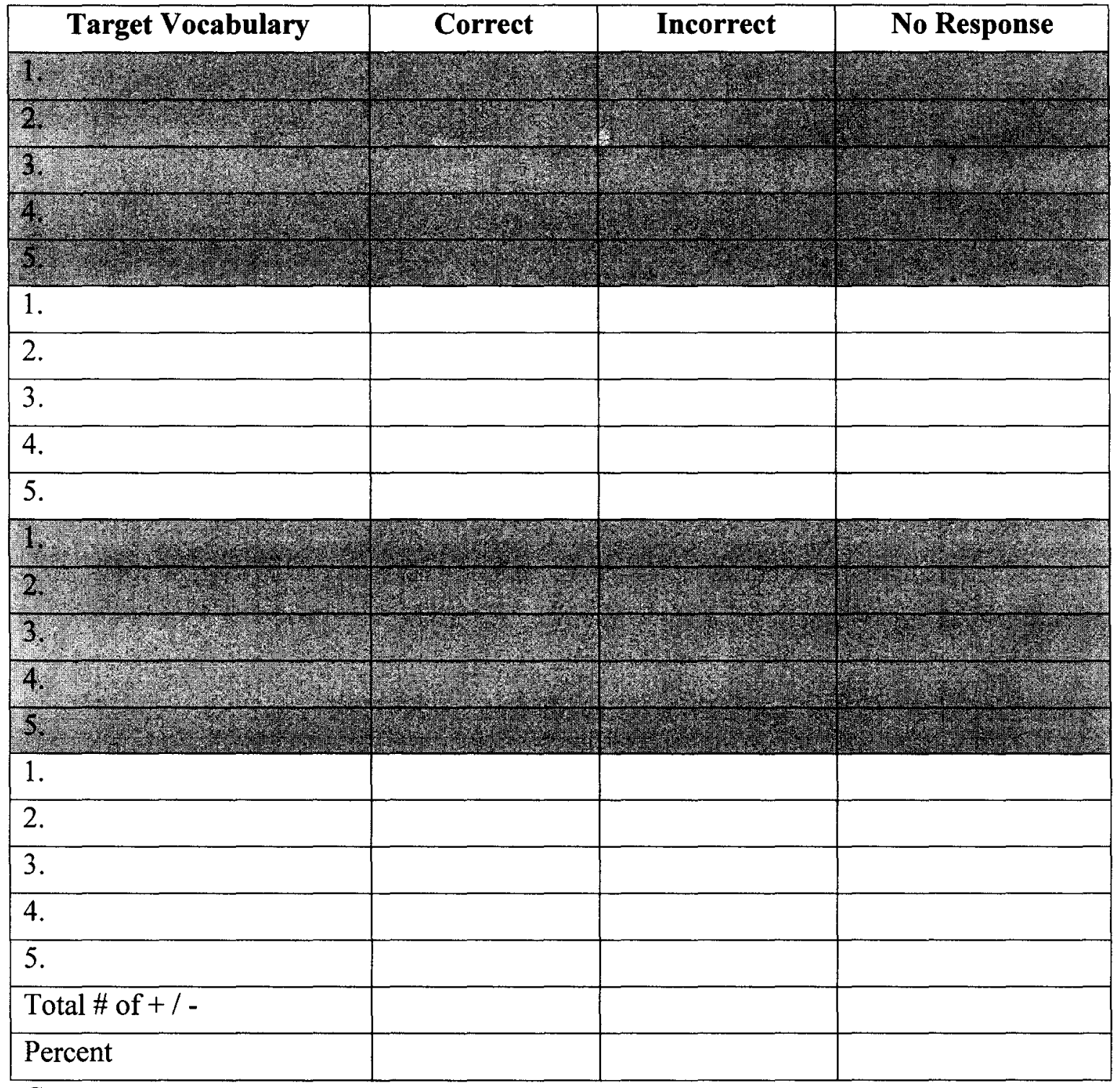

Comments: 
Appendix N

Participant A

Generalization Probe Worksheet 
1. The intersection of two non-collinear rays at a common endpoint.
A. Angle
B. Coplanar
C. Midpoint

2. The point halfway between the endpoints of a segment.
A. Sine
B. Obtuse angle
C. Midpoint

3. For an acute angle of a right triangle, the ratio of the measure of the leg opposite the acute angle to the measure of the hypotenuse.
A. Coplanar
B. Angle
C. Sine

4. An angle with degree measure greater than 90 and less than 180 .
A. Sine
B. Obtuse angle
C. Angle

5. Points that lie in the same plane.
A. Obtuse angle
B. Coplanar
C. Midpoint 


\section{Appendix O}

\section{Participant B}

\section{Generalization Probe Worksheet}


1. A line that can be drawn through a plane figure so that the figure on the one side is the reflection image of the figure on the opposite side.
A. Line of symmetry
B. N-gon
C. Midpoint

2. A polygon with $\mathrm{n}$ sides.
A. Transversal
B. Obtuse Angle
C. N-gon

3. A line that intersects two or more lines in a plane at different points.
A .Line of symmetry
B. Midpoint
C. Transversal

4. An angle with degree measure greater than 90 and less than 180 .
A. Transversal
B. Line of symmetry
C. Obtuse angle

5. The point halfway between the endpoints of a segment.
A. N-gon
B. Midpoint
C. Obtuse angle 
Appendix $\mathrm{P}$

Participant C

Generalization Probe Worksheet 
1. The angle between the line of sight and the horizontal when the observer looks downward.
A. Angle of depression
B. Coplanar
C. Degree

2. A unit of measure used in measuring angles and arcs.
A. Radius
B. Pi
C. Degree

3. In a circle, any segment with endpoints that are the center of the circle and a point on the circle.
A. Coplanar
B. Radius
C. Angle of depression

4. An irrational number represented by the ratio of the circumference of a circle to the diameter of the circle.
A. Pi
B. Angel of depression
C. Radius

5. Points that lie in the same plane.
A. Degree
B. Coplanar
C. Pi 


\section{Appendix Q}

Procedural Reliability Checklist 
Date:

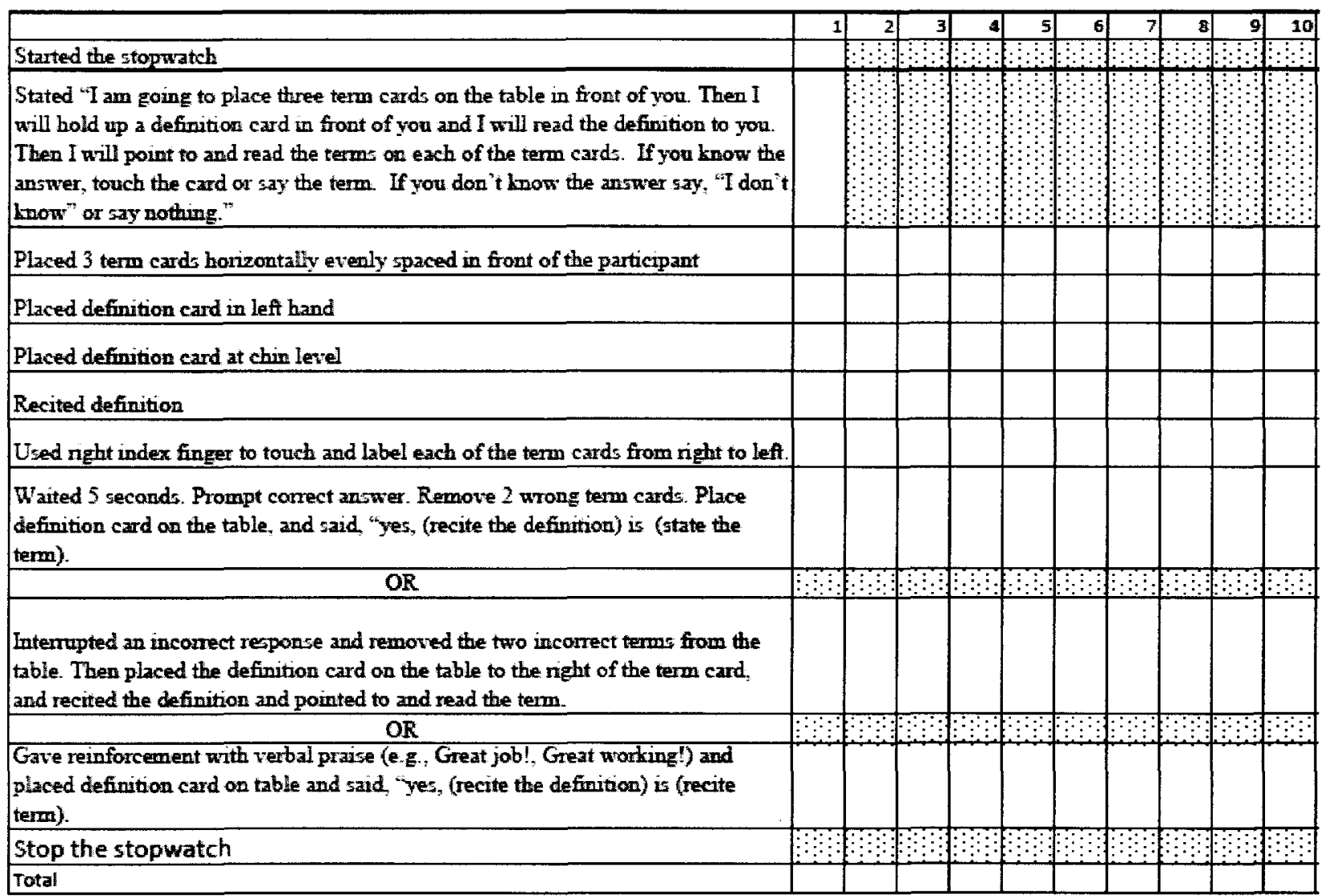




\begin{tabular}{|c|c|c|c|c|c|c|c|c|c|c|}
\hline & 11 & 12 & 13 & 14 & \begin{tabular}{|c|}
15 \\
\end{tabular} & 16 & 17 & 18 & 19 & 20 \\
\hline Started the stopwatch & 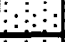 & 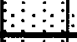 & & 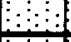 & 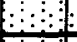 & 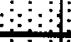 & $\vdots$ & $\therefore:$ & $\vdots$ & : \\
\hline $\begin{array}{l}\text { Stated "I am going to place three tem cards on the table in front of you. Then I } \\
\text { will hold up a definition card in front of you and I will read the definition to you. } \\
\text { Then I will point to and read the terms on each of the tenm cards. If you know the } \\
\text { answer, touch the card or say the term. If you don't know the answer say. "I don't } \\
\text { know" or say nothing." }\end{array}$ & $\therefore$ & E: : & & $: \because: 3$ & : : : & $\because: \vdots:$ & 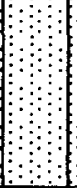 & & 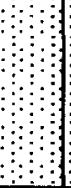 & 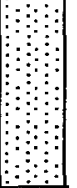 \\
\hline Placed 3 term cards borizontally evenly spaced in front of the participant & & & & & & & & & & \\
\hline Placed definition card in left hand & & & & & & & & & & \\
\hline Placed definition card at chin level & & & & & & & & & & \\
\hline Recited definition & & & & & & & & & & \\
\hline Used right index finger to touch and label each of the tern cards from night to left & & & & & & & & & & \\
\hline $\begin{array}{l}\text { Waited } 5 \text { seconds. Prompt correct answer. Remove } 2 \text { wrong term cards. Place } \\
\text { definition card on the table, and said "yes, (recite the definition) is (state the } \\
\text { term). }\end{array}$ & & & & & & & & & & \\
\hline $\mathrm{OR}$ & & $\vdots \vdots$ & 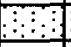 & $\therefore$ & $\because \because \because$ & $\because \vdots$ & 3 & $\vdots \vdots$ & 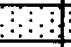 & : \\
\hline $\begin{array}{l}\text { Intervapted an incorrect response and remored the two inconrect term from the } \\
\text { table. Then placed the definition card on the table to the night of the term card. } \\
\text { and recited the definition and pointed to and read the term. }\end{array}$ & & & & & & & & & & \\
\hline 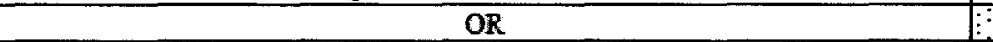 & $\because \because \because$ & & $\because$ & & & $\vdots$ & $\because:$ & & $\because$ & \\
\hline $\begin{array}{l}\text { Gave reinforcement with verbal praise (e.g., Great job!, Great working!) and } \\
\text { placed definition card on table and said, "yes, (recite the definition) is (recite } \\
\text { term). }\end{array}$ & & & & & & & & & & \\
\hline Stop the stopwatch & & $\because$ & $\because:$ & $\because$ & $\because$ & $\because:$ & $\because \because$ & 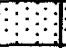 & $:$ & \\
\hline Total & & & & & & & & & & \\
\hline
\end{tabular}


Appendix R

Participant Sessions Times in Seconds Listed Numerically 
Instructional Participant Participant Participant Participant Participant Participant

\begin{tabular}{|c|c|c|c|c|c|c|}
\hline Day & $A$ & B & C & $D$ & $E$ & $F$ \\
\hline 1 & 289 & 524 & 316 & 397 & 455 & 432 \\
\hline 2 & 322 & 541 & 338 & 429 & 506 & 486 \\
\hline 3 & 340 & 622 & 360 & 435 & 507 & 509 \\
\hline 4 & 416 & 636 & 427 & 436 & 514 & 618 \\
\hline 5 & 422 & 643 & 448 & 455 & 528 & 624 \\
\hline 6 & 436 & 648 & 464 & 463 & 537 & 625 \\
\hline 7 & 447 & 655 & 525 & 468 & 538 & 639 \\
\hline 8 & 456 & 658 & 542 & 477 & 540 & 647 \\
\hline 9 & 475 & 698 & & 494 & 551 & 655 \\
\hline 10 & 478 & 703 & & 495 & 564 & 662 \\
\hline 11 & 537 & 713 & & 497 & 573 & 665 \\
\hline 12 & 538 & 745 & & 499 & 588 & 671 \\
\hline 13 & 575 & 757 & & 500 & 592 & 674 \\
\hline 14 & & 781 & & 507 & 600 & 681 \\
\hline 15 & & 786 & & 508 & 603 & 698 \\
\hline 16 & & 798 & & 515 & 617 & 700 \\
\hline 17 & & 839 & & 519 & 622 & 703 \\
\hline 18 & & 871 & & 521 & 625 & 719 \\
\hline 19 & & & & 522 & 628 & 751 \\
\hline 20 & & & & 522 & 631 & 846 \\
\hline 21 & & & & 523 & 633 & 872 \\
\hline 22 & & & & 524 & 634 & \\
\hline 23 & & & & 525 & 635 & \\
\hline 24 & & & & 528 & 638 & \\
\hline 25 & & & & 535 & 642 & \\
\hline 26 & & & & 536 & 646 & \\
\hline 27 & & & & 537 & 667 & \\
\hline 28 & & & & 538 & 668 & \\
\hline 29 & & & & 539 & 682 & \\
\hline 30 & & & & 539 & 691 & \\
\hline 31 & & & & 549 & 729 & \\
\hline 32 & & & & 552 & 766 & \\
\hline 33 & & & & 552 & 893 & \\
\hline 34 & & & & 553 & & \\
\hline 35 & & & & 557 & & \\
\hline 36 & & & & 563 & & \\
\hline
\end{tabular}

Instructional Participant Participant Participant Participant Participant Participant Day

A B

C

D E 
568

41

594

42

600

601

606

632

636

46

47

48

668

674

675

50

680

707 


\section{CURRICULUM VITAE}

NAME: Connie Elaine Morrison

ADDRESS: 1475 Bonnie Brae Drive

Shelbyville, KY 40065

DOB: $\quad$ Louisville, Kentucky - November 17, 1974

EDUCATION

\& TRAINING

B.S., Psychology

Eastern Kentucky University

1993-1997

M.A., Special Education

University of Louisville

1999-2002

Rank 1 Moderate and Severe

University of Louisville

2004-2006

Ph. D., Curriculum and Instruction Special Education

University of Louisville

2007-2011

TEACHING

EXPERIENCE

Oldham County High School

Buckner, Kentucky

2003 to present

Community Based Instruction Classroom

Servicing Moderate and Severe

Behavior Intervention for Autistic Children

Lexington, Kentucky

1999 to 2003

Verbal Behavior Consultant and therapist

Servicing Autism 